Chapman University

Chapman University Digital Commons

Educational Studies Dissertations

Summer 8-14-2018

\title{
Collegiate Women in Saudi Arabia: Leading Collectively for the Development of Self, Others, and Society
}

\author{
Miznah Alomair \\ Chapman University, aloma109@mail.chapman.edu
}

Follow this and additional works at: https://digitalcommons.chapman.edu/ces_dissertations

Part of the Higher Education Commons

\section{Recommended Citation}

Alomair, M. (2018). Collegiate women in Saudi Arabia: Leading collectively for the development of self, others, and society (Doctoral dissertation). https://doi.org/10.36837/chapman.000033

This Dissertation is brought to you for free and open access by Chapman University Digital Commons. It has been accepted for inclusion in Educational Studies Dissertations by an authorized administrator of Chapman University Digital Commons. For more information, please contact laughtin@chapman.edu. 
Collegiate Women in Saudi Arabia: Leading Collectively for the Development of Self, Others, and Society
A Dissertation by
Miznah O. Alomair

Chapman University

Orange, California

Attallah College of Educational Studies

Submitted in partial fulfillment of the requirements for the degree of

Ph.D. in Education

August 2018

Committee in charge:

Whitney McIntyre Miller, Ph.D., chair

Amal S. Al-Shaman, Ph.D.

Margaret Grogan, Ph.D.

J. Mark Maier, Ph.D. 
This dissertation of Miznah O. Alomair is approved.

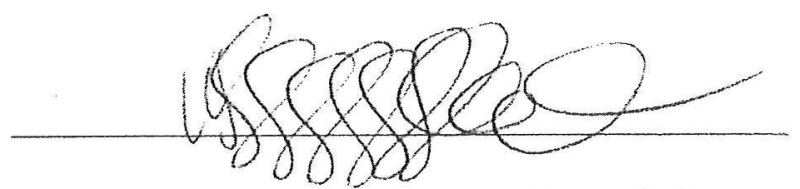

Dr. Whitney McIntyre Miller, chair

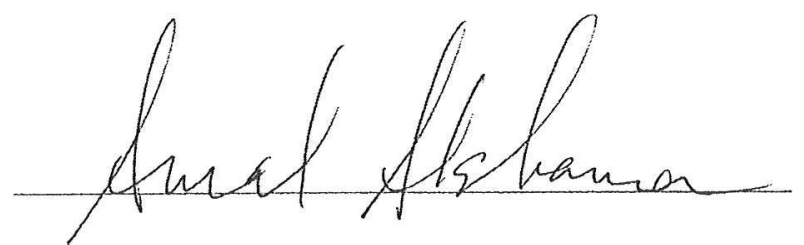

Amal S. Al-Shaman, Ph.D.
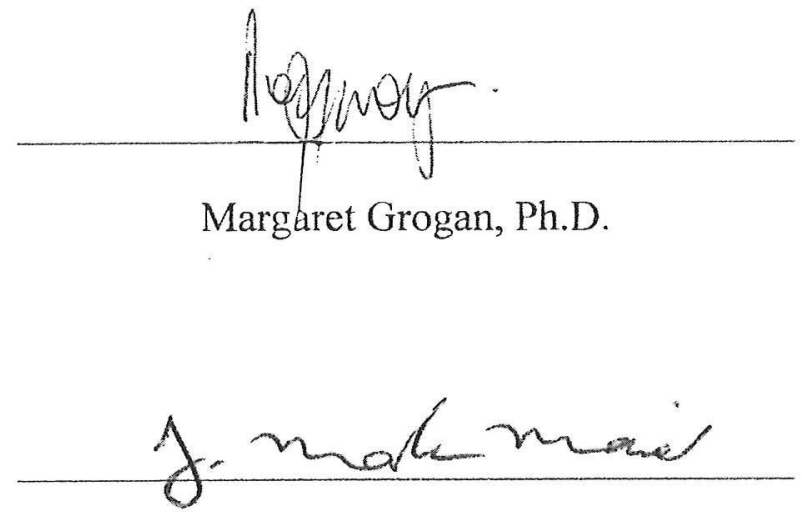

J. Mark Maier, Ph.D.

April 2018 
Collegiate Women in Saudi Arabia: Leading Collectively for the Development of Self,

Others, and Society

Copyright $\odot 2018$

by Miznah O. Alomair 


\section{DEDICATION}

\section{To Omair and Monirah (my beloved parents)}

For believing in the right to education and in the right to receive quality education.

Thank you for your unconditional love and support, and making our education a priority. 


\section{ACKNOWLEDGEMENTS}

First and foremost, I want to thank Allah (God) for his mighty blessings that surround me. It is only through His blessings that my Ph.D. journey was successful.

I would like to acknowledge my doctoral dissertation committee. I want to express my deepest gratitude and appreciation for their time, guidance, and feedback throughout the dissertation process.

To Dr. Whitney McIntyre Miller, thank you for mentoring me throughout my Ph.D. journey. Thank you for recognizing my potential and for shaping me and developing my competency as a researcher. Thank you for modeling an authentic commitment toward a just, peaceful, and sustainable world. Thank you for taking me with you along the path of peace leadership and helping view the world with a new perspective on peace.

To Dr. Amal Al-Shamaan, thank you for being a constant source of knowledge and inspiration to me. Thank you for believing in my potential and for always encouraging me to challenge myself. You have consistently provided me with unconditional support. I will be forever grateful.

To Dr. Margaret Grogan, thank you for challenging me to think in new ways throughout the dissertation process. You have taught me a lot about qualitative research. Thank you for helping me expand my boundaries of inquiry and curiosity.

To Dr. J. Mark Maier, thank you for your insight and suggestions that enhanced the dissertation study. Your invaluable advice and expertise motivated me throughout this process. Thank you for supporting me and getting the best out of me.

I could not have gone through my Ph.D. journey without the unconditional love 
and support of my family. I want to thank my father and mother, Omair and Monirah, for instilling in me the value of education and hard work. Thank you for always believing in me and supporting me throughout my life's journeys. I would like to express my deepest appreciation to my siblings and nieces. Thank you Sofanah, Hadeel, Abdullah, Norah, Haifa, Joharah, Anoud, Sadeem, Mayce, and Norah for always believing in me. This would not have been possible without your constant love, care, and support.

I want to express my deepest gratitude and appreciation to all my friends who cheered me on throughout this process. A special thank you to Sarah, Razan, Rana, Manal, May, Mayadah, Maram, Moneerah, Mai, Lulwah, AlAnoud, Halah, Maha, Hatoun, Haifa, Reem, Nofe, and Sarah Mista for being a phenomenal support system.

I would like to acknowledge the Attallah College of Educational Studies at Chapman University for an outstanding Ph.D. program. I want to thank all the staff members for their administrative support. Moreover, a special thank you to Dr. Penny Bryan, Dr. Don Cardinal, Dr. Scott Danforth, Dr. Kris De Pedro, Dr. Dianne Ferguson, Dr. Phil Ferguson, Dr. Michael Hass, Dr. Keith Howard, Dr. Dawn Hunter, Dr. Gerri McNinny, Dr. Lilia Monzó, and Dr. Suzanne SooHoo for helping me expand my knowledge and pushing me to think in new ways.

I would like to express my appreciation to my fellow peers at the Ph.D. program who I came to know and learn from in this journey. I want to thank Elizabeth Yomantas, Beatriz Valencia, C. J. Bishop, Christopher Jackson, Michael Fernandez, Maria Martinez, Margaret Vento-Wilson, Jackie Aparicio, K. P. Williams, Danny Bonilla, and Rachel Round for enriching my Ph.D. experience and journey. Also, I want to thank Pamela Ezell for showing me what dedication, commitment, strength, and resilience looks like. I 
appreciate your support throughout this journey. I will forever cherish our friendship. I would like to acknowledge my former mentors, co-workers, colleagues, and students at Prince Sultan University in Saudi Arabia in which I had the honor to work with and learn from tremendously prior to my Ph.D. journey. I want to thank the Student Affairs team for their unconditional support throughout this endeavor.

I would like to acknowledge the four private non-profit universities in which the participants were recruited from. I want to express my sincere appreciation to these universities for approving my formal request to interview participants and for assisting me throughout the recruitment process.

Lastly, and certainly not least, I would like to thank the twenty-five young women of this study for sharing their time and experiences with me. I thank you for opening your hearts to me and trusting me with your thoughts and feelings. I will forever be grateful. 


\begin{abstract}
Collegiate Women in Saudi Arabia: Leading Collectively for the Development of Self, Others, and Society

by Miznah O. Alomair
\end{abstract}

This is a constructivist grounded theory study that explored and investigated the leadership understandings of collegiate women in Saudi Arabia's private non-profit universities, the opportunities they have to develop leadership, and how and why they develop leadership. The researcher engaged in semi-structured interviews with 25 collegiate women who have experiences in student leadership in one or more cocurricular program at their respective university. The findings revealed that collegiate women: (a) have a collective sense of the importance in developing their leadership potential to better themselves, to better each other, and for the betterment of the Saudi Arabian society; (b) they are interested in and motivated to develop their leadership potential; (c) develop leadership in inconsistent and informal ways; and (d) understand leadership as a relational practice. This is an unprecedented study in the field of college student leadership development within the context of Saudi Arabia. The findings have a number of important implications for action and future research in Saudi Arabia, as well as in neighboring countries that share similar complexities pertaining to women's role and status in society. 


\section{TABLE OF CONTENTS}

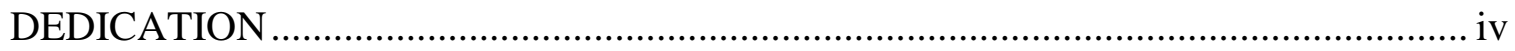

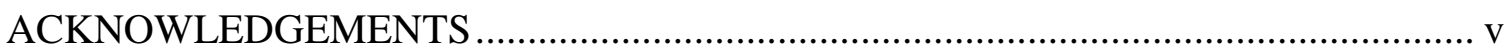

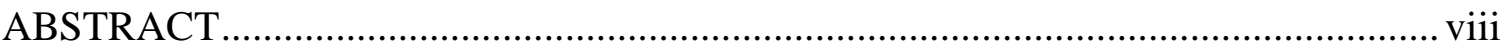

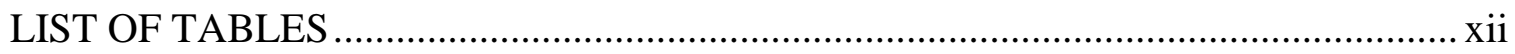

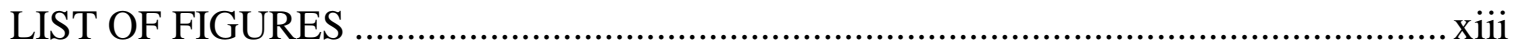

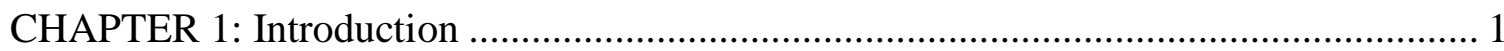

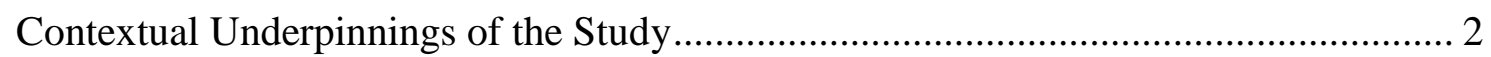

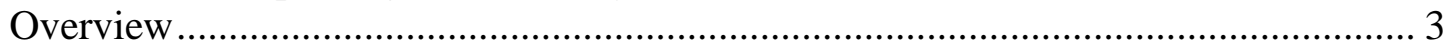

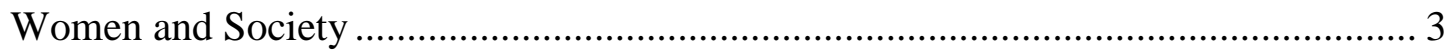

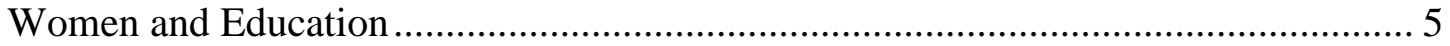

Current Status of Women in Saudi Arabia ................................................................. 7

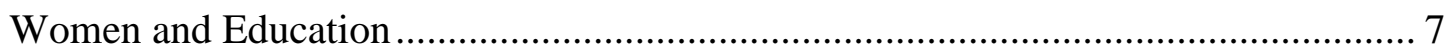

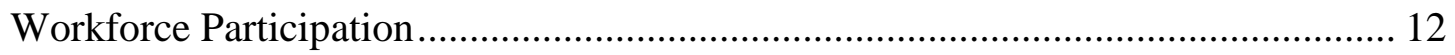

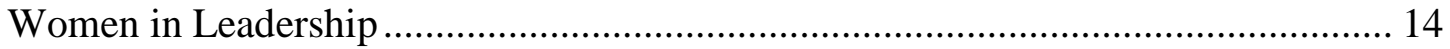

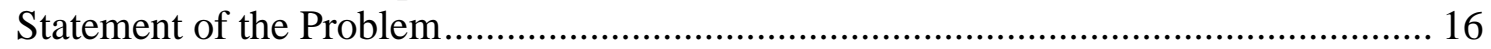

Puspose Statement and Research Questions ................................................................. 18

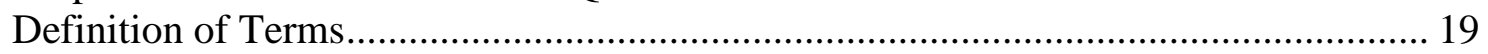

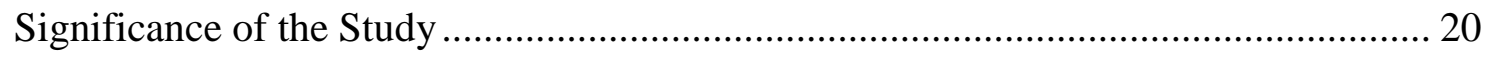

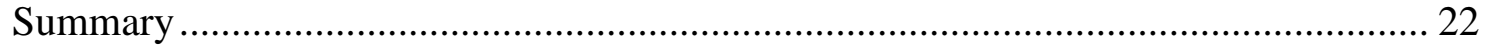

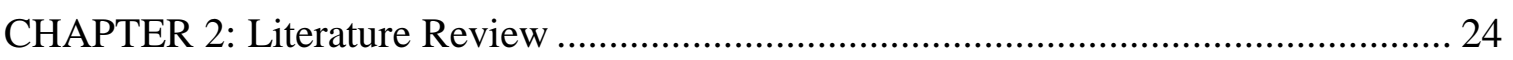

College Student Leadership in American Higher Education .......................................... 24

The Importance of Leadership Development for Collegiate Students........................ 25

Key Leadership Frameworks and Models for Collegiate Students ............................. 26

Elements of the Collegiate Context .......................................................................... 30

The Impact of Leadership Deevelopment on Collegiate Women................................. 33

Leadership Development of Collegiate Women in the Arab Gulf States ..................... 35

Leadership Development of Collegiate women in the UAE ...................................... 37

Leadership Development in Other Arab Gulf Countries ............................................ 39

Leadership Development of Collegiate Women in Saudi Arabia................................... 40

Opportunities for Leadership Development............................................................... 41

Collegiate Women's Perspective and Understanding of Leadership.......................... 43

Factors promoting and Impeding Leadership Opportunities ...................................... 46

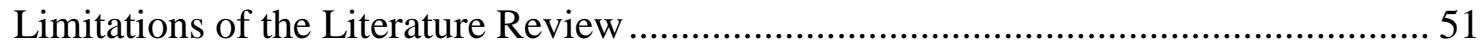

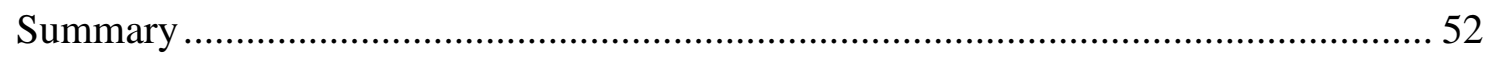

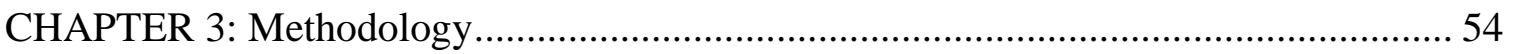

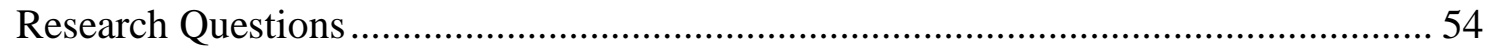

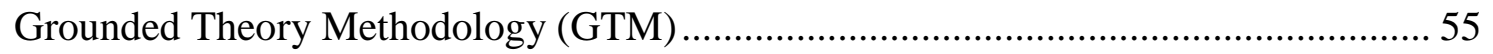




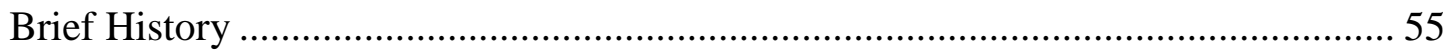

Constructvist Grounded Theory (CGT) ………………....................................... 56

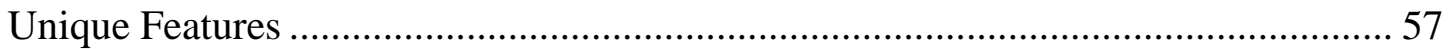

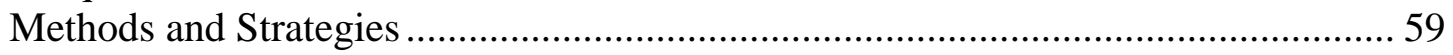

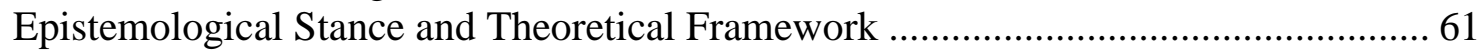

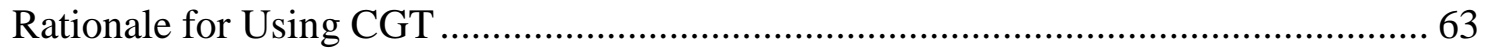

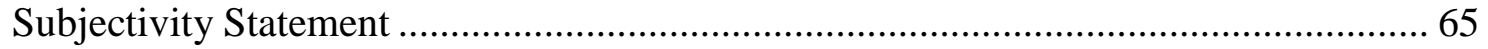

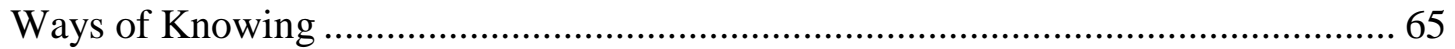

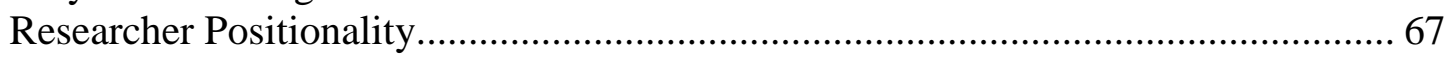

Ethical Framing ................................................................................................. 70

Culturally Responsive Methodology (CRM) ………………............................... 70

Authentic and Rigorous Inquiry....................................................................... 71

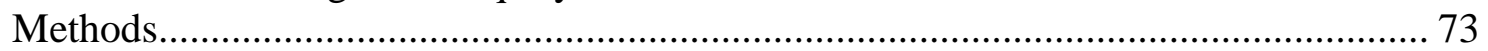

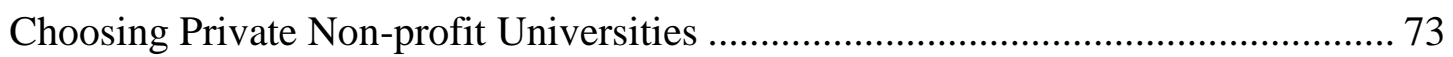

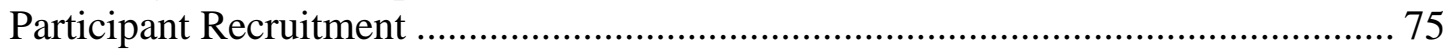

Research Participants ....................................................................................... 78

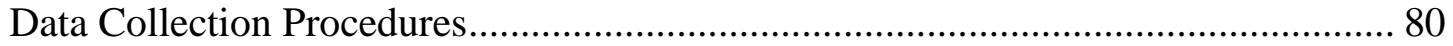

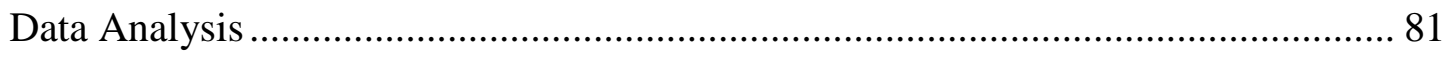

Enhancing Trustworthiness and Credibility ............................................................ 83

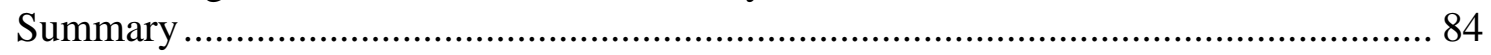

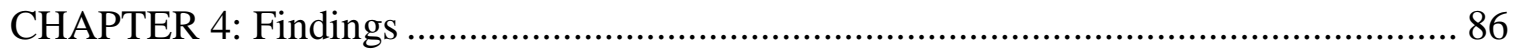

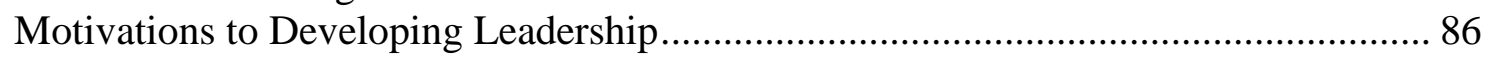

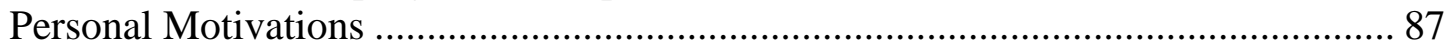

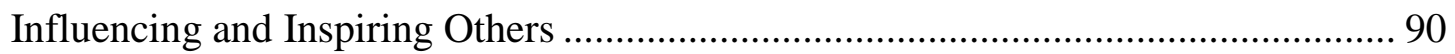

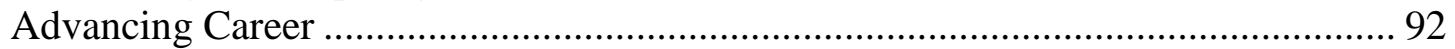

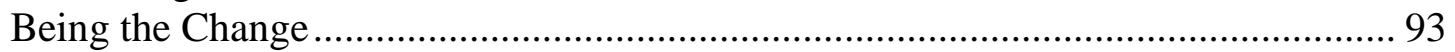

Factors Promoting and Hindering Leadership Development.......................................... 96

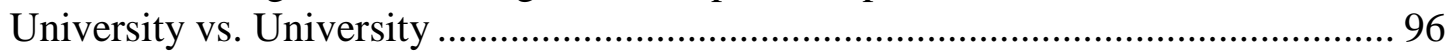

Family Support vs. Social Influences ............................................................... 100

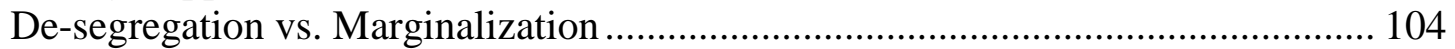

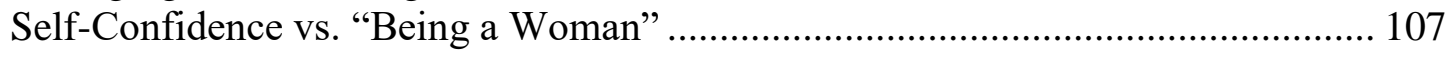

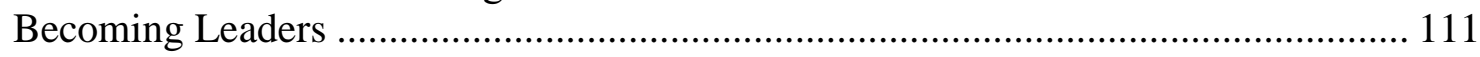

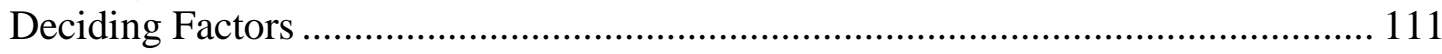

Student Leadership Opportunities................................................................... 117

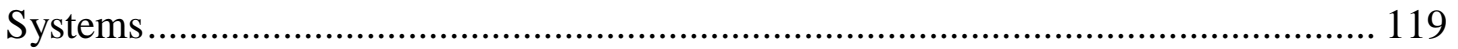

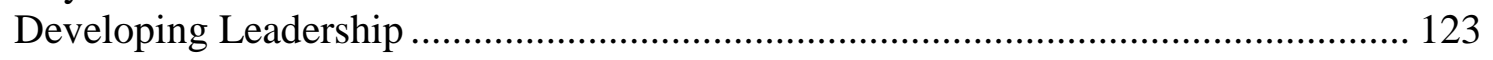

Memberships and Observations ........................................................................ 123

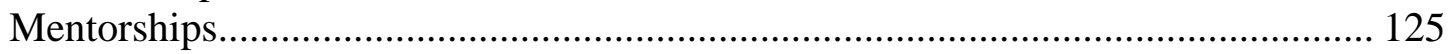

Experiencing Leadership ................................................................................. 127

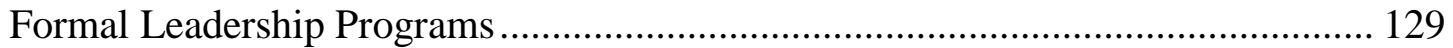

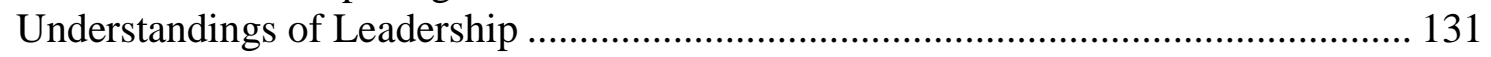

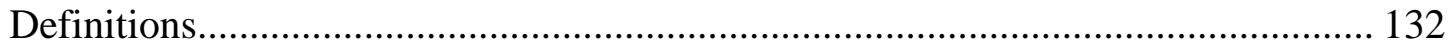

Sources of Leadership Understanding ………………….................................. 142

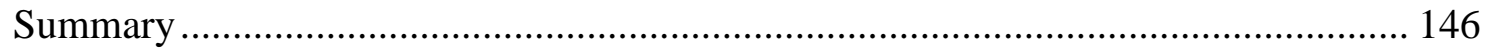




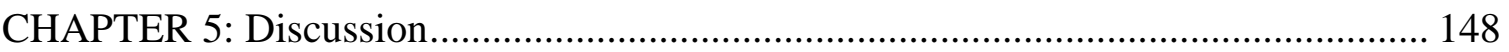

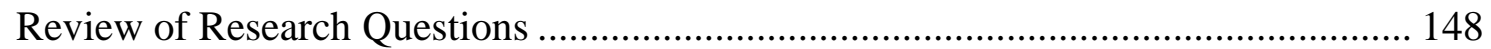

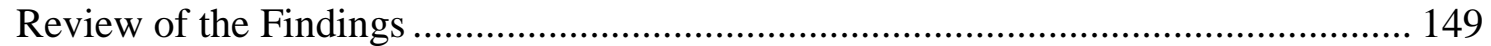

Motivations for Leadership Development ……………...................................... 150

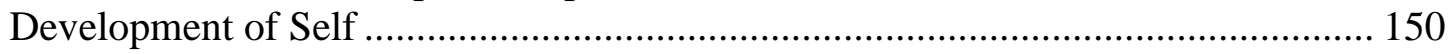

Development of Others .................................................................................... 152

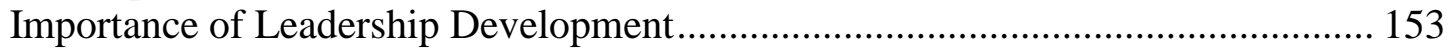

Leadership Development Opportunities and Experiences ........................................... 156

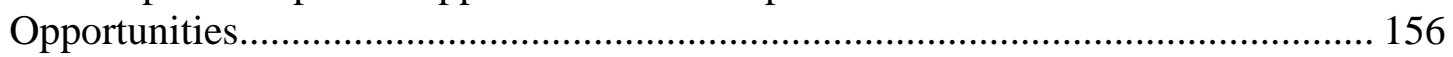

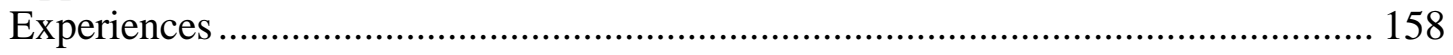

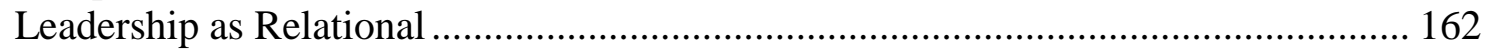

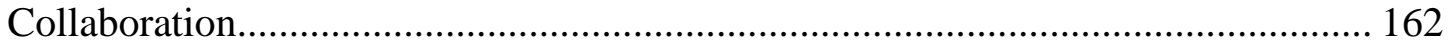

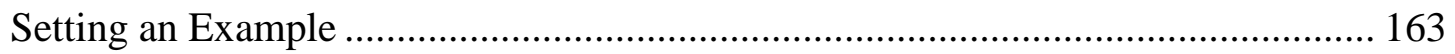

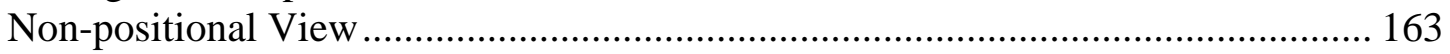

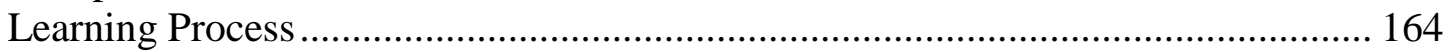

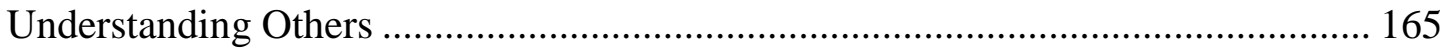

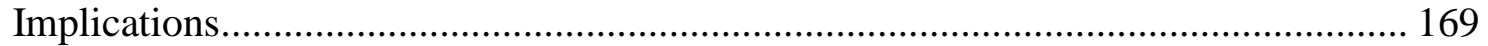

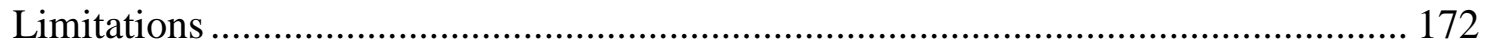

Recommendations for Future Research ................................................................. 173

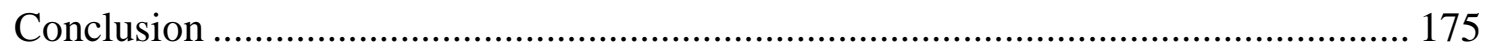

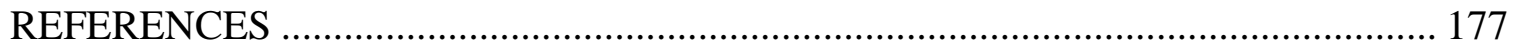

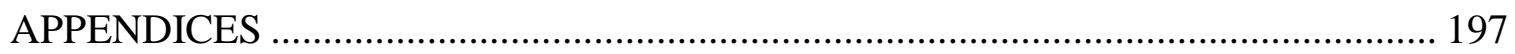




\section{LIST OF TABLES}

Table 1. Women's Enrollment Rates in Higher Education by Sector and Year................ 9

Table 2. Women's Graduation Rates from Higher Education by Sector and Year .......... 10

Table 3. Study Abroad Scholarship Program and Women's Enrollment and Graduation Rates by Year ................................................................................. 10

Table 4. Economic Participation Rates by Year, Gender, Saudi Nationality .................. 13

Table 5. Unemployment Rates by Year, Gender, Saudi Nationality .............................. 14

Table 6. Important Milestones for Women in Saudi Arabia (2009-2018)...................... 15

Table 7. Participants by Private Non-profit University ........................................... 78

Table 8. Number of Participants by Course Level and Field of Study .......................... 79

Table 9. Number of Leadership Positions Participants Held by Student Leadership

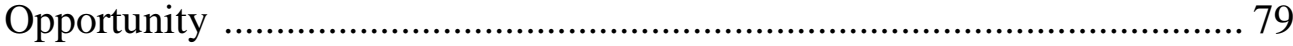




\section{LIST OF FIGURES}

Figure 1. Relationship between Motivations for Leadership Development

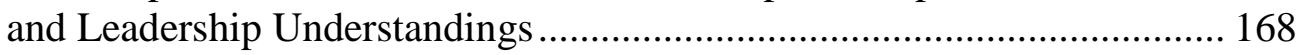




\section{Chapter One: Introduction}

The past decade witnessed dramatic changes to the role of women in Saudi Arabia. The government's initiated reforms have been supporting women's advancements in society and paving the way for their inclusion and participation in public and private spheres. As a result, women gained further access to educational and professional opportunities that empowered them to participate in decision-making processes and take on senior leadership positions in areas such as politics, medicine, education, law, business and finance, and technology (AbuSulayman, 2017; AlMunajjed, 2010; Al-Ahmadi, 2011; Hamdan, 2012; Thompson, 2015). While systematic and gradual, the changing role of women in Saudi Arabia serves to reconstruct attitudes and misperceptions about women in leadership, redefine gender roles and stereotypes regarding women in the country, and advance opportunities for women in public and private domains (Al-Ahmadi, 2011).

Although women in Saudi Arabia appear to be making headway in influencing social change, their inclusion and full participation in society continues to be challenged. As discussed below, efforts aimed at expanding and diversifying women's role in society fail to recognize the significance of and need for young women in Saudi Arabia to become self-empowered throughout their educational journey by means of leadership development. For example, the Saudi government's initiated economic plan (Vision 2030, 2016) stated the need to increase women's representation in senior leadership positions by expanding and diversifying women's participation in the workforce, as well as empowering them and honing in on their potential. While the ground-breaking economic plan is committed to improving and further advancing women's role in Saudi 
Arabia, it overlooks collegiate women in particular as important stakeholders for social change and as a major source of untapped leadership potential. Thus, there is a need to attend to the leadership development experiences of collegiate women in the country.

Collegiate men and women in Saudi Arabia are on the cusp of pursuing professional careers that may take them on a path toward leadership roles and positions. Given that collegiate women account for more than $50 \%$ of undergraduate students in the country (GASTAT, 2016c), it becomes even more critical to draw attention to their understandings of leadership and the processes they engage in to develop leadership. Therefore, this qualitative study explored and investigated the leadership understandings of collegiate women in Saudi Arabia's private non-profit universities, the opportunities they have to develop leadership, and how and why they develop leadership. The findings of this study generated an understanding of the perspective collegiate women in Saudi Arabia's private non-profit universities have of leadership as a relational practice they engage in to better themselves and others, and to have a greater impact on the Saudi Arabian society.

\section{Contextual Underpinnings of the Study}

Despite the recent turning points in the country's history, the role of women in society has been for decades a contentious issue rooted in sociocultural complexities that impede their inclusion and full participation. Understanding women's role in Saudi Arabia will require an understanding of the context. This section provides an overview of Saudi Arabia, underline the role of Muslim women in Islam, discuss Saudi Arabia's social norms and traditional attitudes as dominant forces, and address historical aspects of women's education in the country. 


\section{Overview}

Saudi Arabia holds a unique political, economic, religious, and sociocultural position within the international community in general, and within the Middle East region in particular. With at least one third of the world's known oil reserves, Saudi Arabia is an absolute monarchy held by the Al-Saud family since it was established by King AbdulAziz Al-Saud in 1932 (Fatany, 2013; Hamdan, 2005). Moreover, it is the birthplace of Islam and the home to the religion's two Holy Mosques; Masjid Al-Haram in the city of Makkah Al-Mukarramah and Masjid An-Nabawi in the city of Al-Madinah AlMunawwarah (Fatany, 2013). Thus, Islam is at the heart of the Saudi society and culture, and thereby influencing the way people think and act.

Since the inception of Islam in the early seventh century, and throughout its history, Muslim women not only played a significant role in society, but also advanced in political, economic, and scientific fields (Oxford Islamic Studies Online, 2017). For example, Prophet Mohammed's (Peace Be Upon Him) first wife Khadijah was a prominent business woman, and his daughter Fatima and granddaughter Zainab were activists and advocates for social justice (Ballandalus, 2014; Hamdan, 2005). During the tenth century, Lubna of Cordoba was a skilled mathematician and an avid literary figure who presided over the royal library in Spain (Ballandalus, 2014). These women were only a few of many prominent Muslim women leaders (Aldawsari, 2016; Hamdan, 2005). Historically, women played a pivotal role in Muslim societies.

\section{Women and Society}

Despite women's visible role in Islamic history, it was quite the opposite in some Muslim societies during the twentieth century. For example, since the establishment of 
Saudi Arabia, women's social roles, and their education, has been guided by social attitudes and norms deeply rooted in patriarchal practices, and in misinterpretations of authentic Islamic principles by religious conservative scholars (Alyahya, 2016; Fatany, 2013; Hamdan, 2005). Feminist Muslim scholars argued that misinterpretations of the Quarn, and the omission of historical accounts about Muslim women leaders from school curriculum and textbooks, perpetuate the patriarchal practice of male-dominance to maintain the exclusion and marginalization of women from society (Aldawsari, 2016; Alyahya, 2016; Hamdan 2012). In the patriarchal society of Saudi Arabia, misinterpretations of authentic Islamic principles produced policies and practices, some of which include the male-guardianship law, gender segregation, and the driving ban on women ${ }^{1}$ that are discriminatory and in violation of women's basic rights (Alharbi, 2015; Alyahya, 2016; Fatany, 2013). For example, as one of the most controversial laws in Saudi Arabia that restrict women's rights in almost all aspects of life, the maleguardianship law requires "the approval or presence of the male guardian in order to accomplish what should be feasible according to their legal rights" (Alharbi, 2015, p. 1). As a result, such practices maintain men's dominance and control over women and preserve gender inequality, thereby limiting women's basic rights, autonomy to participate in decision-making processes, and career opportunities and advancements (Aldawsari, 2016; Alyahya, 2016).

The deeply entrenched gender inequalities in Saudi Arabia's society produced and normalized defined gender roles and male dominance, which shaped attitudes toward socially accepted academic disciplines, educational levels, and career choices for women

\footnotetext{
${ }^{1}$ On September 26, 2017, a royal decree was issued to lift the driving ban on women in
} Saudi Arabia starting June 24, 2018 (Baker, 2018; Sadek, 2017). 
to pursue (AlMunajjed, 2010; Hamdan, 2005, 2012). Moreover, gender roles distorted perceptions and beliefs about women's competencies and capabilities to achieve their educational and professional goals, as well as to pursue their leadership aspirations (Hamdan, 2012). The pervasiveness of defined gender roles and male dominance, as well as legal constraints, not only established gender-based occupations, but also trivialized women's need to participate in the workforce, and thereby contributing to their unemployment status and underrepresentation in leadership positions (Aldawsari, 2016; AlDoubi, 2014; AlMunajjed, 2010; Alyahya, 2016; Mimouni \& Metcalfe, 2011). Thus, it could be implied that these context-specific sociocultural complexities perpetuate gender inequalities and inhibit women's inclusion and full participation in society.

\section{Women and Education}

A significant element to the changing role of women in Saudi Arabia is education. However, the aforementioned social complexities have been a formidable barrier throughout the history of women's education. Thus, it is necessary to address historical aspects of women's education in Saudi Arabia that have contributed to the ebb and flow of women's inclusion and full participation in society.

In 1960, the inception of formal education for women in Saudi Arabia faced resistance and demonstrations from religious conservative scholars, who argued that education will liberate women from their Muslim identity (Hamdan, 2005; Jamjoom \& Kelly, 2013). These opponents came to the support of women's education after certain conditions were met such as mandating gender-segregation at schools, teaching girls their religious and domestic roles, and establishing women's education under a separate department of education than the Ministry of Education, which oversaw young men's 
education (Hamdan 2005, 2012). Women's education in Saudi Arabia was governed by the General Presidency for Girls' Education, a department of education established under the supervision of the government's religious guidance department (Al Fassi, 2010; Hamdan, 2005). For more than 40 years, religious conservative scholars maintained control over women's education to ensure educational institutions conformed to their strict religious philosophy (Al Fassi, 2010; AlDoubi, 2014; Hamdan, 2005, 2012).

The formation of colleges and universities in Saudi Arabia during the late 1960s and early 1970s enabled women to enroll in gender-segregated campuses to pursue degrees in non-scientific disciplines in social studies, Islamic studies, and Arabic studies (AlDoubi, 2014; Hamdan, 2005; Jamjoom \& Kelly, 2013). Given the gender inequalities embedded in society, collegiate women in Saudi Arabia had limited academic subjects to specialize in, prompting some families to send their daughters abroad and pursue their educational goals at international universities (Aldawsari, 2016; Hamdan 2005). At the turn of the century, social attitudes gradually shifted toward women's higher education, whereby academic disciplines and subjects were expanded for collegiate women (Hamdan, 2005). For instance, it was only in recent years where collegiate women in Saudi Arabia were provided with opportunities to pursue college degrees in law, design and engineering, journalism, and archeology (Al Fassi, 2010).

Although the history of education and higher education in Saudi Arabia is relatively short, the dominance of traditional social attitudes and practices had serious implications on women's learning outcomes, career aspirations, and inclusion as equal members of society. For many years, women in Saudi Arabia received their education within restrictive and regulated conditions, thereby limiting their right to experience and 
obtain equal learning opportunities and outcomes as men (Al Fassi, 2010). For example, under the General Presidency's governance and the religious guidance department's control, women's education suffered from inequalities related to budgetary and financial allocations, proper facilities and learning environments, learning content, and pedagogical approaches (Hamdan, 2005, 2012). Furthermore, the gradual expansion of higher education through a permission-granting process of academic disciplines for collegiate women kept a tight rein on their progress and empowerment. Thus, the pervasiveness of gender inequalities created roadblocks for women to achieve legitimate and nondiscriminatory experiences and outcomes.

\section{Current Status of Women in Saudi Arabia}

Since the beginning of the twenty first century, the Saudi government's commitment to and support of women's education paved the way for social change. For more than a decade, a series of events and developments in Saudi Arabia occurred that improved women's status in society substantially. This section highlights these events and turning points in Saudi Arabian history by addressing women's education, workforce participation, and representation in leadership positions.

\section{Women and Education}

Literacy rate. Despite the sociocultural influences and restrictive practices to women's education in Saudi Arabia, these did not deter women from seeking and pursuing their basic right to literacy. Moreover, to increase literacy rate among men and women, the Saudi government made education compulsory and tuition-free at public schools (Hamdan, 2005). According to the United Nations Educational, Scientific, and Cultural Organization (2016), the literacy rate among women in Saudi Arabia aged 15 
and older increased from an estimated $57 \%$ in 1992, to approximately $76 \%$ in 2004 , and to almost $92 \%$ in 2015 . Given the increase in the literacy rate of women in Saudi Arabia over the years, the government initiated necessary reforms to the education system, particularly to higher education, that are discussed in the following sub-section.

Educational reforms. Faced with local, regional, and global challenges since 2001, the Saudi government placed conscious effort to implement necessary educational reforms that are in alignment with its vision to eliminate extremism and terrorism, diversify its economic source away from oil, and accommodate the growing young population (Al Fassi, 2010). For instance, the government's overall dissatisfaction with the status of education resulted in the merge of women's education department with the Ministry of Education in 2002, to ensure equitable learning opportunities and outcomes (Fatany, 2013; Hamdan, 2005). Moreover, reforms were initiated to improve the quality of education by revising Islamic curricula, strengthening mathematics and science curricula, teaching English as a second language at public schools, and providing teachertraining programs to help reverse the traditional methods of teaching and learning (Fatany, 2013).

With sociopolitical and socioeconomic development and sustainability of the country in mind, the Saudi government implemented higher education reforms aimed to accommodate the rapid increase in college enrollment, produce a knowledge-based economy, and influence societal change (Fatany, 2013; “Ministry of Higher Education's Plan”, 2010). The reforms focused on expanding infrastructure projects, strengthening research and knowledge production, enhancing workforce participation through private higher education, and increasing academic achievements and human capital by means of 
a study abroad scholarship program (Fatany, 2013; Habibi, 2015; Hamdan, 2013). Given the increasing number of collegiate women in Saudi Arabia, these reforms have contributed to improving women's status in education.

College enrollment and graduation. Throughout the past two decades, collegiate women's enrollment rates in Saudi Arabia's higher education institutions increased substantially. For example, college enrollment rates of women increased from $28.57 \%$ in 1981 to $48.47 \%$ in 2005 (Jamjoom, 2012). More than a decade later, women in Saudi Arabia's higher education institutions accounted for more than half of undergraduate students and of their graduating class (GASTAT, 2015b, 2015c, 2016b, 2016c, 2017a), as shown in Table 1 and Table 2.

Table 1

Women's Enrollment Rates in Higher Education by Sector and Year

\begin{tabular}{|c|c|c|c|}
\hline Year & All sectors & Public & Private \\
\hline 2015 & 52.42 & 52.46 & 52.20 \\
\hline 2016 & 52.04 & 52.10 & 52.09 \\
\hline 2017 & 53.66 & 54.23 & 43.68 \\
\hline \multicolumn{4}{|c|}{$\begin{array}{l}\text { Note. Rates in percentages. Adapted from "Education and Training," by the General } \\
\text { Authority for Statistics, Kingdom of Saudi Arabia, Statistical Yearbooks of 2015-2017. } \\
\text { Copyright 2015, 2016, } 2017 \text { by the General Authority for Statistics, Kingdom of Saudi } \\
\text { Arabia. (GASTAT, 2015b, 2015c, 2016b, 2016c, 2017a). }\end{array}$} \\
\hline
\end{tabular}


Table 2

Women's Graduation Rates from Higher Education by Sector and Year

\begin{tabular}{|c|c|c|c|}
\hline Year & All sectors & Public & Private \\
\hline 2014 & 55.33 & 56.75 & 47.65 \\
\hline 2015 & 56.75 & 57.15 & 50.91 \\
\hline
\end{tabular}

Note. Rates in percentages. Adapted from "Education and Training," by the General Authority for Statistics, Kingdom of Saudi Arabia, Statistical Yearbooks of 2015-2016. Copyright 2015, 2016 by the General Authority for Statistics, Kingdom of Saudi Arabia. (GASTAT, 2015b, 2015c, 2016b, 2016c).

Study abroad scholarship program. Established in 2005, the study abroad scholarship program aims to enhance the plans and development of the Saudi workforce significantly through learner mobility in major international universities, and become equipped with the knowledge and skills necessary to build business and leadership capacity within the country. In 2011, around 20 percent of total study abroad scholarship recipients were women (Bukhari \& Denman, 2013). A decade after the establishment of this program, Saudi women's enrollment and graduation rates increased (see Table 3).

Table 3

Study Abroad Scholarship Program and Women's Enrollment and Graduation Rates by Year

\begin{tabular}{|c|c|c|c|}
\hline Year & $2014^{\mathrm{a}}$ & 2015 & $2016^{\mathrm{b}}$ \\
\hline Enrollment & & 27.30 & 29.17 \\
\hline Graduation & 28.50 & 29.40 & \\
\hline
\end{tabular}

Note. Rates in percentages. ${ }^{a}$ Data for 2014 enrollment in scholarship program is unavailable. ' Data for 2016 graduation from scholarship program is unavailable. Adapted from "Education and Training," by the General Authority for Statistics, Kingdom of Saudi Arabia, Statistical Yearbooks of 2015-2016. Copyright 2015, 2016 by the General Authority for Statistics, Kingdom of Saudi Arabia. (GASTAT, 2015d, 2016d). 
Infrastructure projects. To support women's education and accommodate the rapidly increasing number of collegiate women, two important infrastructure projects aimed to reduce gender disparities at the collegiate level. For example, the 2010 establishment of King Abdullah University of Science and Technology (KAUST), a coeducational private non-profit graduate research university (Fatany, 2013; Smith \& Abouammoh, 2013), signals a shift toward reducing gender inequalities and stereotypes regarding women's pursuit of academic disciplines, levels of education, and career choices. Moreover, the 2011 campus expansion project of Princess Nourah bint Abdulrahman University (PNU), a public university for women and led by women, accommodates up to 60,000 collegiate women pursuing their educational goals in various disciplines (Jamjoom \& Kelly, 2013; Smith \& Abouammoh, 2013).

Private higher education. The establishment of Saudi Arabia's private higher education in 1999 aimed to accommodate the growing young population, develop the country's private economic sector, and diversify educational and professional experiences and opportunities for collegiate men and women (Al Dali, Fnais, \& Newbould, 2013; Smith \& Abouammoh, 2013). As of 2018, there are about 52 private higher education institutions in Saudi Arabia that cater for collegiate men and women in gender-segregated campuses, with the exception of KAUST's co-educational environment (Ministry of Education, 2018). While private higher education in the country is relatively new, enrollment rate of collegiate women increased over the years. As shown in Table 1, collegiate women accounted for $52.09 \%$ of private higher education students in 2016 (GASTAT, 2016c). Clearly, the presence of collegiate women in private higher education reflect the dominant trend of the collegiate women population growth in Saudi Arabia. 
There are six private higher education institutions in Saudi Arabia that identify themselves as non-profit universities (Ministry of Education, 2018), two of which are for and led by women (Jamjoom, 2012). Private non-profit universities offer collegiate students, particularly collegiate women, opportunities to pursue undergraduate and graduate degrees in fields of studies that have been otherwise unavailable to them at public universities such as science, technology, engineering, and law (Fatany, 2013). These universities earned a reputation of preparing collegiate students for a globalized economy by adopting Western-style education through partnerships with reputable international universities (Hamdan, 2013). In addition, they foster collegiate students' professional development and leadership skills through co-curricular programs such as student organizations, volunteering, community service and engagement, and short-term and long-term leadership courses (Alexander, 2011; Ibrahim \& Sarirete, 2014; Jamjoom, 2012). Recent evidence showed that leadership education is unfolding in some private non-profit institutions. In the 2017-2018 academic year, a newly established private nonprofit business college for graduate students launched an executive education program that offered business and leadership-related courses and topics (MBSC, 2017). Given the developments and reform efforts implemented to enhance higher education, there has been an improvement to women's status in Saudi Arabia at the collegiate level.

\section{Workforce Participation}

Despite women's access to education and their rapidly increasing number in higher education in Saudi Arabia, they have the lowest rate of employment in the region (AlMunajjed, 2010). According to the General Authority for Statistics (2015a, 2016a, 2017b), Saudi women's economic participation increased from $17.30 \%$ in 2015 to $19.3 \%$ 
in 2016 , whereas their unemployment increased from $32.80 \%$ in 2015 to $34.50 \%$ in 2016 , as shown in Table 4 and Table 5.

Studies and reports indicated that legislative, social, educational, and work-related obstacles contributed to women's low participation in the workforce over the years (AlMunajjed, 2010; Alyahya, 2016). AlMunajjed (2010) argued that the education system fails to prepare collegiate women for employment in non-traditional fields, the laws and policies of gender-specific and gender-segregated work environments exclude women from equal opportunities, and the lack of support services in the workplace discourage women from employment. In addition, Alyahya (2016) indicated that social influences continue to act as dominant forces in determining women's professional choices, which may suggest that advancing women's status in Saudi Arabia is unforeseeable.

Table 4

Economic Participation Rates by Year, Gender, Saudi Nationality

\begin{tabular}{|c|c|c|c|c|}
\hline Year & Total men & Total women & Saudi men & Saudi women \\
\hline 2015 & 77.80 & 20.20 & 64.10 & 17.30 \\
\hline 2016 & 79.50 & 22.80 & 64.60 & 19.30 \\
\hline $2017^{\mathrm{a}}$ & 79.00 & 20.90 & 63.40 & 19.40 \\
\hline \multicolumn{5}{|c|}{$\begin{array}{l}\text { Note. Rates in percentages. "Data for } 2017 \text { economic participation are estimations by } \\
\text { GASTAT. Total men and total women include Saudi and non-Saudi nationals. Adapted } \\
\text { from "Labor Force Survey," by the General Authority for Statistics, Kingdom of Saudi } \\
\text { Arabia. Copyright 2015, 2016, } 2017 \text { by the General Authority for Statistics. (GASTAT, } \\
\text { 2015a, 2016a, 2017b). }\end{array}$} \\
\hline
\end{tabular}


Table 5

Unemployment Rates by Year, Gender, Saudi Nationality

\begin{tabular}{ccccc}
\hline Year & Total men & Total women & Saudi men & Saudi women \\
\hline 2015 & 2.70 & 21.80 & 5.70 & 32.80 \\
\hline 2016 & 2.60 & 21.30 & 5.90 & 34.50 \\
\hline $2017^{\text {a }}$ & 3.20 & 21.10 & 7.50 & 31.00 \\
\hline
\end{tabular}

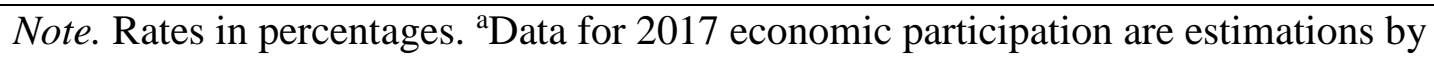
GASTAT. Total men and total women include Saudi and non-Saudi nationals. Adapted from "Labor Force Survey," by the General Authority for Statistics, Kingdom of Saudi Arabia. Copyright 2015, 2016, 2017 by the General Authority for Statistics. (GASTAT, 2015a, 2016a, 2017b).

\section{Women in Leadership}

Since 2009, Saudi Arabia made significant gains regarding women's status in society, and in senior leadership positions at the government level (see Table 6). Despite opposition from religious conservatives, women leaders in Saudi Arabia have been able to uphold roles such as deputy ministers, public university presidents, political advisors and members of the consultative council to the country's king, chief executive officers of financial institutions, and board members and leaders of private organizations (AbuSulayman, 2017). Moreover, women exercised their civic rights and duties in 2015 by voting and running in municipal elections (Alyahya, 2016).

While women in Saudi Arabia have been recognized as instrumental to the country's development and sustainability, they remain underrepresented in leadership positions (Albakry, 2015; AlDoubi, 2014; Aldowsari, 2016; Alyahya, 2016; Al-Ahmadi, 2011). To advance the role of women in society and increase their representation in senior leadership positions, a number of initiatives have been implemented through 
strategic partnerships with reputable business schools to offer leadership trainings and workshops to develop the capacities of professional women (Al-Ahmadi, 2011; Kattan, de Pablos Heredero, Montes Botella, \& Margalina, 2016). However, little is known about the outcomes of these leadership programs.

Table 6

Important Milestones for Women in Saudi Arabia (2009-2018)

\begin{tabular}{|c|c|}
\hline Year & Important Milestones for Women in Saudi Arabia \\
\hline 2009 & $\begin{array}{l}\text { The appointment of the first woman as the Deputy Minister of Education } \\
\text { for Girls' Affairs (Thompson, 2015). }\end{array}$ \\
\hline 2010 & $\begin{array}{l}\text { The establishment of KAUST enabled women to enroll at a co-educational } \\
\text { private non-profit graduate research university (Fatany, 2013). }\end{array}$ \\
\hline 2011 & $\begin{array}{l}\text { The campus expansion of PNU, which accommodates up to } 60,000 \text { female } \\
\text { students (Jamjoom \& Kelly, 2013). }\end{array}$ \\
\hline 2012 & $\begin{array}{l}\text { Women athletes competed for the first time in the Summer Olympics } \\
\text { (Quinn, 2012). }\end{array}$ \\
\hline 2013 & $\begin{array}{l}\text { A royal decree was issued to appoint } 30 \text { women to the Shura Council, a } \\
\text { consultative council that provides the country's king with recommendations } \\
\text { on policy-making ("Saudi Arabia's king," 2013). }\end{array}$ \\
\hline 2015 & Seventeen women were elected for municipal seats (Black, 2015). \\
\hline 2016 & $\begin{array}{l}\text { The initiation of Vision } 2030 \text { that aims to advance women's role in the } \\
\text { country's social and economic development (Vision 2030, 2016). }\end{array}$ \\
\hline $\begin{array}{l}2016 \\
\text { and } \\
2017\end{array}$ & $\begin{array}{l}\text { The appointment of the first woman as the Vice President of the Saudi } \\
\text { General Authority for Sports in 2016, and as the President of the Saudi } \\
\text { Federation for Community Sports in } 2017 \text { (Khatib, 2017). }\end{array}$ \\
\hline 2017 & $\begin{array}{l}\text { A woman was elected for the first time to chair the Saudi Stock Exchange } \\
\text { (Tadawul), the largest stock market in the Middle East (Mabrouk, Warrier, } \\
\text { \& Lasrado, 2017). } \\
\text { A royal decree was issued to lift the driving ban on women beginning June } \\
24,2018 \text { (Baker, 2018; Gaouette \& Labott, 2017; Sadek, 2017). }\end{array}$ \\
\hline 2018 & $\begin{array}{l}\text { The appointment of the first woman as the Deputy Minister of Labor and } \\
\text { Social Development ("First Saudi woman appointed," 2018). }\end{array}$ \\
\hline
\end{tabular}




\section{Statement of the Problem}

The past decade witnessed remarkable advancements and achievements to the education of women in Saudi Arabia, whereby collegiate women outnumbered collegiate men in higher education enrollment rates (Al Ankari, 2013; GASTAT, 2015b, 2015c, 2016b, 2016c). This fact alone signals a decrease in gender disparities at the collegiate level, which may suggest a decrease in these disparities overtime at the societal level. However, the inclusion and full participation of women in society is uncertain. The aforementioned context-specific complexities sustain the disparities and inequalities women face in Saudi Arabia, making it difficult for them to advance, participate, and be included in all public and private spheres. Evidence showed that collegiate women in Saudi Arabia gained grounds academically, yet they are an underutilized resource for social and human capital. As a rapidly growing population in all sectors of higher education, collegiate women are overlooked as a source of untapped leadership potential in transforming and sustaining social progress in Saudi Arabia. Thus, it becomes essential to investigate the leadership development of collegiate women in the country.

While the topic of collegiate student leadership development is heavily emphasized in Western higher education, it is largely ignored in non-Western higher education contexts (Renn \& Lytle, 2010). Investigating the leadership understandings of collegiate women in Saudi Arabia and what leadership means to them offer scholars an opportunity to investigate and understand a non-Western perspective of leadership. Thus, contributing valuable insight and knowledge to the field of leadership studies that is increasingly exploring non-Western leadership practices (Miller, 2016; Toh \& Leonardelli, 2013). 
Higher education institutions in Western societies place emphasis on collegiate student leadership development as an important student learning outcome (Komives, Dugan, Owen, Slack, \& Wagner, 2011), and an essential factor to build a better society (Astin \& Astin, 2000). Yet, it is unknown if this is the case in Saudi Arabia, for which the notion of collegiate student leadership development is an unexplored domain in the country's higher education systems. While evidence showed that women have access to education and are slowly advancing in positions of leadership at the professional level (Al-Ahmadi, 2011; Fatany, 2013), much is unknown about how and why young women in Saudi Arabia develop leadership at the collegiate level.

Although private higher education institutions in Saudi Arabia were established to enhance workforce participation by expanding educational experiences and opportunities for collegiate men and women (Al Dali et al., 2013), they pay little attention to the learning outcomes of college student leadership development. As discussed earlier in this chapter, private non-profit universities in the country offer co-curricular programs, such as student organizations and community service and engagement, as opportunities for collegiate women to develop their leadership potential (Alexander, 2011; Ibrahim \& Sarirete, 2014; Jamjoom, 2012). Yet, there is no data in the literature that explores and investigates the perspective of collegiate women as to how and why they develop leadership. To further advance women in society, enhance their participation in the workforce, and increase their representation in leadership positions, it is necessary for private non-profit universities in Saudi Arabia to be cognizant of and understand how collegiate women develop leadership. These questions are uncharted territory within the context of private non-profit universities in the country, for which there have been no 
empirical studies that explain this phenomenon. Therefore, this study aims to explore and investigate the opportunities collegiate women in Saudi Arabia's private non-profit universities have to develop their leadership potential.

Private non-profit universities in Saudi Arabia provide collegiate women with opportunities to develop leadership for reasons that may suggest to further advance women's role in society. However, there is no data in the literature that provides an explanation and an understanding to this phenomenon. There is a lack of empirical studies within the context of Saudi Arabia's private non-profit universities that investigate collegiate women's leadership understandings, as well as their experiences in and motivations for leadership development. Therefore, this study attempts to address these gaps in the literature.

\section{Purpose Statement and Research Questions}

This study explored and investigated the leadership understandings of collegiate women in Saudi Arabia's private non-profit universities, the opportunities they have to develop leadership, and how and why they develop leadership. The study seeks to answer the following research questions:

- In Saudi Arabia's private non-profit universities, what are collegiate women's understanding of leadership and leadership opportunities?

- What opportunities do collegiate women in Saudi Arabia's private non-profit universities have to develop leadership?

- From their perspective, how do collegiate women in Saudi Arabia's private nonprofit universities develop leadership? 
- Why do collegiate women in Saudi Arabia's private non-profit universities develop leadership?

\section{Definition of Terms}

To gain a better understanding of the study, the following key terms are defined. Collegiate women are referred to female undergraduate college students. In the context of Saudi Arabia, private non-profit universities refer to not-for-profit higher education institutions that are neither government-operated, nor government-funded (Hamdan, 2013). For this study, private non-profit universities are defined as not-for-profit-making universities that are established by and operated under a philanthropic foundation or a charitable organization. Formal leadership programs are defined as "an intentional collection of leadership experiences that are integrated into the overall experience. It is designed with purpose of developing or enhancing leadership skills, knowledge, and capacity" (Haber, 2011a, p.232). They include leadership trainings, workshops, lectures and seminars, and academic courses that vary in time and duration (Dugan, 2011; Haber, 2011a; Smist, 2011). Co-curricular programs refer to out-of-class programs or activities that provide students with opportunities to exercise and develop leadership such as involvement in student organizations, campus part-time employment, intercollegiate athletics and sports, community service and engagement, mentorships, volunteering, and student-led committees (Smist, 2011).

Leadership has been defined in various ways. For example, Walumbwa, Avolio, Gardner, Wernsing, and Peterson (2008) defined leadership as "a pattern of leader behavior that draws upon and promotes both positive psychological capacities and a positive ethical climate, to foster greater self-awareness, an internalized moral 
perspective, balanced processing of information, and relational transparency on the part of leaders working with followers, fostering positive self-development" (p. 94). For Komives, Lucas, and McMahon (1998), they defined leadership as a relational and ethical process rooted in collaboration to achieve positive change. Kouzes and Posner (2014) defined leadership as "the art of mobilizing others to want to struggle for shared aspirations" (p.2). Based on Heifetz, Grashow, and Linsky (2009), leadership is "the practice of mobilizing people to tackle tough challenges and thrive" (p. 14). Given that there is no agreed upon definition of leadership, reflecting on the aforementioned definition, I provide my own definition of leadership as a process, a practice, and a way of being and connecting with others that is rooted in collaborative and collective effort to navigate through challenges and create social change.

\section{Significance of the Study}

With the changing societal structures in Saudi Arabia, there is a need to further understand the phenomenon of collegiate women's leadership development. The scarcity of empirical studies that address the leadership outcomes and experiences of collegiate women in Saudi Arabia, particularly those in private non-profit universities, provides an opportunity to expand the literature base on higher education in the country. Investigating the leadership understandings of collegiate women in Saudi Arabia's private non-profit universities, the opportunities they have to develop leadership, and how and why they develop leadership offer invaluable insight to university administrators, faculty members, prospective employers, and government leaders.

First, women in Saudi Arabia are entering the workforce with extremely limited leadership training, and in some cases are taking on leadership roles without developing 
the necessary skills and competencies (Albakry, 2015; Aldawsari, 2016; AlDoubi, 2014; Al-Ahmadi, 2011). Findings from this study revealed how collegiate women in Saudi Arabia's private non-profit universities develop leadership that prepares them for opportunities, experiences, and challenges that lie ahead. Second, the surge in collegiate women's enrollment and graduation rates in Saudi Arabia create windows of opportunities to hone in on their leadership potential (Hamdan, 2012). Information generated from this study about collegiate women's perspective and understanding of what leadership means to them helps in the design of co-curricular and formal leadership programs and in the implementation of effective leadership development opportunities that serve the leadership needs of young women in Saudi Arabia.

Third, while this study is limited to collegiate women at private non-profit universities in Saudi Arabia, it created spaces for their inclusion as members of their campus community. Information gleaned from this study offered insight into the role gender-desegregated environments play in the leadership development experiences of collegiate women within and outside the context of Saudi Arabia. Fourth, given that the four private non-profit universities selected for this study offer a Western-style education and curricula within a local context, findings from this study serve as a template for future investigations of the extent to which Western-style education shapes collegiate women's leadership understandings and leadership development experiences in Saudi Arabia.

Fifth, in light of the changing role of women in Saudi Arabia, women leaders and activists have been advocating for legislative and policy reform to bring an end to gender disparities and inequalities in all public and private spheres (AbuSulayman, 2017; Fatany, 
2013). Despite the presence of a women's grassroots movement in Saudi Arabia, the scarcity of empirical studies about the changing role of women in the country weakens efforts to understand their inclusion and advancement in society. This study provided insight into collegiate women's motivations to engage in student leadership opportunities and develop their leadership potential, which yields to future investigations on the role advocacy and activism play in the leadership practices of women in the country.

The significance of this dissertation study is multi-layered. The information gleaned from collegiate women in this qualitative study provided an in-depth understanding to their experiences in and motivation for developing leadership in Saudi Arabia. By sharing their perspective on what leadership means to them and how they came to their understanding of leadership within the context of Saudi Arabia, collegiate women in the study offered insight into a non-Western perspective of leadership that contributes knowledge to the field of leadership studies.

\section{Summary}

The rapidly increasing number of collegiate women in Saudi Arabia signals their academic achievement and advancements by means of education. While there has been a series of events in Saudi Arabia that suggest women's inclusion and full participation as equal members of society, collegiate women are an underutilized resource for social and human capital that can transform and sustain the country's social progress. Despite efforts by Saudi Arabia's private non-profit universities to expand educational experiences through co-curricular programs that entail student leadership opportunities, collegiate women at these universities are a source of untapped leadership potential. The notion of college student leadership development is an unexplored domain in Saudi 
Arabia's higher education, for which there is no data in the literature that offers an explanation and an in-depth understanding to collegiate women's perspective on leadership and leadership development. Therefore, this dissertation study utilized a qualitative inquiry approach to explore and investigate the leadership understandings of collegiate women in Saudi Arabia's private non-profit universities, the opportunities they have to develop leadership, and how and why they develop leadership. The findings of this study generated an understanding of the perspective collegiate women in Saudi Arabia's private non-profit universities have of leadership as a relational practice they engage in to better themselves and others, and to have a greater impact on the Saudi Arabian society. By focusing on collegiate women's perspective, this study provided an in-depth understanding to their experiences in and motivations for leadership development. To explore collegiate women's understandings of leadership and their experiences in leadership development, the following chapter, Chapter Two, provides a review of the literature. 


\section{Chapter Two: Literature Review}

Given the myriad of challenges and complexities in today's world, the demand for insights on leadership theory and practice within the paradigm of college student leadership beyond U.S. borders as related to collegiate women is more pertinent than before. However, leadership scholarship pertaining to collegiate women in non-Western contexts is limited (Kemp, 2013; Madsen, 2010a, 2010b; Renn \& Lytle, 2010). This is particularly true when considering leadership education, training, and development of collegiate women in Arab countries. As indicated in the previous chapter, very little is known about leadership development of collegiate women in Saudi Arabia. Therefore, this chapter reviews the literature to help inform the study's research questions.

To gain an understanding of what leadership means to collegiate women in Saudi Arabia's private non-profit universities and how and why develop leadership, this literature review has four objectives: (1) to highlight the literature on college student leadership development in the United States, (2) to present the literature on leadership development opportunities of collegiate women in the Arab Gulf countries, particularly in the United Arab Emirates (UAE), (3) to review the available literature on leadership development of collegiate women in Saudi Arabia, and (4) to address the limitations in the literature.

\section{College Student Leadership in American Higher Education}

Educating and developing future leaders who thrive in a diverse and democratic society has long-served as one of higher education's core mission in the United States (Astin \& Astin, 2000; Komives, 2011; McIntire, 1989; Zimmerman-Oster \& Burkhardt, 2001). This section provides a literature review of college student leadership 
development within the context of American higher education. It addresses the importance of leadership development for collegiate students, identifies key leadership frameworks and models widely used with collegiate students, discusses dimensions of collegiate context that contribute to students' leadership development, and examines the impact of leadership development on collegiate women. While this section of the literature review emphasizes on a Western higher education context, it can provide insight to the findings of this dissertation study.

\section{The Importance of Leadership Development for Collegiate Students}

The literature addressed varying reasons to the importance of leadership development for collegiate students in American higher education (Astin \& Astin, 2000; Cress et al., 2001; Chambers \& Phelps, 1993; McIntire, 1989). There are four different, yet interconnected views in which scholars maintained. First, McIntire (1989) identified student leadership development as a central student learning outcome. This view highlighted the need for student affairs professionals to integrate theory with practice in leadership development programs in order to help collegiate students fulfill and meet leadership development as a learning outcome (McIntire, 1989). This view supports Kolb's (1984) theory on experiential learning. Second, Chambers and Phelps (1993) asserted that leadership development is significant for collegiate students as it provides opportunities for students to be involved in their own learning and exercise different leadership roles. The authors reflected their view on the significance of student activism as a form of student leadership and the role it played throughout the history of higher education in the United States. Third, Astin and Astin (2000) presented a progressive view of leadership development for collegiate students as a necessity to build a better 
society. By viewing it as a lifelong goal, the authors (Astin \& Astin, 2000) highlighted how leadership development improves collaboration with others and enhancing a shared purpose, becoming responsible citizens, achieving a greater awareness of community needs and social issues, and addressing complex issues effectively. Fourth, Cress et al. (2001) provided an interconnected view on leadership development that emphasizes its positive effect on student development outcomes, educational gains, and leadership capacities.

\section{Key Leadership Frameworks and Models for Collegiate Students}

The historical evolution of leadership theory reflects a shift from the industrial paradigm's leader-centric theories to the postindustrial paradigm's transformative, adaptive, collaborative, relational, and value-based leadership theories (Northouse, 2013), such as authentic leadership (Avolio \& Gardner, 2005; Walumbwa et al., 2008), transformational leadership (Bass \& Riggio, 2006), collective leadership (Grogan \& Shakeshaft, 2011), and systems-based leadership theories (Heifetz et al., 2009; Senge, 1990; Wheatley, 1994). Hence, theoretical frameworks and models of college student leadership development are derived from and influenced by the postindustrial leadership theories. There are six key leadership frameworks and models that have been applied to and designed for college student leadership development.

Applied leadership models. Robert Greenleaf’s (1970/1977) servant leadership model has been one of the earliest and most widely applied models in higher education. As a theoretical bridge between industrial and postindustrial leadership paradigms, servant leadership is a value-based leadership concept of shared processes and mutual outcome in that emphasis is placed on serving others, empowering them, and helping 
them develop their capacities (Dugan \& Komives, 2011; Northouse, 2013). Although servant leadership is often applied to community service and civic engagement programs, Dugan and Komives (2011) cautioned that the model maintains a leader-centric approach to leadership by focusing on the leader's traits and behavior, which are counter to the underlying premise of community service and civic engagement.

Another framework that has been adapted and applied to college student leadership programs is Kouzes and Posner's (2012) the leadership challenge. It identifies five practices of exemplary leaders such as modeling the way, inspiring a shared vision, challenging the process, enabling others to act, and encouraging the heart. Through evidence-based research, Kouzes and Posner (2014) updated and adapted the student leadership challenge framework for collegiate students to guide them in building and developing their capacities for leadership.

The emotionally intelligent leadership model (EIL) is one of the newly adapted models to college student leadership (Shankman \& Allan, 2008). The model conceptualizes leadership as a dynamic relationship between the consciousness of self, consciousness of others, and consciousness of context and asserts that long-term and sustainable leadership requires leaders to have awareness and regulation of emotions in self and others (Northouse, 2013; Shankman \& Allan, 2008). The three facets of EIL are reflected through 21 leadership capacities, some of which are self-awareness, authenticity, emotional self-perception, flexibility, emotional self-control, empathy, change agent, developing relationships, citizenship, and environmental awareness. Given that EIL is a relatively new model that promotes leadership capacities for college students 
to develop, little is known about collegiate students' leadership development outcomes using this framework (Haber et al., 2012; Shankman, Haber, Facca, \& Allen, 2010).

Designed leadership models. Developed by Komives et al. (1998), the relational leadership model was designed to expand the leadership capacity of individuals in order to engage effectively with others within a leadership context. According to the model, leadership is defined as a relational and ethical process rooted in collaboration to achieve positive change. Komives et al. (1998) asserted that purposefulness, inclusiveness, empowerment, ethical practices, and process orientation are five key dimensions for relational leadership. However, Dugan and Komives (2011) highlighted one of the model's limitations in which the five interconnected dimensions have not been examined extensively within leadership development programs. Therefore, little is known about relational leadership and collegiate students' leadership outcomes.

The leadership identity development model was developed by Komives, Owen, Longerbeam, Mainella, and Osteen (2005) to understand how college students perceived, learned, and developed leadership overtime. It is a grounded theory study consisting of six sequential stages students advance through to develop a leadership identity that is stable and congruent with their own social identity (Komives et al., 2005; Wagner, 2011). In the first two stages (awareness and exploration/engagement), student leaders develop a broad approach to leadership that is constantly shifting in meaning as they explore and engage in self-development processes. They typically enter college during the third stage (leader identified) with a view and an approach to leadership based on notions of hierarchy and position. According to Komives et al. (2005), some collegiate students transition to the fourth stage (leadership differentiated) as they come to recognize the 
relational component in leadership and begin to differentiate their view of leadership as a non-positional and process-oriented. Advancing to the final two stages (generativity and integration/synthesis) occurs as a result of an expanded view of leadership to one that is process-oriented and participatory, and thereby develop a leadership identity that becomes relatively stable over time (Komives et al., 2005; Wagner, 2011). Although the model provides an understanding of how collegiate students perceive leadership and their own identity as leaders, little is known about the development of leadership identity among diverse student groups in college, and post college (Haber, 2012; Wagner, 2011).

As the most commonly used theoretical framework with the college student population, the social change model of leadership development (SCM) (HERI, 1996) views leadership as "a purposeful, collaborative, value-based process that results in positive social change" (Komives \& Wagner, 2009, xii). The model's primary goals are to enhance student learning and development through greater self-knowledge and leadership competency, as well as to be a catalyst for positive social change in the community. Collegiate students are able to achieve these goals by developing seven values of social change such as consciousness of self, congruence, commitment, common purpose, collaboration, controversy with civility, and citizenship across interacting dimensions of individual, group, and community in order to achieve the eighth core value of change (Komives \& Wagner, 2009). Despite its considerable use in leadership scholarship and development, the model is limited by the lack of values associated with cultural competence and its failure to examine the different contextual influences that shape the development and practice of leadership (Dugan \& Komives, 2011). 
In essence, postindustrial leadership theories have been influential in the study of college student leadership development. The aforementioned frameworks and models provide a better understanding of the more contemporary views and practices of college student leadership that are non-hierarchical, purposeful, inclusive, collaborative, valuebased, and transformative (Komives, 2011; Komives \& Wagner, 2009; Osteen \& Coburn, 2012; Zimmerman-Oster \& Burkhardt, 2001). Although limitations are associated with these models, leadership scholars emphasize the need to link leadership theory with educational outcomes in order to design and deliver effective leadership development programs for collegiate students.

\section{Elements of the Collegiate Context}

A wide range of elements and dimensions of the collegiate context have been effective in enhancing students' college experiences and developing their leadership capacities (Dugan, 2011; Haber, 2012). Some are identified as curricular elements such as formal leadership programs, or as co-curricular elements such as involvement in student organizations, formal leadership roles, and community service (Dugan, 2011). A number of studies examined the extent to which these particular elements influence student leadership development and enhance the collegiate experiences of students (Cress et al., 2001; Dugan, 2006b; Dugan \& Komives, 2007; Haber et al., 2012).

In a longitudinal database study, Cress et al. (2001) investigated the impact of student participation in leadership development programs on educational and personal development. The results indicated that those who participated in leadership programs improved significantly on leadership involvement measures such as conflict resolution skills, the ability to set goals, and interest in developing leadership in others. Moreover, 
the results showed that students' participation in leadership activities such as volunteering, in-class collaborative projects, and internships positively influenced developmental areas related to educational and personal growth. For example, volunteering had a positive influence on all five developmental outcomes of leadership skills, leadership understanding, personal and social values, multicultural and community awareness, and civic responsibility.

Drawing on the impact of college-related experiences on student leadership development, Dugan (2006b) examined the role of involvement in community service, positional leadership roles, student organizations, and formal leadership programs across the eight leadership constructs associated with SCM. The findings of this study suggested that student involvement in community service experiences had the most influence on leadership development. Moreover, those involved in positional leadership roles presented significantly high scores on four leadership constructs of the SCM. Although the results indicated that involvement in student organizations and formal leadership programs had the least influence on leadership development, other studies countered this finding (Dugan \& Komives, 2007; Haber et al., 2012).

Dugan and Komives (2007) developed and conducted the Multi-Institutional Study of Leadership (MSL) to understand how various aspects and dimensions within higher education institutions in the United States contribute to college students' leadership development. Guided by the SCM as the study's theoretical framework, the results showed that collegiate students' overall engagement and involvement in the collegiate environment has a positive influence on their leadership capacity (Dugan, 2011). In particular, providing spaces and opportunities for collegiate students to engage 
in discussions about important issues such as diversity and social justice was the strongest element of collegiate environment to significantly influence SCM's eight leadership values. Furthermore, positional leadership roles and involvement in student organizations significantly influenced the SCM's leadership values.

Building on similar notions of leadership development and involvement in student organizations, Haber et al. (2012) conducted a quantitative study with 566 college students from 139 higher education institutions to examine the extent to which college students' self-reported emotional intelligent leadership behaviors differed based on their level of involvement in student organizations and holding formal leadership roles. Using the EIL model to guide their study, the researchers investigated the differences among the model's three leadership behavioral constructs (consciousness of self, consciousness of others, and consciousness of context) based on the breath of involvement in student organizations. Haber et al. (2012) indicated that student leaders involved in four or more student organizations presented higher scores on the emotionally intelligent leadership scale. Moreover, the results revealed that higher levels of emotionally intelligent leadership, particularly consciousness of context and consciousness of others, were associated with collegiate students who held a formal leadership role in a student organization. Thus, the researchers suggested that holding a formal leadership role is associated with student leaders' high levels of empathy and their ability to develop relationships and work with others in a particular environment.

The aforementioned studies (Cress et al., 2001; Dugan, 2006b; Dugan \& Komives, 2007; Haber et al., 2012) examined how particular elements of the collegiate context such as involvement in student organizations, positional leadership roles, and 
community service influence student leadership development and enhanced students' collegiate leadership experiences. Despite the limitations, these studies demonstrated that curricular and co-curricular programs and activities contribute to collegiate students' educational and personal development, socially responsible leadership values, positive leadership experiences, and emotionally intelligent leadership behavior.

\section{The Impact of Leadership Development on Collegiate Women}

Considering the fact that $57 \%$ of collegiate students in American higher education in 2013 were women (NCES, 2016), topics related to gender and student leadership development have been gaining interest among some researchers (Dugan, 2011; HaberCurren, 2013). This is particularly true considering the literature on college student leadership development as related to gender differences, leadership styles, and leadership experiences (Dugan, 2006a; Dugan \& Komives, 2007; Komives, 1994; Haber, 2011b; Posner, 2009).

In a longitudinal study, Posner (2009) investigated whether or not completing a formal leadership development program influences leadership behavior over time, and examined the impact of gender on leadership behavior and leadership development. Using Kouzes and Posner's (2008) Student Leadership Practice Inventory (S-LPI), data was collected from business students in their freshman year as participants in a leadership development program. The S-LPI was administered three years later to all senior students in the business school. The study revealed that the leadership development program significantly influenced students' leadership behavior over time. For example, senior students significantly engaged more in all five practices of the student leadership challenge than when they were freshman students. In addition, scores of all five 
leadership practices for male and female students increased significantly over the years. Thus, gender was not a predictor of students' leadership behavior and development.

Haber (2011b) conducted a qualitative study that explored the perceptions of four collegiate women leaders as related to their experiences in leadership in a student organization. The study examined the leadership styles, factors that influenced leadership behavior, and the impact of gender on the leadership experiences of collegiate women leaders. The findings revealed a number of leadership styles collegiate women engage in such as relationship-oriented style, task-oriented style, a hybrid of both approaches, and an amalgam of other approaches that promote empowerment and responsibility to others and the organization. Moreover, the results showed three overarching factors that influence how collegiate women lead such as leadership behaviors of past leaders in the organization, gender representation of the group and the organization's structure and purpose, and principles of authenticity and inclusion that helped affirm their identity as leaders. Although they did not perceive gender as factor impacting their leadership experiences, the findings highlighted how gender interacts with leadership, which signals gender as a factor impacting leadership experiences.

The proliferation and increased presence of varying leadership programs on college campuses generated considerable attention from leadership scholars and educators (Komives et al., 2011). This section presented a literature review on college student leadership development within the context of American higher education. Based on the literature, there were four interrelated views on the significance of college student leadership development, whereby it is an important learning outcome, an opportunity to exercise student activism, a requirement to build a better society, and a source for 
development outcomes, educational gains, leadership capacities. Moreover, the frameworks adapted and specifically designed for college student leadership can only confirm the need to link leadership theory with educational outcomes. Through scholarship, researchers provided empirical evidence that demonstrated the extend to which student involvement, as well as gender, contributed to the leadership development of collegiate students. While these studies are significant and provide insight to leadership development at the collegiate level, they explored the phenomenon within the context of American higher education. Thus, it is necessary to explore leadership development of collegiate women in the Arab Gulf States.

\section{Leadership Development of Collegiate Women in the Arab Gulf States}

Within the context of Arab societies, the notion of collegiate women and leadership is relatively new. There is scant scholarly research on the overarching topic of women and leadership development in educational and non-educational settings in Arab countries (Kemp, 2013; Madsen, 2010a, 2010b; Metcalfe, 2007, 2011). With the youth population surging, enrollment and graduation of women increasing, and rapid social, economic, and political changes occurring in the Arab region (Kemp, 2013; UNESCO, 2011), there is a need and an opportunity for leadership scholars and educators to expand the literature base on areas pertaining to leadership development of collegiate women in the region.

In the Arab Gulf countries (Bahrain, Kuwait, Oman, Qatar, Saudi Arabia, and the UAE), more than half of college students are women (Dubai Women Establishment, 2011; Kemp, 2013; Madsen \& Kemp, 2013; Metcalfe, 2007). However, women in these states are challenged by high unemployment rates and underrepresentation in leadership 
positions. For example, in 2006, women in Qatar represented a little over $40 \%$ of the total unemployment population (Dubai Women Establishment, 2011). Moreover, a recent study revealed that, compared with other Arab Gulf countries, Qatar has one of the lowest percentages on women leaders overall with 3.6\% (Kemp et al., 2015). Similarly, while women in the UAE are faced with unemployment challenges, the 2009 unemployment rate of college-educated women was approximately 14\% (Kemp, 2013). Kemp et al. (2015) indicated that the UAE has the highest percentage of women in leadership with $5.1 \%$ compared to other neighboring countries. Despite collegiate women's access to education in Arab Gulf countries, there seems to be a gap between student learning outcomes and leadership development, which may contribute considerably to the challenges women face in those countries.

To understand and address these challenges, a review of the literature is presented on the leadership development opportunities collegiate women have within the context of the UAE. As a country that is rapidly developing and transforming politically, economically, socially, and academically, the UAE serves as an optimal example to include in this literature review for the following reasons. First, the UAE recently exerted efforts to empower young women through leadership development and training programs on and off college campuses (Dubai Women Establishment, 2011; Madsen, 2010a). Second, while relatively small in numbers, women in the UAE are advancing and taking on leadership roles at the government, economic, collegiate, and societal levels (Dubai Women Establishment, 2011; Kemp, 2013; Kemp et al., 2015). Third, women in the UAE face social, cultural, and educational challenges that are analogous to those faced by women in other Arab Gulf countries (Metcalfe, 2007, 2011), such as Saudi Arabia. 
Therefore, this section reviews the literature on leadership development opportunities collegiate women have in the UAE, as well as presents available information on opportunities young women in other Arab Gulf countries have to develop leadership.

\section{Leadership Development of Collegiate Women in the UAE}

The available literature on leadership development in the UAE are predominantly

focused on understanding the current progress and experiences of women and leadership (Kemp et al., 2015; Madsen, 2009a, 2010b; Metcalfe, 2011; Wright \& Bennett, 2013). However, only a few studies addressed leadership development of young women within the context of higher education (Madsen, 2009b, 2010a; Wright \& Bennett, 2013). Madsen (2009b, 2010a) studied how Emirati collegiate women learn and develop in an educational environment. Using a survey study, Madsen (2009b) explored collegiate women's perception of transformational learning experiences and identified the influences that may affect these perceptions. According to the results, the participants perceived themselves to have experienced transformational learning at the college. The study found that all three influencing factors; such as individuals, learning assignments and activities, and outside college-related opportunities; contributed to experiencing transformational learning. Madsen (2009b) indicated that engaging in reflective assignments influenced students' perceptions of experiencing transformational learning.

Building on her earlier work, Madsen (2010a) conducted a phenomenological research study to explore the transformational learning experiences of collegiate women in the UAE. According to the results, participants' transformational learning experiences helped them develop leadership competencies. For example, engaging in presentation assignments helped them develop self-confidence, which contributed to their English 
language learning. In addition, engaging in critical reflections and applied learning helped transform their learning experiences. Faculty mentoring, peer support, and the overall campus environment are factors that influenced collegiate women's transformational learning experiences. The findings revealed that involvement in cocurricular activities such as peer tutoring and mentoring, student council, participating in student forums and conferences, internships, and community service transformed their learning experiences significantly. This finding demonstrated that collegiate women at a university in the UAE engaged in co-curricular and formal leadership programs.

To explore interactions within team settings, Wright and Bennett (2013) conducted a study to understanding how collegiate women in the UAE develop team leadership skills. The researchers collected data from two higher education institutions in the UAE in which one served to educate Emirati collegiate women only, while the other served to educate collegiate men and women of Emirati and other diverse nationalities. Also, the researchers included a comparison group sample of Asian and Anglo collegiate students. The results indicated that Emirati collegiate women perceived their team leadership experiences to be characterized by conflict when working in diverse team settings. Moreover, the researchers asserted that perceptions of conflict decreased when Emirati women work in a homogenous team setting. An interesting finding was that during a situation of conflict, the group of Emirati women reported higher tendencies to be silent in the homogenous team compared to the mixed-gender and diverse group (Wright \& Bennett, 2013). While the findings from this study provided an overview on students' perceptions of teamwork and collaboration, it did not provide an assessment of leadership competencies such as communication skills, negotiation, and collaboration. 
Although the scholarship on leadership development of college students in the UAE is extremely limited, the reviewed studies helped in identifying gaps in the literature on this topic. They demonstrated that higher education in the UAE offers unintentional opportunities to develop collegiate women's leadership potential. Thus, there are a great deal of opportunities for leadership scholars to explore and investigate the experiences of collegiate women involved in co-curricular programs, such as student council and mentoring, that facilitate and promote leadership development.

\section{Leadership Development in Other Arab Gulf Countries}

While the overarching topic of women and leadership in the UAE seems to be gaining considerable interest from scholars, little is known within the context of other Arab Gulf countries. Kemp et al. (2015) conducted a comparative study of over 2,800 private and public companies across the six Arab Gulf countries (Bahrain, Kuwait, Oman, Qatar, Saudi Arabia, and the UAE) to document the status of women leaders and the positions they hold. While the study was comparative in nature and had its limitations (Kemp et al., 2015), it is the only known scholarly study that was conducted on these countries. Therefore, this sub-section presents an overview of the only known leadership development program in the literature for young women across the Arab Gulf countries.

In Qatar, the Young Women Leaders Academy is an intensive leadership program designed to empower young adult women to participate in the political process by developing political and advocacy skills and leadership capabilities. It entails a 10-day academic training program, followed by an internship that fosters experiences in political processes (NDI, 2009). Although the program offers a rich opportunity for young thriving 
women to enhance their leadership capacities and bring about social and political change, it does lacks empirical evidence of learning and development outcomes.

There is scant information published on the overarching topic of leadership development programs on and off college campuses within the Arab Gulf countries. The scarcity of available information on leadership development of young women is alarming given the surging youth population in the region. Hence, with the rise of female unemployment and a dearth of leadership development opportunities for young women in the Arab Gulf countries, it is safe to assert the critical need for higher education in this region to assume responsibility by fostering collegiate women's personal, social, educational, professional, and leadership development and preparing them to become effective and socially responsible leaders.

\section{Leadership Development of Collegiate Women in Saudi Arabia}

In Saudi Arabia, the rapid growth in higher education enrollment rates of collegiate women over the years has been overwhelming. Despite women's access to higher education in the country, the exclusion and marginalization of collegiate women in Saudi Arabia from public and private domains is concerning. Women have the lowest rate of employment in which they accounted for only $15.15 \%$ of the employed population in Saudi Arabia in 2017 (GASTAT, 2017b). Moreover, according to Kemp et al. (2015), Saudi Arabia has the lowest percentage of women in leadership positions with $2.5 \%$ compared to other Arab Gulf countries.

With calls for maximizing women's participation and advancements in the Saudi workforce, the available literature on leadership development and women in Saudi Arabia is largely centered at the professional level (Abalkhail, 2017; Abalkhail \& Allen, 2015; 
Al-Ahmadi, 2011; Bechtold, 2014), focused on challenges and obstacles women face in the workplace (Albakry, 2015; Alyahya, 2016; Al-Ahmadi, 2011; Elamin \& Omair, 2010; Kattan et al., 2016; Thompson, 2015), and concentrated within the context of business or higher education administration (Aldawsari, 2016; AlDoubi, 2014; Al-kayed, 2015; Kattan et al., 2016). Little is known about intentional efforts put forth by higher education institutions in Saudi Arabia to develop collegiate women's leadership potential.

In this section, a review of the literature is presented on collegiate women's leadership development in Saudi Arabia to examine the opportunities available to develop leadership, explore the ways in which they learn about leadership, and identify factors that promote and impede their leadership development. Due to the dearth in scholarly work pertaining to leadership development of collegiate women in Saudi Arabia, this section includes an overview of published information that assert leadership development opportunities for collegiate women in Saudi Arabia, reviews three studies about collegiate women in Saudi Arabia that examined their understandings and perceptions of women in leadership, and identifies factors that promote and impede leadership development of collegiate women in Saudi Arabia. Moreover, this section attempts to understand the formal and informal processes collegiate women engage in to develop leadership, the experiences that shape their leadership skills, the motivating factors to develop leadership, the value they place on leadership development, and the outcomes they anticipate from developing leadership.

\section{Opportunities for Leadership Development}

Through co-curricular activities and programs, college students in Saudi Arabia are provided with opportunities to help them develop necessary skills that will prepare 
them for the workforce ("Ministry of Higher Education's Plan", 2010). As discussed in Chapter One, private non-profit universities in Saudi Arabia emphasize co-curricular programs such as student organizations, volunteering, community engagement, and shortterm and long-term leadership courses as opportunities for collegiate women to develop leadership (Alexander, 2011; Bennet, Cornwell, Jamal Al-Lail, \& Schenck, 2012; Ibrahim \& Sarirete, 2014; Jamjoom, 2012). However, limited scholarship is available to support the claim.

Bennet et al. (2012) reported on the Global Liberal Arts Alliance’s Stewardship for the Global Common educational model that advances theory and practice of undergraduate education. The authors (2012) reflected on a member of the alliance, a private non-profit university for women in Saudi Arabia. They indicated that the educational model's core interdisciplinary approach of collaboration and stewardship provided an opportunity for collegiate women from this university to develop professional competencies, embody socially responsible practices, and enhance their role within their community. While the educational model incorporates basic principles of servant leadership, the authors failed to provide empirical findings that support the model's student learning and leadership outcomes.

From a survey study of more than 300 collegiate women enrolled in a private nonprofit university in Saudi Arabia, Ibrahim and Sarirete (2014) investigated participants' perceptions of the university's leadership program. According to the researchers, the program's design was guided by Vygotsky's (1978) social development theory and delivered predominantly through short-term leadership experiences and student involvement activities. The results showed that leadership experiences in the form of 
workshops and lectures were less favorable to students, whereas student involvement experiences such as student organization and community engagement were more favorable. Interestingly, the study was not empirically-based, rather descriptive in nature to present its data as part of the university's program evaluation of student affairs services. However, the survey study offered insights into the extent of opportunities provided to collegiate women in Saudi Arabia to develop their leadership potential.

With internationalization trends occurring in Saudi Arabia as part of education reform efforts, there has been a handful of reports on short-term and long-term leadership courses provided to collegiate women in Saudi universities by Western educators in the field of leadership (Tighe, 2014; White, 2016). However, much is unknown about the learning outcomes of these courses. In this sub-section, the selected publications presented a cursory review and an example of the available leadership development opportunities, which provide leadership scholars a starting point to conduct empirical studies that investigate college student leadership development in Saudi Arabia.

\section{Collegiate Women's Perspective and Understanding of Leadership}

The notion of women in leadership is a relatively new concept in Saudi Arabia. Therefore, this sub-section presents and discusses two research studies conducted at a private non-profit university (Alexander, 2011, 2013), and one research study conducted at a public university (Hamdan, Alexander, \& Al-Hattami, 2016), to examine collegiate women's understandings and perceptions of leadership. Alexander (2011) conducted a pre-test/post-test quantitative study to examine the impact of a leadership course on students' perceived leadership competence. Data was collected from a convenience sample of 94 collegiate women enrolled in a leadership course taught by the researcher. 
According to the results, there were statistically significant differences in participants' perceived leadership competence, except for their perceived attitudes toward the value in learning about leadership, making a difference in their community, being an ethical person, and having an impact on others. Yet, the results showed that a leadership course did influence participants' perceptions of their leadership competencies.

In another study, Alexander (2013) conducted a mixed-method research design to examine collegiate women's perceptions of effective female leadership. Data was collected from 50 participants enrolled in a leadership and teamwork course, using their written essays on a Saudi female leader and descriptions of the leader's traits and characteristics that contribute to the notion of effective leadership. In addition, the study included a survey designed by the researcher to examine participants' perceptions of inspirational leaders. The results showed common themes that described successful female leaders such as perseverance in the face of obstacles, being the first woman to achieve a goal in one's field, succeeding in a male dominant profession, achieving a dream or a goal, and inspiring others. Furthermore, the findings from the survey provided additional insights to the perceived leadership style of a successful female leader such as democratic leadership and charismatic leadership styles.

The findings from both studies (Alexander, 2011, 2013) suggested that collegiate women in a private non-profit university seem to view leadership from a leader-centric perspective, while failing to conceptualize the notion of an effective leader from a postindustrial leadership perspective. Moreover, it is safe to assert that prevailing gender differences as related to leadership were evident in one study (Alexander, 2013) for which the researcher argued that a successful female leader is only perceived as such for 
defying the odds and achieving excellence in a male dominant profession. Thus, the study reflected pervasive views that maintain gender bias and stereotypes, which may challenge leadership educators and practitioners in their quest to develop the leadership potential of young women in Saudi Arabia. Although Alexander $(2011,2013)$ provided an overview of collegiate women's perception of an effective female leader, serious limitations must be considered related to the sampling approach, instruments, and design used.

To understand collegiate women's perceptions of leadership, Hamdan et al. (2016) conducted a survey research study with 50 participants from a public university. The research study examined the participants' perceptions of leadership development, effective leadership, characteristics of an effective leader, and women leaders. The findings reveled that all participants perceived the development of leadership skills to be an important element to an individual's education. In addition, the respondents perceived the significance of leadership development to acquire conflict resolution and problem solving skills, to be of service to others and the organization they work at, and to achieve goals.

Moreover, Hamdan et al. (2016) explored participants' perceptions of effective leadership. The results showed that responses were the highest for perceiving effective leadership as a group of skills and practices aimed to achieve a goal, the ability to lead a team by delegating tasks and solving problems, and engaging in on-going communication with team members. The survey asked two interrelated questions about requirements for a leader to be effective and characteristics of an effective leader. The findings revealed overlapping responses in which honesty, fairness, and efficiency were perceived to be requirements for and characteristics of an effective leader. Furthermore, Hamdan et al. 
(2016) asserted that all survey respondents viewed Saudi women as capable of being successful leaders. The results of the study showed that holding an important leadership position, being competent, and developing effective leadership skills were perceived as essential factors for a Saudi woman to succeed as a leader. Although the survey study presented a number of limitations in terms of sampling, methodology, quality of survey instrument, and data analysis, it provided a general understanding of the perceptions collegiate women may have about effective leadership.

This sub-section reviewed the literature on the leadership perceptions of collegiate women in Saudi Arabia. These studied revealed that leadership tends to be viewed as leader-centric, leadership education may influence collegiate women's perception of their own leadership potential, and leadership development is important to their academic learning. However, these studies also revealed that much is unknown about their leadership understandings and the opportunities they have to develop leadership, which create spaces for scholars to address the gaps in the literature.

\section{Factors Promoting and Impeding Leadership Opportunities}

Despite their access to higher education, women in Saudi Arabia are faced with a juxtaposition of factors that support and oppose opportunities for them to develop leadership. A number of studies explored challenges and opportunities women leaders face in Saudi Arabia (Abalkhail, 2017; Albakry, 2015; Aldawsari, 2016; AlDoubi, 2014; Alsubaihi, 2016; Alyahya, 2016; Hodges, 2017; Thompson, 2015). While these studies did not address opportunities for and challenges to collegiate women's leadership development, they provide an understanding of the factors that are likely to hinder and promote opportunities for them to develop and practice leadership post graduation. The 
reviewed research studies identified common themes impeding women's leadership that are clustered under three interrelated and interconnected factors unique to the context of Saudi Arabia: social, legal, and professional.

Social factors. Defined gender roles and stereotypes have been a dominant factor that hinder women's leadership opportunities. Stemming from social norms and practices, the literature pointed to the expectations placed on women to carry out their domestic roles instead of pursuing a career and neglecting their family (Albakry, 2016; Hodges, 2017). In a study on the challenges faced by women leaders in Saudi Arabia, Hodges (2017) indicated that there are widespread social misperceptions about leadership's association with masculine traits in which the pursuit for leadership may signal defiance to socially constructed gender roles, and thereby distort their familial and societal reputation. In addition, women leaders asserted that societal practices place expectations on them to balance family and work responsibilities (Albakry, 2016; Aldawsari, 2016).

Social attitudes maintain gender roles and stereotypes about women's capabilities. Research studies (Aldawsari, 2016; Alsubaihi, 2016; Hodges, 2017) revealed that traditional social attitudes do not view men and women as equal in abilities, whereby there is a prevailing belief that stereotypes men's capabilities as leaders and undermines women's abilities to cope with the demands of leadership. The defined gender roles and stereotypes serve as social constraints that distort women's self-confidence and perception of becoming leaders (Alsubaihi, 2016; Hodges, 2017). According to Hodges (2017), social attitudes and norms maintain the notion of inferiority to men and influence women's mistaken perceptions of themselves, which becomes difficult for women to see themselves as leaders. Furthermore, social attitudes and norms about women's socially 
constructed roles shaped laws and policies that maintain male dominance (Albakry, 2016; Alyahya, 2016). Thus, these social factors hinder opportunities for women in Saudi Arabia to develop and experience leadership.

Legal factors. As discussed in Chapter One, misinterpretations of authentic Islamic principles produced laws, policies, and regulations in Saudi Arabia that serve to limit women's independence and autonomy, and perpetuate their marginalization from society and exclusion from the workplace (Hamdan, 2012). Hodges (2017) argued that laws such as gender-segregated environments and male-guardianship marginalizes and excludes women from ascending to leadership roles and positions, and from obtaining equal opportunities to develop their leadership competencies. This argument corroborated Thompson's (2015) view of the marginalization and exclusion of women leaders in Saudi Arabia from policy-making and decision-making processes counteract the notion of women's empowerment in leadership and in society. Moreover, research studies about the experiences of women leaders in Saudi Arabia (Albakry, 2016; Aldawsari, 2016) found that gender-segregation and the male-guardianship law hinder opportunities for women's progression to leadership positions.

Professional factors. The aforementioned social and legal factors are manifested in workplace environments in Saudi Arabia and have negatively impacted opportunities for women in leadership. For example, stereotypes against women leaders, such as being emotional and the inability to handle the demands of leadership, continue to prevail in workplace environments (Alyahya, 2016). In research studies that investigated the experiences of women leaders in higher education (Aldawsari, 2016; AlDoubi, 2014), the 
findings revealed that women leaders conform to defined gender roles and stereotypes by remaining uninvolved in decision making processes.

As a law and a social practice, gender-segregation in the workplace has been found to influence gender bias and discrimination and produce ineffective leadership practices (Aldawsari, 2016; AlDoubi, 2014). Research studies showed that women leaders in Saudi Arabia experience gender bias, discrimination, and inequality in terms of senior leadership opportunities (Abalkhail, 2017; Aldawsari, 2016; Alsubaihi, 2016). For example, Alsubaihi (2016) indicated that women leaders are provided with minimal opportunities to uphold senior leadership positions at organizations. Presenting similar notions, Abalkhail (2017) and Aldawsari (2016) asserted that organizations tend to favor and be biased toward men over women for senior leadership positions. Furthermore, Thompson (2015) argued that when organizational structures establish women only workplace environments where women leaders operate and are in subordination to the organization's male only environment, they limit women leaders' competencies and effectiveness. For example, a common finding was revealed in studies that investigated women's leadership practices in gender-segregated work environments in Saudi Arabia, whereby women leaders have extremely limited authority in decisions-making processes and limited opportunities to develop their leadership competencies (Abalkhail, 2017; Aldawsari, 2016; Alsubaihi, 2016; Alyahya, 2016; Hodges, 2017). These findings from the reviewed literature revealed the extremely limited leadership experiences women have in Saudi Arabia, and suggested that gender-segregated work environments exclude women from professional and leadership development opportunities. 
Factors promoting leadership. Given that women in leadership is a relatively new phenomenon in Saudi Arabia, the available literature is heavily focused on challenges impeding leadership opportunities for women. There are limited research studies that investigated the perceptions of women leaders of factors that promote leadership (Abalkhail, 2017; Aldawsari, 2016; Alyahya, 2016). In a study that investigated the lived-experiences of women leaders at a public university in Saudi Arabia (Aldawsari, 2016), the results showed that mentoring, family support, and being a woman in the profession were factors that contributed to their advancement to senior leadership positions. Similarly, Abalkhail (2017) found that women academic leaders from two public universities in Saudi Arabia perceived their access to education, male family members' support, and self-confidence as factors influencing their progression to leadership positions. Moreover, Alyahya (2016) found that women's hard work and determination, self-confidence, and exposure to different cultures and viewpoints have been significant factors in promoting and shaping their leadership experiences.

To summarize, this section provided a review of the literature that examined available opportunities in Saudi Arabia for collegiate women to develop leadership. While limited, the literature highlighted curricular and co-curricular activities and programs such as student organizations, community service, short-term and long-term leadership courses as ways in which collegiate women in Saudi Arabia develop leadership. The reviewed literature pointed to collegiate women's ability to learn about leadership by enrolling in undergraduate courses that facilitated leadership education and examined their understandings of effective leadership and perceptions of women in 
leadership. These opportunities may suggest that collegiate women engage in formal and informal processes to develop their leadership potential.

In addition, the literature identified contributing factors that promote and impede opportunities for women to develop and experience leadership. Impeding factors were grouped under three categories — social, legal, and professional. By reviewing the literature on these identified factors pertaining to women leaders, it provided an understanding of the unique complexities collegiate women in Saudi Arabia may face as they participate in the workforce.

\section{Limitations of the Literature Review}

This review of the literature is limited in different ways. First, the literature on college student leadership development in American higher education is limited in presenting an in-depth understanding of the collegiate women's experiences in developing leadership. Second, due to limited empirical evidence on leadership development of collegiate women in Arab Gulf countries, it was necessary to broaden the eligibility for the inclusion of other documents and resources. This chapter included primary sources such as peer-reviewed journals and books, government and institutional reports, as well as news websites. For example, institutional briefs or working papers have been only useful in providing descriptive information on available leadership development programs. Third, the reviewed publications do not extend beyond the Arab Gulf countries, as these countries share unique yet complex social norms and practices compared to other countries in the Middle East. By doing so, it provided a clear understanding of the gaps within the literature. 
Fourth, research studies on the overarching topic of women and leadership in Saudi Arabia are extremely limited. Much of the literature focused on women and leadership from a human resource management framework, and on challenges women leaders experience in ascending to senior leadership positions. Little is known about what has contributed to their success as leaders. Fifth, the literature reviewed on leadership development of collegiate women in Saudi Arabia presented their own limitations as related to sampling methods, sample size and demographics, research design, and theoretical underpinnings. Thus, there is a need to utilize diverse research design approaches and methodologies to understand the leadership development of collegiate women in Saudi Arabia.

\section{Summary}

Many countries in the Middle East fall short in recognizing women leaders as assets to the progress, development, and positive change of their respective nation. While college student leadership development is a relatively new concept in Arab Gulf countries, investigating the leadership development of collegiate women in Saudi Arabia can produce pivotal outcomes that help in preparing them for leadership and for the challenges they may face in life. This literature review chapter not only examined the leadership development of collegiate women within the context of American higher education, but also sought to understand how leadership development of collegiate women applies within the context of Saudi Arabia's higher education systems by exploring opportunities they have to develop leadership and understanding their perceptions of women in leadership. Doing so helped in gaining a comprehensive 
understanding of the factors that promote and impede leadership development of women in Saudi Arabia, which may signal similar factors experienced by collegiate women.

However, many questions remain unanswered pertaining to college student leadership development in Saudi Arabia's higher education systems. Much is unknown about collegiate women's understanding of leadership and leadership opportunities. In addition, little is known about the opportunities universities, particularly private nonprofit universities, provide for collegiate women to develop leadership. Moreover, there is no data that presents an in-depth understanding of collegiate women's perspective as to how and why they develop leadership at the collegiate level. Therefore, this research study aimed to address these gaps in the literature by exploring and investigating collegiate women's understanding of leadership and their experiences in developing leadership within the context of private non-profit universities in Saudi Arabia. The next chapter, Chapter Three, explains the methodology used in this research study. 


\section{Chapter Three: Methodology}

Within the context of Saudi Arabia's higher education, little is known about the leadership development of collegiate women. This dissertation study explored and investigated the leadership understandings of collegiate women in Saudi Arabia's private non-profit universities, the opportunities they have to develop leadership, and how and why they develop leadership. The study pursued a qualitative approach to inquiry utilizing a Constructivist Grounded Theory Methodology that values the voices of participants and creates spaces to understand their subjective experiences.

This chapter (1) states the study's research questions, (2) provides an in-depth discussion of Grounded Theory Methodology, (3) presents the epistemological stance and theoretical framework that guided the study's inquiry approach, (4) explains how the constructivist approach to grounded theory is a fit choice for this study, (5) provides a subjectivity statement reflecting the researcher positionality, (6) discusses how the use of Culturally Responsive Methodology as the ethical framework of this study allowed for an authentic and rigorous inquiry, and (7) describes and illustrates the methods used to collect and analyze this study's data.

\section{Research Questions}

This dissertation study asked the following research questions:

- In Saudi Arabia's private non-profit universities, what are collegiate women's understanding of leadership and leadership opportunities?

- What opportunities do collegiate women in Saudi Arabia's private non-profit universities have to develop leadership? 
- From their perspective, how do collegiate women in Saudi Arabia's private nonprofit universities develop leadership?

- Why do collegiate women in Saudi Arabia's private non-profit universities develop leadership?

\section{Grounded Theory Methodology (GTM)}

Grounded Theory Methodology (GTM) is a rigorous qualitative research methodology that enables researchers to construct substantive theories grounded in the experiences of the participants within the phenomenon (Charmaz, 2011; Creswell, 2013; Schwandt, 2007). This section provides a discussion on GTM that includes a brief history, an overview of the constructivist perspective to GTM, the unique features of the methodology, and the central methods and strategies GTM uses to collect and analyze data. Moreover, this section explains the use of the constructivist approach to GTM as the most suitable choice for this study.

\section{Brief History}

Grounded theory was developed in 1967 by sociologists Barney G. Glaser and Anselm L. Strauss. Despite Glaser's positivist stance and Strauss's philosophical approach rooted in the pragmatist tradition and symbolic interactionism (Corbin \& Strauss, 2015), they challenged quantitative researchers' criticism over qualitative inquiry's inability to meet the criteria of reliability, validity, and replication (Bryant \& Charmaz, 2007). To legitimize qualitative research as a rigorous and credible form of inquiry, Glaser and Strauss offered a clear systematic approach to qualitative research emphasizing data analysis and theory construction instead of data gathering and theory 
verification (Charmaz, 2008). They aimed to shift qualitative research beyond description and into abstract theory construction to explain social processes (Charmaz, 2014a).

Although Glaser and Strauss's (1967) grounded theory provided a concise justification for making qualitative inquiry processes and procedures visible, comprehensible, and replicable, the methodology's weakness resides in its objectivist perspective (Bryant \& Charmaz, 2007). The objectivist perspective to grounded theory relies on authoritative voice of the researcher, highlights the researcher's role as a neutral observer, and makes abstract generalization about the data (Charmaz, 2011, 2014a). For example, Glaser's rigorous codifying methods, concept-indicator approach, and use of qualitative-like language influenced his strategies to utilize explicit methods for grounded theory research (Charmaz, 2014a). Also, Strauss's perspective to grounded theory shifted away from theory construction and toward theory verification by applying technical and rigid strategies (Charmaz, 2014a; Strauss, 1987; Strauss \& Corbin, 1998). These aforementioned examples revealed objectivist and post-positivistic assumptions embedded within Glaser and Strauss's collaborative, yet divergent perspectives to grounded theory (Charmaz, 2011, 2014a).

\section{Constructivist Grounded Theory (CGT)}

In the 1990s, scholars began to shift grounded theory away from its positivistic perspective and toward a constructivist perspective that negates worldviews of objectivity and truth as value-free (Charmaz, 2014a). CGT builds on the epistemological stance of social constructivism reflected within the pragmatist philosophical tradition and symbolic interactionism that Strauss embraced in his approach to grounded theory (Charmaz, 2011). It aligns with pragmatism by acknowledging and looking for multiple perspectives 
and ways of knowing, and reflects symbolic interactionism through human interaction, language, and meaning (Charmaz, 2008, 2011, 2014a).

CGT aims for an interpretive understanding by carrying out inductive inquiry, utilizing comparative logic, applying abductive reasoning, and focusing on interaction throughout the research process (Charmaz, 2008, 2014a; Creswell, 2013). It resists mechanical and prescriptive applications, and instead adopts a flexible and fluid approach to research (Charmaz, 2008). For example, interviews with participants may transform into dialogue and conversations about emerging categories that help researchers make sense of participants' experiences, meaning, and actions (Charmaz, 2011). Through interaction and dialogue, researchers and participants engage in co-construction of knowledge (Charmaz 2008).

CGT emphasizes the researcher's roles and actions throughout the research process (Charmaz, 2011). It views researchers as part of the social world they study, and thereby acknowledges the role in which researchers' subjectivity plays in shaping data construction and interpretation (Charmaz, 2014a). Therefore, constructivist grounded theory emphasizes a researcher's involvement in reflexivity as an integral element to a grounded theory research study (Charmaz, 2011).

\section{Unique Features}

In GTM, analysis begins once data is collected (Corbin \& Strauss, 2015). It

allows researchers to engage in an iterative process of going back and forth between data collection and analysis to ask analytic questions and further enhance the abstract level of their analysis (Charmaz, 2011; Creswell, 2013). For example, constant comparative analysis is a central method of analysis in GTM that uses inductive data to construct 
abstract analytic categories and compare them to emerging codes and categories (Bryant \& Charmaz, 2007; Merriam, 2002). This method not only keeps researchers interacting with the data throughout the research process, but also sharpens their analysis of emerging data (Charmaz, 2011). Moreover, the iterative process in GTM enables researchers to engage in theoretical sampling. A significant method to theory construction, theoretical sampling refers to data collection based on the analysis of the initial data collected (Corbin \& Strauss, 2015).

The simultaneous data collection and analysis feature in GTM is uniquely important. For example, Corbin and Strauss (2015) indicated that collecting all the data at once instead of following up each data-collection session with analysis reduces the significance and value of theoretical sampling to the construction of the theory. Furthermore, collecting all the data at once disengages researchers from the abductive form of reasoning necessary for theoretical sampling (Chamaz, 2011). In grounded theory data analysis, abduction occurs when researchers come across surprising data that do not fit the existing findings (Charmaz, 2014a). The emergence of surprising findings can advance theory construction by leading researchers toward an unexpected theoretical direction to better understand the data (Charmaz, 2011, 2014a). Thus, it can be implied that the interrelatedness of data collection and analysis is a central and unique feature of GTM.

Charmaz (2011) indicated that coding data in action terms, gerunds, gives grounded theory its unique feature. Coding with gerunds allows researchers to recognize implicit processes in the data, make connections between emerging codes, and continue engaging with the data through analysis (Charmaz, 2011). By using gerunds to code for 
actions, researchers are able to envision and understand individual or collective actions (Charmaz, 2011, 2014a).

Another unique feature of grounded theory is the use of sensitizing concepts. According to Charmaz (2014a), sensitizing concepts are used as tentative rather than definitive tools to develop ideas about processes that are found in the data. They provide a staring point for researchers to form interview questions, reflect on and think analytically about the data, and develop their ideas (Charmaz, 2014a). For example, the sensitizing concepts that inform this study included: (1) collegiate women favor involvement in student organizations and community engagement as ways to develop leadership (Ibrahim \& Sarirete, 2014); and (2) collegiate women define successful female leaders as those who persevere in the face of obstacles, become the first to achieve a goal in one's field, succeed in a male dominant profession, achieve a dream or a goal, and inspire others (Alexander, 2011, 2013). These sensitizing concepts or ideas were used as a starting point to form interview questions about leadership experiences in student organizations or community engagement, as well as about factors that promote and impede collegiate women's leadership development. They provided an opportunity to facilitate a conversation-style of interviews, which created spaces for specific data to emerge regardless of the its relevancy to the concepts. Sensitizing concepts that informed this study will be discussed again in Chapter Five.

\section{Methods and Strategies}

In GTM, data is the foundation of the methodology and the methods used are the tools that make sense of it (Charmaz, 2014a). To develop theoretical analysis, rich data is collected through thick descriptions from multiple sources of data gathering such as 
intensive interviews, field notes from observations, documents, and written personal accounts from participants (Charmaz, 2014a). Collecting rich data help "reveal participants' views, feelings, intentions, and actions, as well as the contexts and structures of their lives" (Charmaz, 2014a, p. 23). Thus, enabling researchers to explore the various conditions under which the social phenomenon changes (Charmaz, 2008). Parry (1998) indicated that the use of multiple sources of data gathering enhances the trustworthiness of the research study as it relies on a range of data collection methods besides interviews. However, Charmaz (2014a) focused on intensive interviewing in CGT as a tool to facilitate an open-ended and in-depth process of exploration of a social phenomenon participants experience. She asserted it is the flexibility feature of intensive interviewing that affords researchers with spaces to pursue emerging ideas and gather rich data (Charmaz, 2014a).

Data analysis strategies used in GTM are critical to theory construction. Coding is a qualitative research analysis strategy used to understand the data that allows researchers to analytically question the data (Charmaz, 2014a). It is usually carried out starting with the initial coding phase of engaging with and defining the data, then with the focused coding phase of concentrating on significant or frequent initial codes, followed by the axial coding phase of identifying and relating categories to sub-categories (Charmaz, 2014a). Referred to as selective coding, theoretical coding integrates and synthesizes categories that have emerged from previous coding schemes whereby it begins to identify the possible relationship between categories and shift toward theory formation (Saldaña, 2013). To emphasize process and capture participants' voices and experiences, in vivo coding is commonly used during grounded theory's initial and focused coding stages 
(Charmaz, 2014a; Saldaña, 2013). Although coding schemes in grounded theory help researchers make sense of the data, they have been approached differently by scholars. For example, Strauss and Corbin (1998) included a structured systematic approach to coding, whereas Charmaz (2014a) advocated for a flexible approach by piecing together implicit meaning about a category.

In GTM, an important part of theory construction is the use of memo-writing (Charmaz, 2014a). It is a strategy researchers utilize during the simultaneous process of data collection and analysis whereby they write down their ideas and analytic notes about the codes and data (Charmaz, 2014a; Creswell, 2013). Memo-writing offers a place to question and scrutinize data, codes, ideas, and categories, and thereby keeps researchers involved and engaged with the data (Charmaz, 2014a). This study's methods and strategies are discussed later in this chapter. The following section presents the epistemological stance and theoretical framework that guided the study's inquiry approach.

\section{Epistemological Stance and Theoretical Framework}

As aforementioned, this dissertation study adopted a constructivist paradigm guided by an epistemological stance of social constructivism with an interpretive theoretical framing to understand the leadership understandings of collegiate women in Saudi Arabia's private non-profit universities, the opportunities they have to develop leadership, and how and why they develop leadership. Approaching the study from a constructivist paradigm allowed for meaning to be mutually constructed and discovered through an interpretive dialogue (Manning, 1997). By engaging with collegiate women in a co-constructed interpretation of the meaning they attribute to their experiences 
(Manning, 1997), a constructivist paradigm made it possible for me as the researcher to understand how and why they develop leadership.

An epistemological stance of social constructivism emphasizes the notion that human beings are active and creative producers of society, thereby all knowledge and all meaningful realities are socially constructed (Crotty, 2015). Central to the social constructivist premise is the group or individuals' meaning-making and sense-making actions and interactions that they engage with others about social phenomena (Lincoln, Lynham, \& Guba, 2011). It is through the social interactions of collegiate women in Saudi Arabia with others in their communities, as well as through the historical and cultural norms and settings in which they live, that enabled them to make meaning and sense of their experiences in developing leadership (Creswell, 2009).

To understand the meaning collegiate women in Saudi Arabia have constructed about their world and their leadership development experiences, an interpretive theoretical framework was used to help guide the inquiry process. According to Ferguson and Ferguson (2000), an interpretive framework challenges researchers to expand on their ways of knowing. It advanced the study's aim beyond collegiate women's expected descriptions of how and why they develop leadership. An interpretive framework created spaces to understand collegiate women's perspective of leadership and of leadership opportunities in Saudi Arabia by challenging the researcher to adopt a position of a learner (Ferguson \& Ferguson, 2000). The pluralistic approach of an interpretive framework challenged me as the researcher to conceptualize and understand collegiate women's experiences from their perspectives rather than my perspective as an insider to the cultural context and to the identities shared with the participants. 
Symbolic interactionism was adopted to inform the study's interpretive framing. Stemming from George Herbert Mead's thought on pragmatism (Crotty, 2015; Schwandt, 2007), symbolic interactionism assumes that people's actions toward things are based on the meanings they have assigned to them. Furthermore, as a result of the social interactions and dialogue people have with others, meanings are generated and modified through an interpretive process (Crotty, 2015). Through dialogue, the participants come to know their subjective meanings (Manning, 1997). As a researcher assuming the role of a learner rather than an expert on student leadership development in Saudi Arabia, listening to participants' stories gave their subjective meanings voice (Manning, 1997). In turn, I became cognizant of collegiate women's perceptions, feelings, attitudes, and actions toward their leadership development experiences, and I was able to interpret the meanings they assigned to their experiences in, and motivations for, developing leadership. Moreover, I was able to minimize power differences and build a reciprocal and collaborative relationship with the participants that is based on trust, shared knowledge, and authenticity (Manning, 1997). Therefore, symbolic interactionism helped guide the interpretive inquiry process toward understanding what leadership means to collegiate women of this study, and how and why they develop leadership. The following section explains how CGT is a fit choice for this study.

\section{Rationale to Using CGT}

Given the context of this dissertation study, CGT is the most appropriate approach to use for the following reasons. First, CGT reflects the epistemological stance of social constructivism, along with the philosophical tradition of pragmatism and the interpretive theoretical framework of symbolic interactionism. Within the context of 
Saudi Arabia, social norms, attitudes, and practices are gradually being reshaped, reconstructed, and reinterpreted through the actions and interactions of people with each other, with all members of society, and in response to the social changes happening. Through a constructivist paradigm, the methodology offered a flexible approach to inquiry that is adaptable and responsive to the ways of knowing of non-Western cultures (Charmaz, 2014b).

Second, this dissertation study aimed to explore and investigate the leadership understandings of collegiate women in Saudi Arabia's private non-profit universities, the opportunities they have to develop leadership, and how and why they develop leadership. The use of CGT created space to understand how collegiate women understand leadership and how they make meaning of their experiences in developing leadership and of their motivations for developing leadership. In turn, it enabled me to make analytic sense of their meanings and actions, and their interactions with others.

Third, given the lack of empirical studies on how and why collegiate women in Saudi Arabia's private non-profit universities develop leadership, adopting CGT allowed me to investigate this phenomenon from the ground up rather than using a Western perspective of a pre-existing student leadership development theory and model for this study. Thus, by investigating this phenomenon from the perspective of collegiate women in this study, CGT enabled me to come to an understanding that is grounded in their leadership and leadership development experiences. The following section presents a subjectivity statement reflecting my positionality as the study's researcher. 


\section{Subjectivity Statement}

Pursuing an interpretive approach to qualitative inquiry made it possible to know what are the leadership understandings of collegiate women in Saudi Arabia's private non-profit universities, how and why they develop leadership, as well as understand the meaning they make of their experiences. As a Saudi woman with my own experiences in higher education and leadership, my subjectivity will be inevitable. Therefore, it was necessary for me as the researcher to acknowledge and be cognizant of my subjectivity and the ways in which it informs the process of inquiry and knowledge construction. In this section, I reflect on my ways of knowing, as well as on my researcher positionality and the important role it plays within the dissertation research process.

\section{Ways of Knowing}

To explain my ways of knowing, I reflect on the sources contributing to my knowledge. As one of eight adult children in the family, I identify myself as a daughter, a sister, and an aunt to three nieces. My parents' belief in the value of education influenced my goals and aspirations. Their worldview and ethical principles continue to be infectious. They instilled in my siblings and me the values of compassion, respect, honesty, responsibility, accountability, and fairness to self and others. These values, among others, established a platform of core principles for me to live by that have gradually evolved into qualities that not only guide my personal code of ethics, but also represent the core elements of my character as a human being. Moreover, my ways of knowing are also shaped by and rooted in my Islamic faith and its value and respect for human dignity. From the Qur'an and through its teachings, I learned and adopted the values of integrity, compassion, trust, and justice. I believe that my commitment toward 
upholding these values throughout my life played a vital role in developing my identity as a woman and my ways of knowing.

Having a passion for continuous education and life-long learning influences my ways of knowing. My past experiences as a student in Saudi Arabia's education system were consumed with route memorization and without opportunities to critically think or reflect on information. Yet, it inspired me to pursue a path toward improving educational and social conditions for young women in Saudi Arabia and foster a positive learning and social experience for them where they can reach their full potential and thrive.

It is through my education in the field of psychology and family therapy that I started my journey of self-discovery and inner growth that opened doors for me to find a purpose that is greater than myself. The transformational process of understanding myself was imperative in order to create the necessary and needed spaces for myself and others to interact and reflect. Reflecting on my thoughts, feelings, and actions enhanced my levels of self-awareness and consciousness of others and situations. It enabled me to recognize my actions and interactions with others. This led the way for me to become open to and flexible with change and uncertainty as I worked with clients and college students. I became aware that this process of self-discovery and self-knowledge transcends beyond the purpose of the profession I was seeking at that time. It is from this journey and experience that I came to believe that knowledge is generated through processes of learning and interacting with others.

Moreover, through my work experiences in Saudi Arabia as a family therapist and an educator, and from my leadership position in higher education, I was able to identify my mission and life's purpose. I believe it is my life's purpose, moral obligation, and 
ethical principles to improve social and educational conditions for young women in Saudi Arabia through life-long learning, sharing and gaining new knowledge, connecting with others emotionally, spiritually, and intellectually, and inspiring others to achieve their goals and aspirations. Being passionate about something I genuinely care about that improves conditions for the greater good of humankind drives me toward selfdetermination.

For this dissertation study, it was essential for me to reflect on cultural knowledge and self-determination as ways of knowing that highlight my identity as a Saudi researcher. Tillman (2002) emphasized cultural knowledge of the researcher and the researched as an important dimension for the trustworthiness of a research study, as well as toward a culturally sensitive research whereby it promotes an inclusive strategy that builds on the dynamics between the researcher and the researched. Tillman's (2002) work influenced me to carry out a culturally responsive and sensitive dissertation study with collegiate women in Saudi Arabia that placed culture, gender, language, and faith as central elements to the inquiry process, for they are significant aspects of participants' identities, and to mine as well. Doing so contributed to maintaining and preserving the cultural integrity and authenticity of participants' experiences with intersecting cultural identities such as a Muslim, woman, Arab, Saudi, etc.

\section{Researcher Positionality}

My positionality in this study played an important role in the process of inquiry and knowledge construction. It was essential for me to interrogate my status as an insider and an outsider in relation to the participants of this study and to Saudi Arabia's higher education context. I defined my insider status as a member of the Saudi academic 
community. My affiliation to the Saudi academic community and my previous experiences as a faculty member and administrator at one of Saudi Arabia's private nonprofit universities contributed to my insider status. Moreover, as a Muslim, Arab woman from Saudi Arabia, I shared common identities with collegiate women of this study, which would position me as an insider. By sharing culture, language, and perhaps beliefs and values with the collegiate women of this study, I was able to interpret the meanings they make and have the advantage of conceptualizing and understanding the social and cultural elements that are central to their perspective on leadership and to their experiences in leadership development. However, it was crucial that I do not take my insider status for granted during the study, whereby being overly confident would have enhanced my bias as a researcher and lead me to make inaccurate assumptions about the leadership understandings and leadership development experiences of collegiate women in Saudi Arabia's private non-profit universities.

Problematizing my outsider status required me to adopt a self-reflective stance and engage in ongoing self-interrogation of my position as an outsider researcher (Jankie, 2004). Thus, I problematized my outsider status by the fact that as a college student I have not experienced what it is like to develop leadership in Saudi Arabia's complex sociocultural context. Due to my Western postsecondary education, I do not share the overall learning experiences of collegiate women in Saudi Arabia. Furthermore, although I identified my researcher status as an insider within the Saudi academic community, I also assumed an outsider status to the community due to my pursuit of a doctoral degree in the United States for the past few years. While I maintained a strong and reciprocal relationship with members of the higher education community in Saudi Arabia, the 
physical disengagement from the actual academic environment within the higher education setting could have influenced bias over initiatives that are relevant to collegiate students' learning and development outcomes in Saudi Arabia.

In this study, I positioned myself as an outsider to collegiate women whose nationality is Saudi. Although I was born and raised in the capital city of Riyadh, one can know my family's roots and origin in Saudi Arabia by my last name. While this may not seem to position me as an outsider, it could have been the case for participants I interviewed who identify themselves differently. Moreover, my positionality in this study is an outsider to collegiate women whose nationality is not Saudi but reside in the country, for which they could have positioned me at a status of privilege and power for being a Saudi native.

Furthermore, I was aware of the possibility that my insider and outsider status could become evident based on how the participants of this study position me during the data collection and analysis data process. Thus, I positioned myself as a learner to the experiences of collegiate women participating in the study and to the higher education setting under which student leadership is promoted. Also, I maintained a journal as a personal tool throughout the inquiry process to self-interrogate my positions as an insider and outsider, as well as address and recognize my own cultural knowledge and ways of knowing that could influence accurate interpretations of the findings and authenticate collegiate women's leadership development experiences. This journal I maintained also included memos I was able to write throughout this study's simultaneous process of data collection and analysis. Thus, engaging in self-interrogation and in the iterative process of data collection and analysis helped to achieve the rigor, authenticity, credibility, and 
trustworthiness necessary for this dissertation study. Therefore, the following section discusses the ethical framework of this study.

\section{Ethical Framing}

To ensure a rigorous inquiry process and enhance the credibility and trustworthiness of the study's findings, it was essential that I situate the dissertation study within an ethical lens. While the ethical demands of social science research are important to the trustworthiness of the study, they can be extremely rigid while leaving little or no room for flexibility to adapt research methods and approaches in ways that respect cultural practices and social norms. The cultural dimensions represented within this study's topic, researcher, participants, and setting required me to advance standard ethical considerations in social science inquiry by incorporating principles of Culturally Responsive Methodology. This section presents the tenets of culturally responsive methodology and discusses reciprocity as an important element that contributed to the authenticity and rigor of this CGT dissertation study.

\section{Culturally Responsive Methodology (CRM)}

An ethically-based conceptual framework, CRM situates knowledge, culture, relationships, dialogue, and humility at the center of the research inquiry (Biermann, 2011). It is a transparent approach that reduces misunderstandings by equalizing power between the researcher and participants and serving with humility, humanity, and empathy toward what the researched community determines to be the social good. The framework views knowledge through multiple ways of thinking, conceptualizes ideas within a holistic context, values cultural rituals of the research community and brings cultural experiences to the research, promotes overt ideological frameworks to bring 
about authenticity of the researcher and the researched community's mutual positions, challenges power structures through processes of co-creating and co-constructing knowledge with the researched community, shapes the researcher's attitude to learn from the researched community, fosters dialogic and dynamic knowledge sharing processes that emerged from established relationships, and encourages authenticity of artistic, aesthetic, and dialogic representations (Berryman, SooHoo, \& Nevin, 2013).

CRM challenges the traditional role upheld by researchers that creates an unbalanced and unequal relationship between the researcher and participants. As a researcher with multiple identities and insider knowledge of the Saudi culture and society, engaging in ongoing self-interrogation helped critique power differences that might be at play between myself and collegiate women of this study. Balancing and equalizing power differences between myself and the participants allowed me to carry out a research study that is culturally responsive and socially beneficial for collegiate women in Saudi Arabia who have been undermined as a resourceful group within the Saudi society and marginalized from important decision-making processes that impact their life. Thus, incorporating the principles of CRM into the CGT dissertation design provided spaces for co-construction of knowledge with the participants to accurately interpret the leadership understandings and leadership development experiences of collegiate women in Saudi Arabia's private non-profit universities.

\section{Authentic and Rigorous Inquiry}

Carrying out an authentic and rigorous CGT study that is culturally responsive required me to address reciprocity as a central element to the study of leadership development of collegiate women in Saudi Arabia's private non-profit universities. To 
understand the experiences of collegiate women participating in the study, I was committed to reciprocity throughout the research process (Harrison, MacGibbon, \& Morton, 2001). This started by carrying out my role with humility and self-awareness (Berryman et al., 2013). Both humility and self-awareness reflect the notion of justice and ethics of care that are interconnected and necessary in facilitating my responsibility with the participants to build reciprocal, authentic, and trusting relationships with them. In Nell Nodding's (2005) notion of ethics of care, reciprocity is an important aspect in human relationships where people are equal and care for each other. It minimizes power differences between the researcher and participants to create spaces for co-construction of knowledge (Harrison et al., 2001). As a concept of relevance to the Muslim, Arab, and Saudi culture and societal practices, reciprocity became central to my relationships with the participants. Therefore, in my role as the researcher, I aimed to establish a genuine and authentic relationship with the collegiate women that is reciprocal with the notion of ethics of care at its core, which helped to generate authentic knowledge of their leadership development experiences. While reciprocity contributed to a rigorous and authentic research inquiry, it was a salient strategy to enhancing the credibility and trustworthiness of the study's findings.

By taking an in-depth look into GTM, I explained how the methodology's constructivist perspective allowed me to make sense of the data collected in the dissertation study. The constructivist paradigm under which the CGT is situated provided the flexibility and adaptability needed to reflect on the cultural aspects embedded in the study. Integrating a culturally responsive ethical framework with an interpretive framework of symbolic interactionism afforded spaces to understand the meaning 
collegiate women of this study were making of their leadership development experiences. In the following section, I describe the methods and procedures used to collect and analyse data, as well as the strategies used to enhanced the credibility and trustworthiness of the study's findings.

\section{Methods}

The use of CGT offered a flexible approach to inquiry that is adaptable and responsive to the ways of knowing of non-Western cultures (Charmaz, 2014b). As discussed previously, this constructivist grounded theory (CGT) study explored and investigated the leadership understandings of collegiate women in Saudi Arabia's private non-profit universities, the opportunities they have to develop leadership, and how and why they develop leadership. In the following sub-sections, I provide a rationale for choosing private non-profit universities for participant recruitment, describe and illustrate the participant recruitment process, and the methods and procedures that enabled me to collect rich data about the leadership understanding and leadership development experiences of collegiate women in Saudi Arabia's private non-profit universities. Moreover, I describe the procedures used to analyze data, and discuss the utilized strategies that enhanced the credibility and trustworthiness of the study's findings.

\section{Choosing Private Non-profit Universities}

Established in 1999, private higher education in Saudi Arabia is a relatively new sector (Al Dali et al., 2013). As shown in Tables 1 and 2, enrollment and graduation rates of collegiate women within the private sector reflect the overall population growth of collegiate women in the country. According to the Ministry of Education (2018), there are 52 private higher education institutions in Saudi Arabia that cater for collegiate men 
and women in gender-segregated campuses. However, only six of the 52 private institutions identify themselves on their official websites as non-profit universities, two of which are for and led by women (Jamjoom, 2012; Ministry of Education, 2018). While the notion of college student leadership development is an unexplored domain within all higher education sectors in Saudi Arabia, this study focused on recruiting female participants from private non-profit universities for the following reasons.

First, as presented in Chapter One, private non-profit universities in the country offer collegiate women opportunities to pursue their education in fields of studies that have been otherwise unavailable to them at public universities (Fatany, 2013; Hamdan, 2013). Moreover, they provide collegiate women with opportunities to develop leadership skills through co-curricular programs such as student government and clubs, and to some degree through formal leadership programs such as academic-related courses and lectures (Alexander, 2011, 2013; Bennet et al., 2012; Ibrahim \& Sarirete, 2014). However, much is unknown about the outcomes generated from these programs. Therefore, choosing private non-profit universities for this study presented an opportunity to investigate how collegiate women at these universities develop their leadership potential.

Second, in Chapter One, I defined private non-profit universities as not-for-profit making universities that are established by and operated under a non-governmental philanthropic foundation or a charitable organization. Their financial models align with organizational aims to support the educational experiences of their students through curricular and co-curricular programs, rather than to support the financial interests of investors and shareholders. Thus, focusing on private non-profit universities for this 
study helped to understand collegiate women's perspective of the opportunities they have at these universities to develop leadership.

Third, limited scholarship is available that explored the leadership understandings of collegiate women at private non-profit universities in Saudi Arabia. As presented in Chapter Two, Alexander's $(2011,2013)$ work pertaining to collegiate women's understandings and perceptions of leadership at a Saudi Arabian private non-profit university are the only known research studies that reflect the notion of leadership development and education. Thus, choosing private non-profit universities in Saudi Arabia for this study created spaces to explore and investigate the leadership understandings of collegiate women enrolled at these universities.

Fourth, as presented in Chapter One, Saudi Arabia made significant improvements throughout the past decade that are gradually advancing women's status in society and in senior leadership positions at the governmental level. With the opportunities collegiate women have at private non-profit universities to develop leadership skills through co-curricular programs, and to some degree through formal leadership programs, choosing private non-profit universities for this study provided an opportunity to investigate why collegiate women develop leadership. Given the

aforementioned reasons, private non-profit universities in Saudi Arabia served as an ideal choice to recruit participant from for this study.

\section{Participant Recruitment}

To participate in this study, collegiate women were recruited from four private non-profit universities in Saudi Arabia. Two of the four universities were located in the Western province, and two universities were located in the central province of Saudi 
Arabia. According to their official websites, these four universities stated a number of cocurricular programs and activities that offer collegiate students opportunities for leadership. Therefore, I sought to recruit participants from these four selected universities by engaging in the following steps. First, upon institutional review board (IRB) approval from Chapman University, I established formal contact with the institutional review boards at each of these four universities in Saudi Arabia. This step was necessary to gain their trust, demonstrate credibility of the study and of myself as its researcher, and be granted formal approval to conduct the study with collegiate women from their respective institutions. By providing thorough and necessary documents with the research approval applications, I was granted approval to conduct the study with collegiate women from all four universities.

Second, upon approval from each university's review board, I established contact with student affairs administrative officials and personnel to request assistance with the recruitment phase of the study. For this phase of the study, I provided them with a set of documents that included (1) a brief doctoral dissertation proposal summary to inform the recruiters of the study's purpose and scholarly intentions, (2) IRB approval from Chapman University to verify the study and my credibility as the researcher, (3) a recruitment e-mail letter to be shared with prospective participants (Appendix A), (4) a study information sheet to be shared with prospective participants, and (5) a consent form to be shared with prospective participants (Appendix B). One of the four universities requested a verification letter (Appendix C) from my dissertation committee chair, along with the aforementioned documents. Providing these documents were key in gaining their trust, demonstrating the credibility of the study, as well as my credibility as the 
researcher. Although the research approval process and the participant recruitment process at each of these four universities were successful, the quest to seek approvals from review boards of all four universities lasted for a total of four months. This was partly due to the timing of my request, which coincided with official holidays and vacations in Saudi Arabia. While participants' recruitment for this study depended on the IRB approvals from all four universities, the recruitment process was less arduous and fairly easy. This was partly due to my social relationships with two administrators and a faculty member from these universities who were able to assist in providing me with the accurate contact information of recruiters.

Third, it is with the help of a recruiter, a student affairs personnel, from each university that I was able to reach out to prospective participants. Using a purposive sampling procedure, the recruiters shared my recruitment letter/email (Appendix A) with prospective participants. To be included in the study, participants must have been at least 18 years of age or older; female, undergraduate college students; enrolled at any of the four selected private non-profit universities; involved as student leaders in one or more co-curricular program at their respective university (i.e., student organization, student council, committee, etc.); and able to read and speak English. Due to the Western-style education adopted at private non-profit universities, English is the language of instruction. Therefore, it was not difficult to recruit participants from these universities who are able to speak, read, and write in English fluently.

Once identified from their respective university recruiter, I invited the prospective participants via email or phone messaging to schedule a brief introductory meeting with them at a day and time that is convenient for them. As a crucial step to build rapport and 
trust with them, this brief meeting was facilitated through a phone call or by using an online audio/visual-conferencing program and took no longer than 20 minutes, whereby I provided 15 of the prospective candidates with an overview of the research agenda and with answers to any inquiries or concerns they had, all of whom agreed to participate in this study. Some participants preferred to start the interview process as the information included in the documents were clear. Following their recruitment for the study, each participant was asked to sign a consent form (Appendix B). Written in English, the consent form noted that their participation is voluntary, their interview would be audiorecorded, and they would not be identified by name in any written reports.

\section{Research Participants}

Twenty-five collegiate women from four private non-profit universities in Saudi Arabia were interviewed for this study (see Table 7).

Table 7

Participants $^{a}$ by Private Non-profit University

\begin{tabular}{cccc}
\hline University 1 & University 2 & University 3 & University 4 \\
\hline Maya & Noor & Aseel & Rajwa \\
May & Gaida & Arwa & Alya \\
Asma & Halah & Farah & Salma \\
Manal & Wafa & Ghadeer & Deena \\
Nada & Layan & Razan & Yara \\
Bayan & & Rana & \\
Hana & & Jana & \\
& & Sama & \\
\hline
\end{tabular}

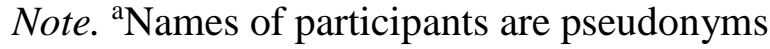

Also, the participants represented three undergraduate levels and six fields of study (see

Table 8). Listed in Table 9 are the participants' student leadership roles or positions. 
Table 8

Number of Participants by Course Level and Field of Study

\section{Field of Study}

\begin{tabular}{|c|c|c|c|c|c|c|}
\hline $\begin{array}{l}\text { Course } \\
\text { Level }\end{array}$ & Business & Engineering & Law & $\begin{array}{l}\text { Humanities } \\
\text { and Social } \\
\text { Sciences }\end{array}$ & $\begin{array}{l}\text { Architecture } \\
\text { and Design }\end{array}$ & Sciences \\
\hline
\end{tabular}

\begin{tabular}{lllllll} 
Sophomore & 2 & 1 & & 1 & 2 & \\
\hline Junior & & 2 & 1 & 1 & 2 \\
\hline Senior & 6 & 2 & 2 & 1 & 2 & \\
\hline
\end{tabular}

Table 9

Number of Leadership Positions Held by Student Leadership Opportunity

\begin{tabular}{lccccc}
\hline Positions & $\begin{array}{c}\text { Student } \\
\text { Government }\end{array}$ & $\begin{array}{c}\text { Student } \\
\text { Organization }\end{array}$ & $\begin{array}{c}\text { Student } \\
\text { Clubs }\end{array}$ & $\begin{array}{l}\text { Group Projects/ } \\
\text { Competitions }\end{array}$ & $\begin{array}{c}\text { Volunteer } \\
\text { Work }\end{array}$ \\
\hline President & 4 & 5 & 4 & & \\
\hline Junior & 2 & 4 & 4 & 8 & \\
\hline Senior & & 4 & 4 & & 2 \\
\hline
\end{tabular}

Confidentiality. To maintain participants' confidentiality and anonymity in this dissertation document, and in any written reports, I engaged in the following two steps. First, the participants' names were not revealed throughout the study. Instead, each participant was assigned a pseudonym and their respective universities were assigned to numbers, as shown in Table 7. Second, participants' academic majors were clustered into six fields of study (see Table 8). Third, the co-curricular programs at all four universities such as volunteer work, event organizing, student group projects, student organization, 
student government, student council, student club, student committee, and student association were categorized under five student leadership opportunities (see Table 9). For example, student councils were classified under student government, student associations were classified under student organizations, event organizing were classified under volunteer work, student committees were classified under student clubs, and student competitions were classified under group projects. As each university has its unique label for leadership opportunities or programs, grouping these programs and opportunities into unified labels was necessary to protect participants' identities. The following section describes the data collection procedures.

\section{Data Collection Procedures}

In this CGT study, data was collected through individual interviews with 25 collegiate women from four private non-profit universities in Saudi Arabia using online audio/video-conferencing programs. Due to the nature of the political climate in the U.S. at the time of this study in regards to travel to and from Muslim countries, it was a sensible choice for me to avoid travel risks by remaining in the United States. Thus, I conducted the individual interviews with 25 participants, who live in Saudi Arabia, through an online audio/video-conferencing program based on their preference such as FaceTime, Skype, Google Hangouts etc.

A semi-structured intensive interview approach was utilized to explore and investigate the leadership understandings of collegiate women in Saudi Arabia's private non-profit universities, the opportunities they have to develop leadership, and how and why they develop leadership. The semi-structured approach to the interviews enabled me to ask open-ended questions that were flexible enough to allow for subsequent and 
follow-up questions to evolve throughout the study. I used an interview protocol (Appendix D) to facilitate the data collection process. It included 12 open-ended questions that were culturally sensitive and encouraged the participants to share their perspective of leadership and experiences in leadership development. By using an intensive approach to the interviews, I asked participants for in-depth descriptions about their experiences in developing leadership, as well as for examples that elicited details and explanations of their lived experiences (Charmaz, 2014a). In turn, the collegiate women of this study became the experts in their leadership development experiences, reflected on their earlier student leadership experiences, and shared significant experiences in developing leadership (Charmaz, 2014a).

Participants of this study were asked to agree to a convenient day and time for the interview. Given the 11-hour difference between the state of California and Saudi Arabia at the time of the study's data collection phase, each participant was interviewed once for approximately 60 to 90 minutes. Follow-up interviews were carried out with three participants for member checking. All interviews were audio-recorded for transcription and analysis.

\section{Data Analysis}

As the researcher, I engaged in the following steps to analyze the data of this study. First, I transcribed all the audio recordings myself. By doing so, I was able to recognize the details in the participants' leadership development experiences, as well as gain an understanding of the knowledge and meaning they make of their leadership development experiences (Charmaz, 2014a). Second, I verified all the transcripts by comparing each transcript to its respective audio-recorded session for accuracy. Third, I 
used a constant comparison approach throughout the coding phases of this study to keep me engaged with the data, be aware of the direction of my analysis, and to recognize the central ideas that emerged from the data (Bryant \& Charmaz, 2007; Charmaz, 2014a; Merriam, 2002). Fourth, to begin the coding process, I used line-by-line initial coding as the first phase of coding to engage with the data and reflect on their contents and nuances (Saldaña, 2013). Fifth, to analyze the data from the participants' perspective, I used gerunds for this study's coding scheme, which helped me preserve the participants' experiences and focus on their meanings and actions in developing leadership (Charmaz, 2014a). Sixth, I used in vivo coding strategy to emphasize participants' understandings of leadership and to capture their voices and experiences in developing leadership (Charmaz, 2014a; Saldaña, 2013).

Seventh, in the second phase of coding, I used focused coding to concentrate on significant or frequent initial codes by "comparing them with the data and determining those codes that have greater analysis power" (Charmaz, 2014a, p.140). Eighth, I used axial coding to identify the categories and sub-categories that emerged from the first phase of coding (Charmaz, 2014a; Saldaña, 2013). Ninth, as the final phase of coding, I used theoretical coding to integrate and synthesize the categories and sub-categories (Saldaña, 2013), identify the relationships between the categories, and help me move toward a "theoretical direction" (Charmaz, 2014a, p.150). Moreover, by using theoretical coding, I was able to reach theoretical saturation.

Finally, as indicated earlier, I used memo-writing throughout the simultaneous process of data collection and analysis, which kept me involved and engaged with the data by writing down ideas and analytic notes about the codes and data (Charmaz, 2014a; 
Creswell, 2013). In addition, memo-writing helped me develop theoretical sensitivity, which Charmaz (2014a) defined as "the ability to understand and define phenomena in abstract terms and to demonstrate abstract relationships between studied phenomena" (p.161). The next sub-section presents the strategies used to enhance the trustworthiness and credibility of this study.

\section{Enhancing Trustworthiness and Credibility}

According to Moss (2004), provisions of trustworthiness and credibility such as authentic trust, reflexivity, and member checking ought to be embedded within a researcher's ethical stance. Establishing an authentic trust with the participants was essential to the overall credibility and trustworthiness of this study's research process and outcomes. I built rapport with the participants whereby they felt safe to gather information about me and the study (Hogg, 2014). For example, by sharing and being open about my experiences and being transparent about my research agenda and intentions, I was able to establish authentic trust with the collegiate women of this study.

To enhance trustworthiness and credibility of the study, I engaged in reflexivity. It is an assessment of the influence a researcher's own background, perceptions, or biases may have in shaping the interpretation of the data collected (Creswell, 2013). As discussed earlier in the chapter, my identity as a Saudi woman with experience in leadership at a private non-profit university in Saudi Arabia influences my subjectivity. Therefore, I used a journal as a personal tool to engage in a conscious process of selfinterrogation and self-reflection of my subjectivity and positionality as the study's researcher, and how they shaped the interpretation of the data. 
With the use of constructivist grounded theory for the dissertation study, I employed member checking of the data to enhance the trustworthiness and credibility of the findings. With the collaborative and reciprocal nature of the relationship I established with the participants, member checking of the data reduced power differences between me and the participants, as well as provided an opportunity to engage in a participatory and democratic process with them (Berryman et al., 2013). Through member checking, I solicited the participants' views of the data, findings, and interpretations to gain an accurate and credible account of their experiences in developing leadership (Creswell, 2013). However, I engaged in member checking with three participants only. As discussed earlier, there was an 11-hour time difference between the state of California and Saudi Arabia at the time of study's data collection and analysis phase, which made it difficult to schedule follow-up interviews for member checking with all the participants.

\section{Summary}

This dissertation study utilized constructivist grounded theory methodology to explore and investigate the leadership understandings of collegiate women in Saudi Arabia's private non-profit universities, the opportunities they have to develop leadership, and how and why they develop leadership. In this chapter, I provided a discussion on CGT, addressed the theoretical and ethical framing, and included a subjectivity statement. In addition, I described and explained the methods I utilized and the procedures I engaged in to collect and analyze data, as well as to enhance the credibility of this study. As a rigorous methodology, CGT enabled me as the researcher to make sense of the data collected by engaging in reflexivity and ongoing selfinterrogation, and establishing an authentic and trusting relationship with the participants 
that is reciprocal to facilitate a co-construction of knowledge of their understanding of leadership and leadership opportunities, and of their perspective as to how and why they develop leadership. The following chapter, Chapter Four, I present the findings of this study. 


\section{Chapter Four: Findings}

This dissertation study explored and investigated the leadership understandings of collegiate women in Saudi Arabia's private non-profit universities, the opportunities they have to develop leadership, and how and why they develop leadership. The findings provided an understanding of the perspective collegiate women of this study have of leadership as a relational practice they engage in to better themselves and others, and for the betterment of the Saudi Arabian society. In this chapter, I present the five themes that emerged from the analysis of the data that is grounded in the experiences of collegiate women in Saudi Arabia's private non-profit universities. The themes center on collegiate women leaders' (1) motivations to developing leadership; (2) perspective of factors promoting and hindering leadership development; (3) approaches to becoming leaders; (4) leadership development; and (5) understandings of leadership. In addition, this chapter includes specific quotations from the participants that reflect the emerging themes and sub-themes.

\section{Motivations to Developing Leadership}

This section presents the motives and driving forces that influence collegiate women in Saudi Arabia’s private non-profit universities to develop leadership. Participants' motivations intersected with, and reinforced, their views on the significance of leadership development. The sub-themes include personal motivations, influencing and inspiring others, advancing career, and contributing to social change in Saudi Arabia. These sub-themes were gleaned from the participants' responses to three interview questions in terms of motivating factors to develop leadership, importance of leadership development, and anticipated outcomes of leadership development. 


\section{Personal Motivations}

Twenty-one collegiate women of this study identified personal motivations to developing leadership. This sub-theme presents developing self, and having interest in and passion for leadership as two main categories that inform collegiate women's personal motivation for leadership development. The following sub-section includes aspects of self-development such as self-improvement and self-confidence.

Developing self. Thirteen of the 25 participants of this study referred to aspects of self-development such as self-improvement and self-confidence. For example, in response to what motivated her to develop leadership, Ghadeer (personal communication, October 4, 2017), she asserted, “With leadership, I'm developing myself. Who doesn't want to get better than they are right now? So that is one thing I guess about selfimprovement." Alya (personal communication, December 4, 2017), reflected on selfimprovement as a motivating factor for her develop leadership. She said, "It's important to become better versions of ourselves. There's always room for improvement. No matter what we're not going to be perfect people. So developing leadership makes us better people from within." The notion of bettering self was indicated in my interview with Farah. She (personal communication, November 2, 2017), stated:

What made me become a leader is me wanting to be a better version of me and not going back to what I used to do in the previous years. Basically, leadership teaches me how to reflect on myself in a better way to get to know who I am and what I'm worth.

For Sama (personal communication, October 7, 2017), self-development is a motivating factor and an anticipated outcome for developing leadership. She reflected: 
I expect self-development and that it will improve my core values. I think it will change my ideas about things. I feel that I will benefit from developing leadership. I think I will have more patience and aspiration. I think it will make me emotionally stronger and have more compassion for others, and humanity. Also, I think it will improve my self-confidence.

Also, May (personal communication, November 9, 2017), referred to confidence as an anticipated outcome to developing leadership. She said, "Honestly, what's important to me is confidence. I feel that if I acquired or developed the proper leadership, then I expect to have the confidence that will allow me to express my ideas and manage things." The following sub-section identifies participants' sense of passion and interest to become leaders as a personal motivation for them to develop leadership.

Having interest and passion for leadership. Over half of the participants of this study indicated that their interest in and passion for being leaders motivated them to develop leadership. For instance, by having interest in leadership, Hana (personal communication, November 12, 2017), shared:

I am studying business and I've always been interested in leadership. When I lead a team or a group, it's nice to see the outcomes later on and realize that I helped in achieving these outcomes. Leadership is very fulfilling. When I'm done leading a group, I feel that I've done something and that I had a big part in achieving something. So it gives me a feeling of accomplishment. Progress is what makes me interested in learning more about leadership and further developing it. Reflecting on the notion of self-actualization in terms of her achievements as a student leader, Salma (personal communication, January 12, 2018), said: 
When I find that things are going great and I have never experienced this before and things are happening to me and I'm succeeding, then it makes me want to continue and do more. This is what motivates me that the fact I'm moving forward and something great is happening makes me want to move forward even more. It gives me the push to do more and give more. This is what motivates me to develop leadership and alhamdulillah ${ }^{2}$ I'm starting to move up that ladder and nothing happened until now that makes me fall back. And if something bad happens then I'll be ok because everything I experienced taught me to try again and ask for help.

On collegiate women in Saudi Arabia, Maya (personal communication, November 8, 2017), reflected, "Female college students have a lot of energy. The energy of female college students, and of youth in general, when combined can rule the world. They have the energy and they have the passion." To have the passion for leadership was reflected in my interview with Bayan in terms of her motivations to develop leadership. She revealed that her motivations to develop leadership is driven by her passion to pursue her goals in becoming a leader in her field of study. Bayan (personal communication, November 11, 2017), asserted:

I'm setting standards for myself and I want to reach particular goals. The passion I have to reach my goals motivates me to develop leadership and it motivates me to learn more and more. To be honest, since I was a child I have a dream or a goal I want to reach. By developing my leadership, I'm reaching my goal. Furthermore, Bayan (personal communication, November 11, 2017), stressed:

\footnotetext{
${ }^{2}$ Alhamdulillah is a general expression of thanks, praise, or relief used among Muslims, which means 'all praise be to God' (Oxford Dictionaries, 2018).
} 
I want to be a good and effective leader in my field, because I believe that I'm going to do a good job in it and because I'm passionate about it rather than just developing my leadership for the sake of doing it.

In the following sub-section, I present the second sub-theme that reflects the participants' motivations to developing leadership.

\section{Influencing and Inspiring Others}

Twelve of the 25 participants referred to phrases such as inspire others, influence others, and be a role model for others in their responses to their motivations for, importance of, and expectations from developing leadership. Using her definition of leadership as 'influence', Salma (personal communication, January 12, 2018), provided a perspective on her leadership development:

If we develop a community of leaders, and going back to my definition of leadership that it's all about influence, then consequently other leaders are going to show up. When leaders start showing up in the community, eventually everyone is going to be productive and everyone will start growing and everyone will be working toward change and to have passion. The cycle will go on. It's not easy, it's never easy to develop leadership skills. But once someone has the passion to develop leadership, then he or she can.

For Alya (personal communication, December 4, 2017), she develops her leadership:

To influence other people with what I accomplished, especially children. I have a soft spot for children and I feel that they always need a good role model. My mom is a role model. She did so much for us and I just want to be someone else's role model. That's one of the major driving forces to why I want to be a leader and 
why I want so much change in our community.

The notion of being a role model for others was noted in my interviews with Yara and Aseel. For Yara (personal communication, December 23, 2017), having an effect on others motivated her to develop leadership. She illustrated:

A student at the university came up to me and told me that she wants to be a student leader like me. She wants to study, travel, and be involved in activities like I did. That makes me motivated to develop my leadership because there's someone who wants to do what I do. Why not improve my skills and set an example for students and others?

Reflecting on the need for good leaders, Aseel (personal communication, October 1, 2017), said:

When it comes to why leadership development is important, there are people who are not good leaders, they are not good with leading people, they can't communicate well with people, they don't understand people's behavior, they have their own thinking. They don't want to listen to others. They would need a role model or a leader to lead them.

Developing leadership to inspire others was gleaned from my interviews with two student government presidents at their respective universities. For instance, Sama (personal communication, October 7, 2017), indicated that she was motivated to develop leadership "because there was a sense of I can motivate others and inspire them and that I can bring students together and foster collaboration.” By developing leadership, Layan (personal communication, February 3, 2018), said:

I expect students to follow my example, not necessarily the same experiences I 
had, but in one way or another they might get inspired, especially that we're around the same age. They might be inspired to become the student president next year, and they might be inspired to be better than I was.

In the following sub-section, I present the third sub-theme that reflects the participants' motivations to developing leadership.

\section{Advancing Career}

Fourteen of the 25 collegiate women of this study referred to aspects of professional development and career readiness as motivations for and importance of leadership development. The responses gleaned from interviews with these participants reflected generalized and specified notions of career goals and leadership aspirations. For example, Aseel (personal communication, October 1, 2017), indicated that she develops leadership "Because I want to go places in my life, I have a plan in my head. It may not be fully accomplished or achieved. So my goals require me to be a better leader and a better person." For Layan (personal communication, February 3, 2018), developing leadership prepares her for future leadership opportunities. She asserted, "I am a leader at the student level. In the future, I will be a leader at an organization, and maybe at the societal or national level." Similarly, Asma (personal communication, November 11, 2017), revealed that developing leadership will enable her to pursue leadership positions in the professional field. She stated, "I want more. I want to achieve something big. I want to be a top government official. Even if I couldn't achieve that, I want to become a senior leader at a prominent hospital." Moreover, Wafa (personal communication, January 28, 2018), reflected on the leadership development as a requirement for employment. She stated: 
I believe that in real life and in my career, leadership is important. No matter what the position is that I end up in, it will require me to have leadership skills.

Developing skills will help me later on whether they are communication skills or leadership skills.... Any position we get, whether it's an internship or a job position or even in life, requires leadership. Even when we deal with people, leadership skills will help us communicate better with them.

In the following sub-section, I present the fourth sub-theme that reflects the participants' motivations to developing leadership.

\section{Being the Change}

The phrase "be the change" emerged from my interview with Maya, who was a leader of a student club. Reflecting on her motivations to develop leadership, Maya (personal communication, November 8, 2017), asserted:

The way I see it is that why not contribute to social change. The reason we are behind in things is society. Sure, there are other reasons, but we should be the change and that we shouldn't wait or assume others will do it. We shouldn't wait for Vision 2030 to happen, but rather we should be Vision 2030. In any environment we find ourselves in, we should be this vision that we long for and aspire to have.

Sixteen of the 25 participants alluded to the concept of social change as motivations for and significance of leadership development. By placing their gender as women at the center of the discussion, these participants reflected on notions of gender equality and self-empowerment as motivational factors to develop leadership. For instance, Rajwa used "undermined" and "undervalue" to refer to the gender bias and 
inequality women in Saudi Arabia face. Being a leader and developing leadership, Rajwa (personal communication, December 2, 2017), explained:

As Saudi women, we're constantly undermined. People undervalue us. We live in a man's world and we're slowly reaching equality very slowly. As a young Saudi woman, people will undermine me where ever I choose to work. That's why I need to show them that I'm in charge, and when they see me as a leader, they'll begin to understand me and respect me more as a leader.

By developing leadership, Farah (personal communication, November 2, 2017), indicated that she navigates through stereotypes of her as a woman, in general, and as a Muslim woman, in particular:

You get to convince people that it is not an obstacle. It is not an obstacle that I got to put away of being a woman because I'm a niqabi ${ }^{3}$. So people see me and then question my leadership, but when they hear my voice they really do find it very weird and unexpected. So I get to put that aside by letting people know what I can do and put stereotypes aside.

For Alya, her motivations to develop leadership are reinforced by the the changes she is witnessing and living through in Saudi Arabia. By developing leadership, Alya (personal communication, December 4, 2017), reflected on shattering stereotype on women and Muslim women in Saudi Arabia:

This whole change that is happening in Saudi Arabia, I want to be part of it in any way I can be. That was a major push that makes me want to develop leadership. Saudi Arabia is changing, I'm changing with it and I want to help change it. I'm a

\footnotetext{
${ }^{3}$ Niqabi refers to a Muslim woman who wears a niqab, which is a veils that covers the hair and face except for the eyes (Merriam-Webster, 2018).
} 
huge feminist, so I want to help change the view that people have of females, of Saudi females, of Saudi females who wear $h i j a b^{4}$. I just want to change the way people view us.

Moreover, notions of self-empowerment emerged from my interview with Maya (personal communication, November 8, 2017), in terms of the importance and anticipated outcome of leadership development. With leadership development, she asserted:

Women would be powerful and more independent. Women will develop their capabilities so that they won't remain voiceless, oppressed, or even accept injustice or inequality. By developing leadership, we'll be able to realize that we have high ambitions and that women should be represented in senior leadership positions in all fields. It'll help us see that we shouldn't be in the back seat, and be secure enough to face any challenges we come across.

For women in Saudi Arabia to develop leadership, Gaida (personal communication, January 23, 2018), indicated that she became aware of their significant role in social change. She stated:

In the past, we didn't know much about women leaders or recognize their important role in social change. Now, we know about them and I feel they have something that's going to help change things in Saudi Arabia. And I feel that even the young women I surround myself with realize the importance of women in leadership.

This section showcased the findings on the motivations collegiate women in Saudi Arabia's private non-profit universities have for leadership development. The

${ }^{4}$ Hijab refers to the headscarf worn by a Muslim woman to cover the hair and neck (Merriam-Wesbter, 2018). 
following section presents the second theme on the factors promoting and hindering opportunities for the participants to develop leadership.

\section{Factors Promoting and Hindering Leadership Development}

The findings of this study revealed key factors that promote opportunities for collegiate women to develop leadership. These factors include university's support, family support, gender de-segregation, and self-confidence and motivation for leadership. However, each of these factors are challenged by factors that hinder opportunities for them to develop leadership such as university's lack of support, social influences, marginalization, and "being a woman". Therefore, this section presents the findings of each promoting factor for leadership development with an opposing factor that hinders opportunities for collegiate women to develop leadership.

\section{University vs. University}

Eighteen of the 25 participants asserted that their respective universities played a pivotal role in promoting leadership development opportunities. Rana (personal communication, November 5, 2017), indicated, "The university provides a lot of opportunities for students to participate in and develop their leadership skills.... The university, from faculty members to administrators, supports leadership and helps us to be leaders." Bayan (personal communication, November 11, 2017), who was a leading member in a student club, acknowledged that her university promoted leadership development opportunities "by giving us the ability to establish student clubs and to speak up and voice our opinion.” Recognizing the student leadership opportunities her university provides, Layan (personal communication, February 3, 2018), a student government president, affirmed, "Without the student clubs, student government and 
associations, we wouldn't have experienced leadership.” Salma (personal

communication, January 12, 2018), reflected, "Student leadership opportunities at the university opened a door for me to experience the leadership training. From the leadership training, I got the internship." Furthermore, May (personal communication, November 9, 2017), described a unique aspect of her university. She said:

I think that the university is very supportive of developing students' leadership skills. It takes us seriously when we propose our ideas. Administrators take us seriously and that's something really nice. You can't find that in a lot of universities in Saudi Arabia where the university is fully supportive of a students' views and ideas.

Despite identifying their respective universities as institutions that promote leadership development opportunities, the participants highlighted the role in which universities play in hindering opportunities for them to develop leadership. According to 13 of the 25 collegiate women of this study, universities hinder opportunities for leadership development by underemphasizing formal leadership programs for collegiate women and utilizing selective practices that exclude them from experiences and opportunities to develop leadership.

Underemphasizing formal leadership. Eight of the 25 participants noted the minimal attention given to the significance of providing formal leadership programs and trainings, as well as offering guidance and mentorship opportunities for collegiate women. For example, Nada, (personal communication, November 9, 2017), recognized the opportunity she had to develop leadership by experiencing student leadership at the university. However, she stated, “At the university, there weren’t opportunities such as 
seminars or workshops to develop leadership.... The university didn't help in terms of learning about or developing leadership in a formal way whether through training programs or in academic courses.” Maya (personal communication, November 8, 2017), asserted:

We wanted the university to provide leadership trainings and workshops, but we didn't get to have these opportunities. This might be the only thing the university didn't offer to support our leadership development. Maybe the university wasn't taking it seriously.

The lack of formal mentorship opportunities by faculty members and educational leaders was gleaned from my interview with a number of participants. For instance, Arwa (personal communication, October 22, 2017), reflected on the lack of experiential learning opportunities at her university. She illustrated:

You'll have a group of students who have ideas but don't necessarily know how to implement them. It's not a general or common thing, but in such situations students need and want the guidance from faculty members or administrators as to how they can implement their ideas. For example, I have an idea to establish a company one day and develop it to be one of the big global companies. But I still can't imagine how I will apply my own knowledge of business and accounting to establish this company.... I feel that we only open our books and study regularly, but we don't have a clear idea of how to put our learning into practice. I mean it's all about exams, assignments, and lectures, but there's very little about applying my knowledge and what I learned.

For Layan (personal communication, February 3, 2018), the need for guidance and 
mentorship is necessary for her and her peers to develop leadership:

Another thing that hinders opportunities for me to develop leadership is the lack of guidance from the administration in developing student leaders. If the administration wants me or other student leaders to not make mistakes, then administrators should at least be available to us and answer our questions and inquiries. I've been a student at the university for five years and we don't even have a policy guide for student leaders to follow that reflect the university's administrative policies.

The following sub-section identifies selectivity as a practice utilized within private nonprofit universities that hinders opportunities for collegiate women to develop leadership.

Selectivity practices. Six participants indicated that opportunities for collegiate women to develop leadership are minimized when administrators, faculty members, and student leaders engage in selective recruitment practices at their respective universities. Although the revelations were gleaned from a small number of participants, it provided an understanding to the limited opportunities collegiate women have to engage in and develop leadership. For example, Jana (personal communication, October 1, 2017), asserted, "Leadership opportunities are limited. Usually, there are opportunities that develop leadership, but are hidden.” This perspective was also shared by Hana at her university. Recognizing the lack of opportunities on and off campus for collegiate women to participate in formal leadership development programs, Hana (personal communication, November 12, 2017), suggested that her university:

Should have an office or a coordinator who is responsible to find us workshops or seminar on leadership that we could register for by sending us emails. I'm sure 
there are leadership workshops and trainings that we aren't aware of. I feel it would be beneficial if we are informed about them and get exposed to upcoming leadership workshops, seminars, and trainings outside of the university, in other cities, or even in other countries.

Ghadeer (personal communication, October 4, 2017), used the word "exclusivity" to describe what hindered opportunities for her to develop leadership. She said:

As for factors that hinder opportunities, there is that exclusivity issue when events happen where a group of people know before others so that might hinder opportunities for other students.... I would suggest for them to provide equal opportunities by announcing the events to all students and not just a selective group. For example, some of the events are advertised to students late, and when some students want to volunteer at these events, they are told that they have enough volunteers. I guess there is exclusivity in opportunities for volunteering. I think they should just open opportunities for volunteering to all students. I understand that some administrative staff have their own student group who they've worked with before and they might not want to take risks with students who haven't worked with them before. So I think that the offices that organize student events should take risks in including all students.

In the following sub-section, I present the second sub-theme on the factors that promote and hinder opportunities for the participants to develop leadership.

\section{Family Support vs. Social Influences}

Nine collegiate women in this study emphasized family support as an instrumental factor that promotes opportunities for them to develop leadership. For 
instance, while Rajwa (personal communication, December 2, 2017), recognized her parents' support in becoming a leader, she shared:

My dad has his doubts about me and sometimes worries about me and about my future. When I show him that I'm a leader, I feel that he's more at ease, he's starting to understand me as a person and what I'm capable of, and that he supports me more.

Acknowledging her family's support in developing leadership, Maya (personal communication, November 8, 2017), added, "They never stood in my way or told me not to." Likewise, Alya (personal communication, December 4, 2017), emphasized her parents' support of her experiences in developing leadership. She asserted:

My dad is very supportive and he'd always tell me that if I know it's good for me then I should do it.... There was nothing blocking my way because of the household I'm in and how my parents raised us. My family allowed me to do whatever I knew is best for me. Even my mom believes that if it benefits us, then we don't care what people say or whether it's socially acceptable or not.

Three of those nine participants revealed the significance of family support in promoting opportunities for them to develop leadership. May (personal communication, November 9, 2017), explained:

Parents play a huge role in promoting opportunities for students to develop leadership. My parents, especially my mother, are supportive. For example, when I told my mother about my experiences and that I'm leading a team, she was very supportive and encouraging and she felt it was going to be a fun and new 
experience for me. If parents aren't supportive and encouraging, then it really affects how students develops leadership.

Without her family's support, Halah (personal communication, January 27, 2018), speculated, "I wouldn't have been able to reach the best levels that I can. Having encouragement pushes me and helps me." Deena (personal communication, December $19,2017)$, indicated placed emphasis on family support as "something we can't ignore." She asserted:

I must admit that the Saudi girl privilege of having a family that is supportive of them, which not all Saudi females have. For example, the youth leadership program or whatever competitions I participated in aren't located in Saudi Arabia, which required traveling and my family were supportive of me traveling alone.... If my family weren't supportive of or accepting of me traveling alone, I simply wouldn't have been able to attend the program or competitions.

However, for collegiate women of this study, conforming to society's approval hinders leadership experiences. Aseel (personal communication, October 1, 2017), explained, "In our society, and in other Arab societies, even if you want to make your own decisions, especially as a woman or a young woman, you have to get your parents' approval and society's approval." Reflecting on the obstacles in her way, Maya (personal communication, November 8, 2017), stated, “I would say the society or society's approval, because there are people who still believe that women should not be leaders." The Saudi Arabian's society has an overpowering influence on the decisions women make. Rajwa (personal communication, December 2, 2017), asserted:

Our society has so much influence on our decisions. Even if I was able to travel to 
the moon and back, there are people who will not approve of it.... I always knew that I loved design but I was so afraid and I needed to be brave to face the society. Anything we do requires us to be brave because our society doesn't respond well to change.

Four of those seven participants reflected on the influence society has on their parents' mindset in terms of leadership development opportunities. Although these collegiate women described their parents as proponents of women's education, they are cognizant of the generational divide that hinders opportunities for them. For instance, Gaida (personal communication, January 23, 2018), described her parents' reaction to the leadership training program she attended:

They were anxious about the leadership training. For example, I was going to the leadership training once a week during the evening hours. They tried to convince me not to go. Even though I went to the training and I completed it, my parents' attitude about it is an example of how it could have hindered an opportunity for me to develop leadership. They were worried about me, but I was able to deal with it by convincing them.... One of the reasons I continue to persist with my parents is that their thinking has nothing to do with religious values, rather they are influenced by social norms and practices.

Reflecting on her part-time employment, Asma (personal communication, November 11, 2017), explained:

Parents in our society value our education, so they don't want us to work or even get married before completing our college degrees. My father values and prioritizes education over anything else. We were raised on the idea of education 
comes first. But, I believe it's difficult to convince or explain [to our] parents because their generation has a different mindset than ours that is developing. Our generation wants to wants more. That's why he doesn't know that I'm a part-time employee.

With an internship, a leadership training experience, a student government leadership role, and the demands of her academic coursework, Salma (personal communication, January 12, 2018), reflected:

The things that hindered opportunities would be family, which all fall under social aspect. For example, when I have to go to the university to the internship, I have to stay a little late to complete my work. Here, the issues come up for my parents. For my parents, it's not in their mind what I'm doing and where I'm going, or that I'm doing things for me that are not about academics. They don't get that there's more for me to achieve other than high grades. To me the opportunities I get to develop my leadership are a priority to me. The concept of developing my leadership does not cross my parents' mind.

In the following sub-section, I present the third sub-theme on the factors that promote and hinder opportunities for the participants to develop leadership.

\section{De-segregation vs. Marginalization}

Despite the gender-segregation policy carried out by most institutions in Saudi Arabia, a group of collegiate women described their leadership and work experiences with men as opportunities to develop leadership. For collegiate women of this study, these opportunities occurred on campus with male faculty members, administrators, and students; at local or national institutions or organizations; or at international events. For 
example, Rana (personal communication, November 5, 2017), reflected on her leadership experience as a representative of and a team leader in an international student organization at an off campus gender de-segregated event. She explained:

In Saudi Arabia, it's a closed community. Being able to communicate with men in boundaries of business and education really helped us develop skills that weren't present before. We got over our fear of talking to or dealing with men.

Halah described her experience at an international forum whereby collegiate men from Saudi Arabia participated. For Halah (personal communication, January 27, 2018), discussing issues related to peace and conflict "with Saudi male participants was really fulfilling and it gave me another perspective or aspect of thinking. It's really different." Meanwhile, May (personal communication, November 9, 2017), indicated that her experience in leading a group of young men and women elevated her awareness of gender bias. She claimed, "I did experience a situation where one of them didn't take me seriously. I think it's partially due to me being a girl. It was easy to feel there was gender bias on his part." Moreover, by working with men, Asma (personal communication, November 11, 2017), said:

I think it helps in developing our leadership by learning how to deal with male individuals, especially for young women in Saudi Arabia because they don't have the social skills to deal with men and tend to be shy when dealing with men. For female students to speak up against male students' disregard is an important leadership skill. So what I love about the university is that it encourages students to develop such skills.

However, a group of participants reflected on the social views and practices that 
marginalize women and maintain gender bias, discrimination, and inequality, and thereby hindering opportunities for collegiate women to develop leadership. For example, addressing the limited leadership opportunities young women have in Saudi Arabia, Maya (personal communication, November 8, 2017), explained:

Young women in Saudi Arabia are somewhat somewhat restricted in a number of professional fields, and generally in life. They don't often have the opportunity to take on the role of a leader. For the most part, they're not at the forefront of things. They tend to be placed second to a man. Men are always at the forefront of things and are always leaders, whereas women are not.

For Aseel (personal communication, October 1, 2017), the available leadership opportunities women have in diverse fields in Saudi Arabia are "Based on society's assumptions of what women want, what women should want, but never on what we actually want, which is why it took so long for us to be allowed to drive." Rana noted the lack of equal opportunities for collegiate women to engage in leadership experiences. She reflected on an event that gave a man an advantage over her to experience a leadership role. Rana (personal communication, November 5, 2017), stated, "There is the issue of inequality. For some reason they underestimate women's abilities."

Some participants referred to the lack of women leaders as role models. Although these participants are cognizant of women leaders in Saudi Arabia who are breaking barriers, the dominance of men as role models maintains gender bias and the marginalization of women leaders. For instance, Hana and Rajwa, who attended different universities at the time of this study, shared similar perspectives on the organized guest speaking lectures and seminars at their respective universities. Hana (personal 
communication, November 12, 2017), explained her lack of motivation to attend lectures and seminars: "Because I see a lot of people whether guest speakers who are CEOs and in senior leadership positions but they're all men. For us as female students, we can't relate as much." Similarly, Rajwa (personal communication, December 2, 2017), noted the underrepresentation of women guest speakers at her university. She said, "I see many successful men giving seminars and conferences. It's nice, but female students would not be able to relate more to a man like a woman." On the lack of women leaders as role models, Asma (personal communication, November 11, 2017), indicated:

We don't hear much about them or other Saudi women who are breaking grounds in different fields. I believe we need to have more role models. Sometimes it frustrates me that not everyone knows about such Saudi women. Why don't we inform girls and young women about these accomplished and successful women and that they could one day become like them if they developed their knowledge, leadership skills, and intelligence among other areas.

In the following sub-section, I present the fourth sub-theme on the factors that promote and hinder opportunities for the participants to develop leadership.

\section{Self-Confidence vs. "Being a Woman"}

Twelve of the 25 participants referred to their confidence and self-motivations as factors promoting opportunities for them to develop leadership. For example, Arwa (personal communication, October 22, 2017), stated, "What helps me to develop leadership is my personality. For example, my personality is capable of developing leadership skills. I feel I am ready to put effort in developing leadership.” Ghadeer (personal communication, October 4, 2017), reflected on her confidence as a factor that 
promoted experiences for her to develop leadership. She said, "I guess confidence and wanting to be better because you need to get out of your comfort zone. Being better might include having better leadership. It might not be leadership over others but leadership over your own life.” For Hana (personal communication, November 12, 2017), gaining confidence for sharing her thoughts with student leaders played a role in developing leadership. She said, "After the feedback and how good the responses were, it made me more open and gave me the confidence to speak up more and initiate different ideas. I felt that was a very prominent jump in my leadership process.”

Salma (personal communication, January 12, 2018), reflected on her motivation to be involved in different opportunities to develop leadership. She claimed, "If I wasn't a person involved in different opportunities such as workshops, clubs, or competitions, I wouldn't have been able to learn about overcoming obstacles and solving problems. All these experiences come up through involvement." Similarly, Wafa (personal communication, January 28, 2018), credited her motivation. She stated, "I'm the type of person who searches for online courses and lectures that align with my goals. I do it myself and I don't have to wait for the university to provide them." Moreover, Halah (personal communication, January 27, 2018), identified speaking up as personal value that promoted an opportunity for her to develop leadership. She asserted:

I developed leadership by speaking up. If you see something wrong and you're a person who believes in the right to speak up to protect your peers, then you have leadership qualities. This is what I believe. I'm not in any leadership position or have the right to represent all the students, but I felt I needed to speak up. It's an example of an opportunity I had to develop my leadership. 
Despite their self-confidence and self-motivations, 15 of the 25 participants referred to their gender as women to highlight social and legal factors that hinder opportunities for them to develop leadership. The phrase being a woman emerged from my interview with Farah, a president of a student organization. Reflecting on the factors that hinder opportunities for her to develop leadership, Farah (personal communication, November 2, 2017), said, “In Saudi Arabia's environment, being a woman hinders opportunities. As women, we kind of get blocked from doing things. Because we are not men, we're going to face a lot of obstacles. So, the environment really does hinder opportunities."

Bayan (personal communication, November 11, 2017), referred to the ways in which social practices perpetuate the challenges women experience in Saudi Arabia. She said:

Regarding what hindered opportunities for me to be a leader or develop leadership, I believe that it has to do with some of the social norms and practices in Saudi Arabia. Just because I'm a female, I'm expected to do certain things. In general, being a woman in Saudi Arabia does hinder opportunities to become a leader or develop leadership, such as I can't go to places alone and how could I be going to certain places alone when I'm a female. It doesn't make sense and it hinders opportunities. Of course, there was the issue of driving, which will no longer be an issue in the near future since women in Saudi Arabia are allowed to drive cars. For example, when I was working with the student club, there were times when I needed to go places but I had to rely on a driver. I needed to prove to myself, I needed to be a leader, I needed to go places and get things done but I 
couldn't because I'm a female and I can't do this or that. I feel that the social norms and expectations of what a female should or should not be doing created obstacles for me.

Two collegiate women referred to the male-guardianship law as a social practice in Saudi Arabia that hinders opportunities to develop leadership. Although their respective families are 'very supportive' of them in developing leadership, these two collegiate women addressed this issue in terms of the social mindsets and views that maintain gender inequality, discrimination, and biases against women in Saudi Arabia. Reflecting on society's mindsets amid some policy changes that were occurring in the country at the time of this study, Alya (personal communication, December 4, 2017), asserted, "Changing mindsets is so difficult." She illustrated:

I recently travelled by myself. It was the first time I travelled by myself. My dad dropped me off at the airport and the security guy made my dad wait because he wasn't sure if I could go in without my guardian. My dad had to wait until I boarded the plane.

For Maya (personal communication, November 8, 2017), she addressed maleguardianship in terms of male superiority that perpetuates gender bias in leadership practices:

Honestly, people still uphold views that it's shameful for a woman to be in a higher position than a man, and that a man has the guardianship over a woman and he's the manager and the leader. Women aren't seen at the forefront. I feel that we're at a time that is obviously different than the past. No person would 
accept to be treated that way and to be restricted, and no woman would want to feel she's at the mercy of a man or under the leadership of a man.

For collegiate women of this study, there are factors that promoted and contributed to their leadership development. Yet, these factors are being challenged by contrasting factors that hinder opportunities for them to develop leadership. The findings indicated that universities promote and hinder opportunities for collegiate women to develop leadership. Moreover, families support and dishearten collegiate women from engaging in leadership development opportunities. In addition, the findings revealed the ways in which gender de-segregation is challenged by women's marginalization through gender bias, discrimination, and inequality. Furthermore, although collegiate women have the confidence and motivation to develop leadership, they are challenged by social and legal factors for being women. The following section presents the third theme on the ways collegiate women in Saudi Arabia's private non-profit universities become leaders.

\section{Becoming Leaders}

This section describes the ways collegiate women in Saudi Arabia's private nonprofit universities become leaders. For the participants, the decisions they make, the student leadership opportunities, and the systems they utilize are starting points to become leaders. The following sub-sections present the factors influencing their decisions to become leaders, the opportunities they have for student leadership, and the systems they utilize to become leaders.

\section{Deciding Factors}

As part of the interview protocol, each participant was asked about her decision in becoming a leader. The participants' remarks included internal and external factors that 
influenced their decisions to become student leaders. In the following sub-sections, I present the findings of both factors, and quotations from the participants.

Internal factors. Nineteen of the 25 participants reflected on internalized aspects influencing their decisions to become leaders. These factors include their passion for leadership, self-knowledge, and their willingness to challenge themselves.

Passion for leadership. Nine participants referred to their passion for and interest in leadership. Explaining the decision to accept her peers' nomination for president of a student organization, Wafa (personal communication, January 28, 2018), a president of a student organization, asserted, "I'm interested in the mission and vision of this organization, especially that it's part of my learning and I'm passionate about it." Salma (personal communication, January 12, 2018), a president of a student government, indicated that her past work experiences contributed to her decision to become a leader. She stated, "My work experience added value to my leadership.... I had the passion to be someone different. I didn't want to be the same as other people. I wanted to be different and to be there for others." On deciding to become the leader of a student club, Maya (personal communication, November 8, 2017), who was a leader of a student club, said:

All I think about is that it's something I'm passionate about and it's something I like. I find myself more interested and I enjoy being the leader of the group, and I also found out that I really like to work in groups rather than individually... The leadership path is what I'm passionate about and makes me happy.

May (personal communication, November 9, 2017), a senior leader in a student club, reflected on her decision to become a leader in a community service student club. She said, "I have an interest for community service. I love to help the community in any 
way I can and be useful to society." On attending her first college student club fair on campus, Farah (personal communication, November 2, 2017), a president of a student organization, said, "I went through a lot of clubs and I signed up for at least 10 clubs because I wanted to be involved in everything around the university." Moreover, Alya (personal communication, December 4, 2017), a leader of student group projects and a youth leader at a community organization, explained her decision to become a leader. She shared:

I felt like I wasn't contributing enough. It's sort of something that drives me to be a leader. Being excluded from making decisions processes or giving feedback influenced me to become a leader or to work towards becoming a leader.

The following sub-section identifies self-knowledge as an internal factor influencing collegiate women's decision to become leaders.

Self-knowledge. Seven participants indicated self-knowledge as an internalized aspect of their decision-making processes. For example, Razan (personal communication, October 6, 2017), a senior leader in a student organization and was a leading member in a student government, reflected on her decision to run for student government president. She said:

I knew where the cracks in the system were, and I was able to cover over the cracks and fix the problem and develop because all we are ever doing there is for the sake of the students, improving the quality of the experiences of students and bridging the gap between students and administrators.

Noor (personal communication, January 18, 2018), a president of a student organization, decided to become a student leader because she wanted to share her ideas with others. 
She asserted, "I'm the type of person that if I have an idea or information that will benefit others, why would I hold it to myself? So I decided to just do it." Also, Deena (personal communication, December 19, 2017), who was a leader of a student club, stated:

When I came to the university, I knew the things that I wanted to do. That was due to several reasons. I knew people who've been at the university before. I knew what kind of student life the university has. The most important thing was that I was motivated.

The following sub-section identifies challenging oneself as an internal factor influencing collegiate women's decision to become leaders.

Challenging self. Seven participants referred to their willingness to challenge themselves and take initiative as an internalized aspect of their decision-making processes to become leaders. For instance, Maya (personal communication, November 8 , 2017), who was a leader of a student club, said, "I took it as a challenge and to prove to myself that I'm capable." Similarly, Nada, (personal communication, November 9, 2017), who was a leading member in a student club, revealed, "I didn't think about the leadership aspect of my involvement with the student club. I just wanted to enhance my social life in college.... It was a challenge I took and it worked out great." On taking the initiative, Rajwa (personal communication, December 2, 2017), a leader of student group projects and a volunteer at on-campus events, maintained, "That's how I became a leader because I see the opportunity and simply take charge." Farah (personal communication, November 2, 2017), a president of a student organization, explained how she took initiative to become a leader in an international student organization. She stated, "At the end of my first semester with the organization, they were nominating leaders. I asked if I 
could nominate myself and the faculty advisor said yes." The following sub-section presents the external factors influencing collegiate women's decision to become leaders.

External factors. Thirteen of the 25 participants in this study reflected on externalized aspects of their decision-making processes to become leaders. These factors include receiving support and encouragement, and selective practices.

Support and encouragement. Nine participants indicated that receiving encouragement and support from their families, faculty members, and peers influenced their decisions. For example, Razan (personal communication, October 6, 2017), reflected on her family's support in becoming a leader. She said:

I mean every time I come up and say that there's this new student club or a student government or any event, I was always supported. They would never one day come up to me and say they don't think I should do this. There's always support, constant support, uninterrupted support. Whenever I go up to my mom or my dad, or my family for that matter, and say that I'm considering running for student president, they'd always say 'yes go for it', because you never know where the opportunities lie and where you might actually develop and I've developed through all the things I've done alhamdulillah.

Rana (personal communication, November 5, 2017), a leader of student group projects and was a leading member in a student organization, credited the support she received from her parents and faculty members. She asserted, "The support I got from my family and from faculty members helped. When they saw something in me, I got a feeling that maybe they're right and that I just had to give it a chance." 
In addition, Arwa (personal communication, October 22, 2017), a leading member in a student club, noted the encouragement she received from a faculty member, and said, "I feel that the motivation from my faculty who supervises the student club helped. She is very motivated and she motivates us. I was encouraged to be part of the student club and take on a leadership role.” Moreover, Bayan (personal communication, November 11, 2017), who was a leading member in a student club, acknowledged the support and encouragement of her peers as part of her decision to become a leader. She shared:

One day, I was hanging out with my friends who share the same passion and vision of wanting to be part of something at the university. I believe friends play a huge role in encouraging me and in supporting me. Because I knew friends who shared the same passion, we went all out and it motivated us to be involved in as much student clubs.

The following sub-section identifies selectivity as an external factor influencing collegiate women's decision to become leaders.

Being selected. Seven participants used words such as asked, told, or recommended to describe how faculty members and their peers informed their decision to become leaders. For example, Manal (personal communication, November 8, 2017), a senior leader in a student club, explained how she was encouraged to become a leader by a colleague's recommendation. She said, "My colleague told me how suitable I was to join the team.... My colleague's recommendation was based on how active I was in solving student-related problems and in taking initiative." Aseel (personal communication, October 1, 2017), described the role faculty members played in her decision. She emphasized: 
Certain professors who see leadership qualities in us assign us as group leaders for in-class activities and projects. Sometimes they ask us to participate in student clubs or volunteer in activities they manage or supervise, because they see that in you. That's encouraging.... I noticed that also with professors, who taught me a couple of business courses. They asked me to partake in events they managed. That encouraged me a lot when I first enrolled at the university. For collegiate women of this study, their decisions to become leaders are influenced by internal and external factors. They referred to self-motivations such as their passion for leadership, self-knowledge, and their willingness to challenge themselves as internal factors that influenced their decision. In addition, they referred to the support and encouragement they received from family, faculty members, and peers, as well as the selective practices at their respective universities as external factors influencing their decisions to become leaders. The following sub-section presents the findings on the opportunities collegiate women have to become leaders.

\section{Student Leadership Opportunities}

Collegiate women of this study revealed the student leadership opportunities they have to become leaders at their respective universities. These opportunities for leadership manifest through co-curricular programs. For example, all 25 collegiate women in this study discussed leading student government or student organizations as opportunities for student leadership. For example, Gaida (personal communication, January 23, 2018), who was a senior leader in a student government, stated, “There's a student government. It opens a lot of opportunities because each student president can improve her cohort by organizing events, activities, conferences, and trips." Manal (personal communication, 
November 8,2017$)$, a senior leader in a student club, said, "The type of activities students can do include leading events, leading academic events, leading entertainment events, or leading a student government." Also, Wafa (personal communication, January $28,2018)$, a president of a student organization, indicated, "Other than student clubs, we have the student government, which is like a small administration run by students."

Moreover, 22 participants of this study indicated that leadership opportunities happen by establishing, leading, or having a leadership role in student clubs. For example, Arwa (personal communication, October 22, 2017), a leading member in a student club, said, "At the university, student leadership happens mostly in activities such as student clubs and student government." For Aseel (personal communication, October 1,2017), a leading member in a student organization, student clubs are beneficial. She stated, "There are student clubs, and you could be a leader in these clubs." At her university, Alya (personal communication, December 4, 2017), a leader of student group projects and a youth leader at a community organization, indicated, "There are student clubs where students can go to student services and open a new club based on a new idea."

In addition, 12 participants referred to volunteer work, participation in student competitions, event organization, and leading an athletic team provide opportunities for them to become leaders. Rana (personal communication, November 5, 2017), a leader of student group projects, said, "There are student clubs, student government, and many volunteering opportunities for every student from any academic department.” Describing student leadership opportunities at her university, Rajwa (personal communication, December 2, 2017), a leader of student group projects and a volunteer at on-campus 
events, said, “The university has different types of student leadership opportunities such as student government, student clubs, volunteer work."

Nine participants indicated that opportunities for leadership are available for collegiate women by leading student group projects. For example, Yara, who was a leader of a student club, indicated student group projects provide an opportunity for student leadership. Similarly, Ghadeer (personal communication, October 4, 2017), a leader of student group projects, said, "Student leadership can happen in group projects, in student clubs. Also, there is student government as an opportunity."

These findings reflect the participants' perspectives on the leadership opportunities collegiate women have at private non-profit universities. Later in this chapter, I will present the findings on the opportunities collegiate women have to develop leadership. The following sub-section describes the systems collegiate women utilize to become leaders.

\section{Systems}

Twenty-four participants referred to systems they utilized to become leaders. These systems include structural systems, application systems, and selective systems. The following sub-sections describe each system and present quotations from the participants.

Structures and hierarchies. Sixteen participants referred to structures and hierarchies as systems embedded within student clubs, government, and organizations. Nine of these participants followed a structured system to become leaders. For example, Nada, (personal communication, November 9, 2017), who had a leadership role within a student club, identified the training and rotation practices that are in place as "part of the club's system" for members to be promoted to leadership roles. To describe the system of 
a student club she was involved in, Bayan (personal communication, November 11, 2017), said, "I began as a member, then moved into a leadership role."

For seven of those 16 participants, the hierarchal structure of a student government, club, or organization created a path to leadership. Hana (personal communication, November 12, 2017), who was a leader in a student club, maintained:

When a student registers for a club, student leadership is a given. Most of the student clubs have a certain hierarchy structure. For example, a student club would have a president, a vice president, and senior leaders. For students in these clubs, being in a leadership role is a given.

For example, Farah (personal communication, November 2, 2017), a president of a student organization, said, "I joined the club as a member, then I was leveled up to a leadership position. A semester later, I got nominated to be the president of the club." Similarly, Deena (personal communication, December 19, 2017), followed a hierarchal structure to become a leader of an international student club. She noted, "As a freshman, I became an intern at the club... Then I was the president of the club in my junior year." Describing how she became a leader in a student club, Ghadeer (personal communication, October 4, 2017), said, “After I joined that club, I became an assistant to one of the student leaders. After she left, I was asked to be a leader for about a year." At the time of the study, May (personal communication, November 9, 2017) was in her third year as a member a student club. She stated:

In my first year with the student club, I started out as a member. I was a very hard working member. I did anything anyone asked me to do in the required time. A year later, the student club leaders asked me to take on a leadership role because 
of my work and commitment.... That same year, I was asked to become a ranking leader within the club.

The following sub-section presents applications as a system collegiate women utilize to become leaders.

Applications. Six of the 24 participants referred to an application system for pursuing a leadership position in student government or student clubs. Halah (personal communication, January 27, 2018), who was a student government president, explained the system in place for becoming a student government president. She illustrated, "When a student wants to run for student government, she fills out an application and includes her plan." Referring to the system she engaged in to become a leader, Salma (personal communication, January 12, 2018), a president of a student government, stated, "For the student government, my CV helped me because it's an important document to include with my application.” Furthermore, Noor (personal communication, January 18, 2018), claimed, "If a student wants to establish her own club, she can do that. ... All she does is fill out the form and start her club and recruit her team." For instance, Manal (personal communication, November 8, 2017), co-founded a student club and said, "There are three leaders in the club. I am the senior leader, and there is a president and a vice president, in addition to managers and members." To become a student leader at the university, Yara (personal communication, December 23, 2017), stated, "I created a student club." The following sub-section identifies selectivity as a system that created a path for collegiate women to become leaders.

Selection. Seven of those 24 participants alluded to a selective system or practice that created a path for them to become leaders. They used words such as nominated, 
recommended, and assigned to refer to the ways they were able to take on leadership roles. As a system, the notion of selectivity differs from being selected as a deciding factor to become a leader. For example, reflecting on a summer job experience, Jana (personal communication, October 1, 2017), recognized the role of her employer and said, "She nominated me to be a manager." Alya (personal communication, December 4, 2017), described how she was recruited to work at a community center to facilitate workshops for teenagers. She stated, "My boss from the learning center recommended me to them. He told them that I'm a good speaker." Also, Rana (personal communication, November 5, 2017), asserted:

Many faculty members and people who know me nominate me for roles in various events. Again, this is all because of the hard work I've done. When I put in hard work for professors, they would remember me because I work hard. Whenever there's an opportunity for volunteering or public speaking or for participating in a conference, I pop into their minds. That's what happened for the conference experience. One of my professors believed I'm qualified to participate in it and recommended me to the committee in charge.

The findings in this section described the internal and external factors involved in the decisions collegiate women of this study make to become leaders. They revealed the perspective collegiate women of this study have of the leadership opportunities at their respective universities. They indicated that student government, organizations, and clubs provide opportunities for them to become leaders. Also, they referred to volunteer work and participation in student competitions and athletic teams offer collegiate women opportunities to become leaders. In addition, the findings showcased structures and 
hierarchies, applications, and selection as three systems collegiate women of this study engaged in to become student leaders. The following section presents the fourth theme on the opportunities collegiate women have to develop leadership.

\section{Developing Leadership}

The findings revealed that collegiate women in Saudi Arabia's private non-profit universities develop leadership by preparing for leadership through memberships and observations, as well as mentorships. In addition, they develop leadership by experiencing and practicing leadership, and through formal leadership programs. The following sub-sections include collegiate women's remarks on memberships and observations, mentorships, leadership experiences, and participation in formal leadership programs.

\section{Memberships and Observations}

Approximately half of the participants of this study noted that their experiences as volunteers or as members of student clubs or organizations helped prepare them for leadership and develop their leadership skills. As a volunteering member of a student club, Manal (personal communication, November 8, 2017), a senior leader in a student club, relied on field observation to prepare for a potential leadership role. She recalled:

I noticed and observed how student leaders in the organization engaged and interacted with each other and with others and what their personalities were like. I built the skill of observing how others interacted with each other because I didn't have contact with everyone in the student organization. You could say that I prepared for my leadership role by observing others.... Maybe my experience as a member of the student organization helped with my leadership. 
Using her membership status in student group projects, Salma (personal communication, January 12, 2018), a president of a student government, prepared for potential leadership roles by observing group leaders. She asserted:

When I'm a member of a group, I observe what a leader does wrong. I learn from my experience of not being a leader, so when I become a leader of a group, I understand how to deal with the student members. I don't create conflicts with anyone, I don't complain to the instructor or professor about the group. What I do is I communicate with all members rather than ignore them.

Ghadeer and others alike used field experiences as an opportunity to learn by observation. Aside from her leadership role in a student club, Ghadeer (personal communication, October 4, 2017), a leader of student group projects, volunteered at an event for a local organization. She said, "I got to see how others do it, how they interact with others at the event.... I learned by observing at the event." While Noor (personal communication, January 18, 2018), a president of a student organization, indicated that she developed leadership "Because of the opportunity and the experience of becoming a leader," learning from other leaders helped in developing her leadership. She asserted, "I like to learn from people who I see as good leaders. So I learn from people." As a president of a student organization, Wafa (personal communication, January 28, 2018), develops leadership by learning from the leadership practices of others. She said: Other than being a president of a student club, I became a member at another student club that is related to my passion. I took a small role, but it makes me observe the dynamic of the student club and the leadership practices in that club. So, I try to involve myself everywhere. Also, I'm currently working as an 
assistant to a professor. I'm learning skills in a different way that will help me become a better leader.

On developing leadership by observing other student leaders, Maya (personal communication, November 8, 2017), who was a leader of a student club, asserted:

I observed what they were doing. I needed to know that everyone has their own experience in their own field. I took in as much information, processed them, then generated outcomes based on the circumstances I'm in. Maybe it was based on the circumstances I was in, the team I was working with, or the challenges or obstacles I faced that I was able to analyze, find solutions, or think of potential consequences for our decisions. This helped me develop leadership skills.

For collegiate women of this study, their memberships in student clubs and organizations helped them prepare for and develop leadership. Through their membership status, they developed leadership by learning from and observing student leaders.

\section{Mentorships}

Preparing for their leadership role, seven of the 25 participants acknowledged their peer mentors. For instance, Wafa (personal communication, January 28, 2018), a president of a student organization, indicated:

What I did to prepare myself was that I tried to involve myself and to have more connection with people who have experience or who are good in their leadership. I try to learn from them. There's a student leader who inspires me a lot. I see how she thinks and how she can control everything. I try as much as I can to involve myself and see how she thinks. So I started step by step. I try to do whatever it is to make myself better as a leader.... Also, I reach out to one of my friend, who is 
a student club president. She's like my advisor. I always go back to her ask for her advice about things that I need to do. She offers a different way of thinking about something. She's always there to help.

Hana (personal communication, November 12, 2017), recalled her experience as a member of a student club. She said:

I had a mentor. She was very effective. She was inspirational. Honestly, the way she managed the team, being in a competitive deadline and stuff like that. So she was very helpful, and motivated me. When I became a student leader, I copied the things she did. I took them into consideration as much as I can. She was a very good example for me to take on a lot of the things she did and try to implement them in my own way. I tried to take into consideration how she did the work and how she managed the team. I was very lucky because she was very motivational and helpful.

Identifying a college student as her "mentor", Deena (personal communication, December 19, 2017), stated:

She introduced me to things I only knew by name in terms of student club activities. ... She advised me to start an intern and by working hard I'll get to where I want to. She encouraged me to apply for a program and it will benefit me. So, she helped a lot. I think being mentored and being privileged to have someone who can mentor me and walk me through that, prepared me for the leadership roles.

In her experience, being mentored by a student leader helped May (personal communication, November 9, 2017), learn how to lead a team of students. For Razan 
(personal communication, October 6, 2017), working with one of her peers helped her develop leadership skills. She explained:

I was working with the founder of the website. She's one of my peers, and she's top of my class, she's truly inspirational. I got to learn a lot by working with her, how her standards for research and referencing they were extremely high. I got to soak up the experiences she had, and I got to learn so much from her. I would implement that, and through that I would elevate my quale of leadership, because I saw how she led and saw that this is something I can implement in the way that I lead because she's running a website and it's a sophisticated website, considering that she's still in college.... When I saw that in her, I felt completely inspired to participate as much as I can in the things she would do. Through that I got to develop my leadership skills.

The findings showed that a group of participants benefitted from peer mentoring. Through peer mentors, these participants were able to prepare for and develop leadership. The following sub-section presents the findings on experiencing leadership as an opportunity to develop leadership.

\section{Experiencing Leadership}

Twenty collegiate women asserted that their experiences as student leaders enabled them to develop leadership. As a leader of a team in a student club, May (personal communication, November 9, 2017), felt that "the best way to develop leadership is student clubs and activities." Yara, who was a leader of a student club, indicated that she developed leadership by establishing and leading a student club. Rajwa (personal communication, December 2, 2017) said, "I did some small things like leading 
a small group for a class project in college and throughout high school. That's how I gained leadership skills."

Seven of those 20 collegiate women noticed that through their student leadership positions, they were able to develop leadership. For example, Aseel (personal communication, October 1, 2017), felt that the rotating practices among leaders within an international student organization helped her develop leadership. She explained, "As members, we can't stay in a position for more than a year. I have to be an active member and engage in different positions and roles. It provides me an opportunity to experience leadership through different experiences." For Layan (personal communication, February 3, 2018), the challenges she faces in her position as a student government president helps her to develop leadership. She explained:

This leadership role I'm in is actually teaching me how to deal with the challenges and conflict inside or outside the university. Whatever is happening inside the university is happening at a smaller scale to what we'll face outside of the university that is at a larger scale. So I'm trying to deal with the challenges at university so I can know how to deal with bigger challenges at the social level. Although Farah (personal communication, November 2, 2017), developed confidence and communication skills as a student leader, leadership was developed indirectly. She added, "It was mostly what I gained from my experiences in the student organization that enhanced all the leadership skills that I developed." Moreover, Maya (personal communication, November 8, 2017), who was a leader of a student club, asserted, "I had to learn from my own experiences and observe and learn from other 
student leaders, reflect on the problems I faced and learn from my mistakes. My leadership skills developed with time and through experience."

Eight of the 20 collegiate women reflected on developing leadership through practice. For instance, Bayan (personal communication, November 11, 2017), who was a leading member in a student club, said, "When I'm in a situation that requires me to step up and be a leader, it develops my leadership. I develop leadership through practicing it. To me leadership is very practical. I have to do it and learn from it." Similarly, Asma (personal communication, November 11, 2017), a senior leader of a student club, asserted, "I learned more on the job. I believe that practical experience is better in developing my leadership skills.” Halah (personal communication, January 27, 2018), who was a student government president, stated, "I believe leadership develops with practice. If I keep doing what I'm doing, I'll develop it with knowledge and experience."

For collegiate women of this study, their experiences as student leaders developed their leadership skills. They indicated that through their leadership position and the challenges associated with it, they develop leadership. Moreover, the findings revealed that they develop leadership through practice and in an indirect way. These findings seem to support participants' source of leadership understanding. The following sub-section presents the findings on the opportunities collegiate women have to develop leadership in formal ways.

\section{Formal Leadership Programs}

Nine of the 25 collegiate women referred to academic courses, short lectures, workshops, and training programs as opportunities they engaged in to develop leadership. These opportunities occurred at their respective university, in local their community, or at 
a different country. To develop leadership, Salma indicated that she learned about leadership from a business course related to her academic major. Furthermore, she referred to a workshop that took place at her university. Salma (personal communication, January 12, 2018), stated, “Another opportunity to develop leadership was through a business workshop at the university that was facilitated by a lecturer from one of the top Western universities." Similarly, Wafa (personal communication, January 28, 2018), a president of a student organization, attended lectures and workshops that are offered at her university to further develop leadership. She stated:

The university hosts weekly lectures, workshops, or seminars where experts from different fields speak at these events. So I attend these lectures and workshops and I try to connect and network with the speakers. For example, student clubs or student government organize lectures or workshops that are facilitated by guest speakers and experts from different fields. I try to attend them even if they were on topic unrelated to my academic major.

Although only a few collegiate women of this study participated in training programs at their local community or at a different country, they expressed positive outcomes. For example, Salma participated in a leadership training program at her local community and benefitted greatly from it. Moreover, on completing a leadership training program, Gaida (personal communication, January 23, 2018), reflected:

I felt more confident in my ability to lead people. I feel I'm on the right path now because I have all these skills that I should've had a long time ago. The training experience changed me. It helped me become more professional as a leader. Deena (personal communication, December 19, 2017), described her training experience 
at a youth leadership program in Jordan that was part of a United Nations Development Program (UNDP) initiative. She revealed:

It was a 1-week program focused on leadership skills to help youth working on sustainability projects. It's been two years since the program, and I now recognize that I might not have been the most exemplary youth member because I didn't have a sustainability project, but I benefited from the leadership aspect of the program such as team management workshops. So, I made use of the workshops. The findings of this study provide an understanding as to how collegiate women in Saudi Arabia's private non-profit universities develop leadership. The findings revealed that collegiate women of this study have limited opportunities to develop leadership in formal ways. The results showed that they prepare for and develop leadership through their membership in student clubs or organizations whereby they learn and develop leadership by observing other leaders. In addition, the results showed that collegiate women develop leadership through peer mentorship. The findings of this study revealed that collegiate women develop leadership by experiencing and practicing leadership. Furthermore, the findings showed that only a few collegiate women engaged in formal programs to develop leadership. The following section presents the fifth theme on the participants' understandings of leadership.

\section{Understandings of Leadership}

This section describes the leadership understandings of collegiate women in Saudi Arabia's private non-profit universities. Their understandings of leadership are presented as definitions of leadership, and of self as a leader. These definitions reflect relationaloriented concepts of leadership. Moreover, the definitions and views collegiate women 
have of leadership are derived from three main sources that inform their understandings of leadership, such as people, leadership experiences, and formal leadership programs.

\section{Definitions}

Collegiate women of this study provided three interrelated definitions of leadership. In addition, they made distinctions between leadership and non-leadership ideas that gave clarity to their definitions. Moreover, collegiate women's view of themselves as leaders supported their definitions of leadership.

Defining leadership. The participants of this study conceptualized leadership as collaboration, setting an example, and a learning process.

Collaboration. The notion of collaboration was highlighted as a dimension of leadership. For example, May (personal communication, November 9, 2017), a senior leader in a student club, said, "It's about working and doing the actual work with others and not just watching what they do.” Rana (personal communication, November 5, 2017), a leader of student group projects and was a leading member in a student organization, claimed, "It's about sharing. Not just telling others what to do, you'll have to share the task and work together." Both Rana and May indicated that leaders engage in a mutual sharing of information and ideas with others. May said, "I feel that being a leader is about sharing and participating with others." Rana explained that as a leader, "You have to share your ideas with the group. Even though you're the leader, that doesn't make you any better. You have to share your thoughts and you have to take other people's opinion." Within the dimension of collaboration, the idea of involving others was reflected in how Arwa (personal communication, October 22, 2017), a leading member in a student club, defined leadership: 
It's a contribution between the leader and the followers. It's about involving them in your leadership journey. A leader doesn't just give them orders. Instead, a leader makes them share their ideas and thoughts that can add to his or her leadership.

Elaborating on the extent to which leaders involve others, Deena (personal communication, December 19, 2017), who was a leader of a student club, stated that leaders "Involve others in making decisions, make them feel comfortable to come to work, and make it clear what we're doing, and make everyone involved in the determination of the vision and the path we're going to take." The following sub-section presents the participants' definition of leadership as setting an example.

Setting an example. Other participants defined leadership as setting an example for others. Razan (personal communication, October 6, 2017), a senior leader in a student organization and was a leading member in a student government, said, "To me, leadership is leading by example." This understanding of leadership was described as the act of inspiring and being a role model for others. Maya (personal communication, November 8, 2017), who was a leader of a student club, explained, "It is to inspire people to work, and to be the role model for others.... It is to encourage and inspire others to be in a position where they give with passion and become leaders one day.” This internalized view of leadership is reflected in why Salma (personal communication, January 12,2018), a president of a student government, considered leadership as influence. She said, "I consider it an influence, because I get influenced by others to go and do more, and they themselves start moving and doing something." Another participant, Halah (personal communication, January 27, 2018), who was a student 
government president, felt that leadership is about influencing others indirectly. Halah said, "I believe leaders are influencers. They influence their followers and not in a direct way.... They affect their followers' attitudes and behaviors to achieve a goal or an objective." The following sub-section presents the participants' definition of leadership as a learning process.

Learning process. A group of participants identified leadership as a learning process. These collegiate women were holding a student leadership position at the time of this study. They noted that leadership is assimilated with experience and from others. For example, Farah (personal communication, November 2, 2017), a president of a student organization, reflected on the notion of learning from others. In her definition of leadership, Farah said, "It is getting to know what other people are doing, and doing the same thing over a period of time. To learn what other people are doing and being experienced, and then helping people do other things as well."

Gaida (personal communication, January 23, 2018), who was a senior leader in a student government and had just completed a leadership training program at the time of this study, asserted, “Leadership is something that I learn. I can't immediately be this perfect leader, but I needed to develop leadership, learn in, and practice it." May (personal communication, November 9, 2017), a senior leader in a student club, claimed, "It is something that someone acquires with experience." Sama (personal communication, October 7, 2017), a president of a student government, stated, "It's a learning process, and I am very optimistic about the experience.” The following sub-section presents the participants' understanding of what leadership is not. 
Making distinctions. To further explain their understandings of leadership, approximately half of the sample in this study provided leadership definitions by describing what leadership is not. These collegiate women noted some misperceptions people have of leadership. For example, Aseel (personal communication, October 1, 2017), a leading member in a student organization, claimed, "For our generation, the idea of a leader is someone who forces something on others. Obviously, that's not who a leader is." Deena (personal communication, December 19, 2017), who was a leader of a student club, said, "Some people think leadership is about being bossy." May (personal communication, November 9, 2017), a senior leader in a student club, indicated, "I think a lot of students think a leader is a boss who gives out commands, but obviously that's the wrong description or the wrong way of seeing leadership." To clarify her nonpositional view of leadership, Wafa (personal communication, January 28, 2018), a president of a student organization, said, "It's not about the position. It's about what we do with leadership and it's about inspiring people and encouraging them to work."

Other participants rejected the leader-centric or positional view of leadership in their definitions. They used concepts such as supervise, boss, superior, and control to make distinctions between leadership and non-leadership ideas. For example, Maya (personal communication, November 8, 2017), who was a leader of a student club, said, "Leadership is to delegate and not supervise." Jana (personal communication, October 1, 2017), a leader of student group projects, asserted, "In leadership, there is no boss. A leader would not think of himself or herself superior to others." Noor (personal communication, January 18, 2018), a president of a student organization, said, "It's not really about being a boss or controlling people but it's having the most responsibility and 
being able to see the whole picture or the big picture that the whole team is working to achieve."

A couple of participants shared explicit descriptions to further clarify their understandings of leadership. These descriptions used the concept of control to reject the leader-centric view of leadership. Farah (personal communication, November 2, 2017), a president of a student organization, stated:

You just can't expect yourself to be a leader by just telling people that they need to do this and that. It's not a position of control. You can't expect yourself to control people and then be called a leader. A leader isn't someone who controls people.

Moreover, Manal (personal communication, November 8, 2017), a senior leader in a student club, described her experience with a controlling manager. She said:

I've seen a manager who is controlling people to get things done. I've see how he treats people and I've seen how this relationship is not built on any emotional or personal thing. Basically, at the end, things are getting done but the team is not inspired and well-guided. He's controlling them to achieve his goal, but that doesn't make him or her a leader.

The following sub-section presents the participants' definition of themselves as leaders.

Defining self as a leader. Collegiate women of this study were recruited on the basis of being identified as student leaders. All 25 participants were asked to identify ways in which they see themselves as leaders. They viewed themselves as leaders in terms of practices and skills they attributed to leadership such as taking initiative, being role models, listening to and understanding others, and communicating with others. 
Taking initiative. Fourteen of the the 25 participants saw themselves as leaders who take initiative. For example, Rajwa (personal communication, December 2, 2017), a leader of student group projects and a volunteer at on-campus events, said "I take initiative and that's a part of me, which is sometimes positive and sometimes negative because I need to take charge, I like to know what I'm doing, and I like to organize people’s tasks.” Bayan (personal communication, November 11, 2017), who was a leading member in a student club, asserted:

I believe I'm an independent person and I take initiative. I feel that I'm not as much of a risk taker as I'm the type of person who isn't afraid to decide on something and do it, while recognizing what the consequences are.

Alya (personal communication, December 4, 2017), a leader of student group projects and a youth leader at a community organization, elaborated:

I think it falls under taking initiative, such as being the first one to raise my hand or getting up in class to demonstrate something or just helping in any way because I think leadership and helping come hand-in-hand. At the end, I'm helping people. I think that to be the first one to raise my hand in class or to volunteer in general. While many participants defined themselves as leaders who take initiative, a few of them explained that they take initiative because others do not. Describing a typical group project situation, Rana (personal communication, November 5, 2017) said, "In a group work, we sit together, start chatting, and get to know each other. After a few minutes, I initiate the discussion about the project and distribute tasks because none of the members took initiative." Sama (personal communication, October 7, 2017), a president of a student government, indicated, "Whether in class or outside of class, I 
immediately take the role of a leader because most people don't want to take control and assign tasks to others." In her explicit reasoning, Razan (personal communication, October 4,2017), a senior leader in a student organization and a leader of student group projects said:

Sometimes people don't want to take the responsibility of doing whatever, so I would automatically take that position. For example, when I'm doing projects for classes or just participating in whatever, I find myself automatically being the leader, declaring myself the leader because I think I have that strength to take on the responsibility and should anything fail in this project whatever it was, I'm willing to say that it is my fault. So I felt comfortable admitting that I was wrong if ever I needed to do that.

The following sub-section presents the participants' definition of themselves as role models.

Role models. Eleven of the 25 participants in this study defined themselves as leaders using concepts such as being a role model, inspiring, and motivating. Alya (personal communication, December 4, 2017), a youth leader at a community organization, viewed herself as a "role model" for children. Noor (personal communication, January 18, 2018), a president of a student organization, said, "I have the ability to inspire and motivate people to do something. If a leader doesn't have that then people might not be doing things from the heart." Wafa (personal communication, January 28, 2018), a president of a student organization, explained:

When we come up with an event or a trip, I start working so they can start working. I don't just give them the tasks and leave them to do it. I work with 
them, try as much as I can to motivate them and keep them excited, try to create a work climate that isn't dull or boring.

The following sub-section presents the participants' definition of themselves as leaders who listen to and understand others.

Listening and understanding. Almost half of the participants defined themselves as leaders using concepts such as listening to and understanding others. For example, Rana (personal communication, November 5, 2017), a leader of student group projects, indicated that she listens to others because it is an "important" practice in leadership. Similarly, Razan (personal communication, October 6, 2017), a senior leader in a student organization, defined herself as a leader by having the ability to listen to others. She said, “There's a very big importance in listening to the other person. For example, someone is talking to me and I would very actively listen to what they are saying so I can reciprocate what I believe." As an “extrovert”, Alya (personal communication, December 4, 2017), a youth leader at a community organization, claimed, "I learn how to listen more and always try to find common ground with others."

Aseel (personal communication, October 1, 2017), a leading member in a student organization, noted that working with others enables her to "get an understanding of what they are going through and what they need and want." Nada, (personal communication, November 9, 2017), who was a leading member in a student club, asserted:

It's important to me to be able to listen to what people have to say, and understand their point of view. If I have a different point of view, I try to convince them about it. The main thing is that I make sure that I understand others. 
The following sub-section presents the participants' definition of themselves as leaders with communication skills.

Communicating. A group of participants stated communication skills to define themselves as leaders. For example, Aseel (personal communication, October 1, 2017), a leading member in a student organization, asserted, "I have good communication with people. My communication skills are good.” Salma (personal communication, January 12, 2018), a president of a student government, identified her communication skills as "important" and said, "Communication skills and the adaption to diversity and to people of different nationalities is very important. I have friends from different nationalities. I'm not the type of person to only have friends of Saudi nationality." Farah (personal communication, November 2, 2017), a president of a student organization, stated:

I got to learn that communication is the first part of being a leader. I have to communicate with people on a daily and hourly basis. I had to learn how to convince people. I can’t just go into the leadership phase without knowing how to convince people on a specific topic.

Although the participants shared diverse perspectives of themselves as leaders and had experiences in leading their peers, almost half of them indicated they did not view themselves as leaders. For example, May (personal communication, November 9, 2017), a senior leader in a student club, said, "Honestly, I think I'm still developing as a leader. I don't think I reached my highest point. What I see in myself as a leader is that I try to be thoughtful of other people's situation.” Rajwa (personal communication, December 2, 2017), a leader of student group projects, said, “I don’t think I'm a leader.... I haven’t had the opportunity to lead anything big. I've been more of a team member but not the 
leader." When asked about the ways she views herself as a leader, Jana (personal communication, October 1, 2017), a leader of student group projects, said, "I like to get out of my comfort zone. ... I think this has something to do with leadership, because it requires strength to take risks, and to be uncertain sometimes helps me to grow." Yet, Jana added:

I don't view myself as a leader. It's usually people who tell me that I'm a leader. I didn't realize that until recently. I usually don't like to be a leader of a group if I'm not interested in that certain activity.

Other participants stated that they were viewed as leaders by others. For example, although Aseel (personal communication, October 1, 2017), a leading member in a student organization, described herself as intuitive and a decision maker, she said, "Ever since I was a kid, my mom always told me that I am a leader and that I have that in me... I kind of knew it because it was, you know, planted in me.” Rana (personal communication, November 5, 2017), a leader of student group projects, said:

At first, I really didn't see myself as a leader. I'm just trying to help everyone and I'm just trying to get work done. The students just saw something and told me, and that made me think that I may have the qualities of a leader.

Overall, collegiate women of this study defined leadership along three dimensions. First, they conceptualized leadership as an interdependent relationship between leaders and followers, a practice of leading by example, and a learning process. Second, they viewed leadership as non-positional. Third, their understanding of leadership reflected their understanding of themselves as student leaders who take initiative, inspire and motivate others, listen to and understand others, and communicate 
well with others. The following sub-section presents the sources of the participants' leadership understanding.

\section{Sources of Leadership Understanding}

Collegiate women of this study attributed their understandings of leadership to at least one of three sources. These sources include people, leadership experiences, and formal leadership programs. The following sub-sections include a description of each source and quotations from the participants.

People. Approximately half of the participants in this study identified either a family member or a mentor as a source who shaped their understandings of leadership. For example, Razan (personal communication, October 6, 2017), a senior leader in a student organization and was a leading member in a student government, said, "The concept of leadership has been in my family for as long as I could remember." Crediting her father as the source of her leadership knowledge, Razan stated, "His job entailed a lot of leadership roles. He would talk about it on a daily basis." Bayan (personal communication, November 11, 2017), who was a leading member in a student club, said:

To be honest, I'm surrounded by a lot of people who are leaders. Being a leader is emphasized in my family. We are always encouraged to take leadership steps. For example, when we were taught what is right or wrong, we're taught if whether or not it's a leadership attribute.... It's something my family stands for that we have to be leaders in our life. From the things I learned from my parents is that leadership is about knowing what is right and what is wrong.

Other participants referred to mentors as their source of leadership knowledge.

For instance, Jana (personal communication, October 1, 2017), a leader of student group 
projects, claimed that her understanding of leadership, in terms of encouraging and helping one another, was shaped by a summer job employer. Other participants credited student leaders as their source of leadership understanding. For example, Nada, who was a leading member in a student club, learned from and observed student leaders who mentored her during her first year as a student club member. Similarly, Wafa (personal communication, January 28, 2018), a president of a student organization, indicated that she understood leadership by observing others. She said:

My friends are leaders and other students are leaders. I see them as leaders by how they work, how they inspire people, how they change, and how they act. So, I learned what leadership is from the university environment because leaders are everywhere at the university.

The following sub-section presents leadership experiences as the participants' source of their leadership understanding.

Experiencing leadership. For collegiate women of this study, experiencing leadership was identified the most as their source of leadership understanding. They indicated that their experiences in leadership roles such as leading student group projects, organizations, clubs, etc. shaped their understandings. For example, Jana (personal communication, October 1, 2017), a leader of student group projects, claimed, "The experience with the students had the larger impact on me."

Thirteen of the 25 participants in the study asserted that their experiences as leaders of student clubs and organizations helped them in understanding leadership. For instance, Razan (personal communication, October 4, 2017), indicated that she learned 
about leadership and its significance after joining a student club at the university.

Describing the leadership opportunities at her university, she said:

There were a lot of leadership roles, and I never really considered its importance up until I signed up for something like Toastmasters. That was a stepping stone for me. It was very important for me to gain a better understanding of what leadership is, what good leadership is, [and] how to lead through example.

Farah (personal communication, November 2, 2017), a president of a student organization, stated, "Holding a position of a leader in extra-curricular activities helped me understand that it's not about bossing people around. It's basically getting to know what I need to do on my part helping other people in what they're doing."

Moreover, a group of participants reflected on the interdependence relationship between their understandings and practicalities of leadership. For example, referring to her understanding of leadership, Hana (personal communication, November 12, 2017), who was a leading member in a student club, said, "It's very much based on practicing leadership." Halah (personal communication, January 27, 2018), who was a president of a student government, stated, "It was a combination between what I learned in class, and what I practiced. I applied what I learned. I took the knowledge and I tried to apply it in my leadership role.” May (personal communication, November 9, 2017), a senior leader in a student club, asserted:

I learned from my mistakes, [which] really helped because at that time I felt a huge amount of stress as a result of not letting others help.... I mean when I think about leadership, no one can be a leader without really failing then learning from it, or without making mistakes because it's bound to happen at some point. 
Deena (personal communication, December 19, 2017), who was a leader of a student club, said:

I applied my understanding of leadership to situations I was part of. So when I was part of a team, I wanted a leader to show me the path and to tell me what's next. I did experience situations in which I had people helping me with that and telling me what the vision is and what the next step should be. Then when I came to be at a leadership position, I tried to do the same.

The following sub-section presents formal programs as the participants' source of their leadership understanding.

Formal leadership programs. The leadership understandings of several collegiate women of this study are informed by formal leadership learning programs. Only eight of the 25 participants attributed their understandings of leadership to academic courses, lectures, seminars, and trainings on leadership or leadership-related topics. For example, Wafa (personal communication, January 28, 2018), a president of a student organization, claimed that she came to understand leadership "by attending workshops, learning through courses on leadership.” Arwa (personal communication, October 22, 2017), a leading member in a student club, stated, 'I'm taking a behavioral organization course this semester and it is helping with my understanding about leadership." Gaida (personal communication, January 23, 2018), said, "When I started college, I realized that the university focuses on leadership and I took a course on leadership, which made me learn about it more and I began to connect everything together, connect my experiences with my learning." Halah (personal communication, January 27, 2018) reflected, “As I studied business courses, I feel that everyone should be familiar with them and study 
them. It shouldn't be only for people in the field, but for everyone to learn and practice in life."

As aforementioned, for collegiate women of this study, leadership is defined as a collaboration, setting an example, and a learning process. In addition, their definition rejects the positional view of leadership. Moreover, based on the interview data, they viewed themselves as leaders who take initiative in their leadership practice, inspire and motivate others, understand and listen to others, and have good communication skills. Furthermore, they came to understand what leadership is from family members and peer mentors, by experiencing leadership as student leaders, and to some degree from formal programs such as academic courses, trainings and workshops, and seminars on leadership. Most collegiate women of this study referred to their leadership experiences as the source of their leadership understanding.

\section{Summary}

All in all, the study's findings revealed that despite the challenges they face, collegiate women in Saudi Arabia's private non-profit universities have the motivation to develop leadership for themselves, for others, and for social transformation. For collegiate women of this study, the decisions they make, the opportunities they have for student leadership, and the systems they utilize create a path for them to become leaders. The results showed that collegiate women in Saudi Arabia's private non-profit universities prepare for and develop leadership through memberships and observations, mentorships, and experiences in student leadership. However, they have limited opportunities to develop leadership in formal ways.

The findings from this study provided insights into the leadership understandings 
of collegiate women in Saudi Arabia's private non-profit universities. The results revealed that they understand leadership as a practice of collaboration, setting an example, and a learning process. Furthermore, their understanding of leadership reflects a non-positional view of leadership. From the findings of this study, the participants defined themselves as leaders who take initiative and challenge themselves, are role model for others, listen to and understand others, and communicate well with others. Moreover, the results showed that collegiate women generate their understandings of leadership from people, leadership experiences, and to some degree through formal programs. As presented in this chapter, the findings highlighted the perspective collegiate women of this study have of leadership as a relational practice they engage in to better themselves and others, and for the betterment of the Saudi Arabian society. The following chapter, Chapter Five, provides a discussion of this study's findings. 


\section{Chapter Five: Discussion}

This study explored and investigated the leadership understandings of collegiate women in Saudi Arabia's private non-profit universities, the opportunities they have to develop leadership, and how and why they develop leadership. The review of the literature revealed that much is unknown about what leadership means to collegiate women in Saud Arabia, and about their experiences in developing leadership and motivations for leadership development. Taking into account the social and cultural context of this phenomenon, the existing Western perspective of student leadership development theories and models were viewed unfitting as a theoretical framework for this study. Therefore, this study utilized constructivist grounded theory methodology. The use of this methodology afforded the needed space and flexibility to understand what the participants understand leadership to be, and how they make meaning of their experiences in and motivations for leadership development. The findings, discussed here,

generated an understanding of the perspective collegiate women in Saudi Arabia's private non-profit universities have of leadership as a relational practice they engage in to better themselves and others, and to have a greater impact on the Saudi Arabian society. This chapter restates the research questions of this study, presents an overview of the findings, and provides a discussion of the findings, implications, limitations, and recommendations for future research.

\section{Review of Research Questions}

The research questions that informed this study were:

(1) In Saudi Arabia's private non-profit universities, what are collegiate women's understanding of leadership and leadership opportunities? 
(2) What opportunities do collegiate women in Saudi Arabia's private non-profit universities have to develop leadership?

(3) From their perspective, how do collegiate women in Saudi Arabia's private non-profit universities develop leadership?

(4) Why do collegiate women in Saudi Arabia's private non-profit universities develop leadership?

Answers to these research questions were obtained from the results of the study. The findings and concepts this study generated are discussed in the following section.

\section{Review of the Findings}

The aim of this dissertation study was to explore and investigate the leadership understandings of collegiate women in Saudi Arabia's private non-profit universities, the opportunities they have to develop leadership, and how and why they develop leadership. In presenting this study's findings, I explained collegiate women's motivation to develop leadership, perspective of the factors that promote and hinder opportunities for them to leadership development, approaches to becoming leaders, leadership development, and understandings of leadership.

This study found that despite the challenges the participants face in Saudi Arabia, they are motivated to develop leadership for themselves, to influence and inspire others, and to contribute to social change. Their decision to become leaders are driven by personal and external factors. Moreover, the opportunities and experiences they have to develop leadership are limited and are manifested in informal and inconsistent ways. Furthermore, the participants' understanding of leadership is relationship-oriented. They 
view themselves as leaders who take initiative and challenge themselves, are role model for others, listen to and understand others, and communicate well with others.

As discussed below, findings from this study indicated that collegiate women in Saudi Arabia's private non-profit universities (1) have a collective sense of the importance in developing their leadership potential to better themselves, to better each other, and for the betterment of the Saudi Arabian society, (2) develop leadership in inconsistent and informal ways, and (3) understand leadership from a relational lens. Although collegiate women in Saudi Arabia's private non-profit universities develop leadership in inconsistent and informal ways, this study revealed that they are interested in and motivated to develop their leadership potential. The following sections discuss these emerging ideas. The following sections discuss these emerging ideas.

\section{Motivations for Leadership Development}

This section provides answers to the study's fourth research question that asked why collegiate women in Saudi Arabia's private non-profit universities develop leadership. The results showed that they develop leadership to better themselves and each other, and for the betterment of the Saudi Arabian society. In the following sub-sections, a discussion is provided on the development of self, development of others, and the importance of leadership development for Saudi Arabia's society as three main motivational factors for collegiate women to develop their leadership potential.

\section{Development of Self}

The current study found that collegiate women in Saudi Arabia's private nonprofit universities develop leadership to develop themselves. An interesting finding was that having self-confidence provided them with the needed motivation to develop 
leadership. In addition, by building their self-confidence in their capabilities as student leaders, collegiate women of this study developed the willingness to challenge themselves and and take risks. These findings support the ideas of Kouzes and Posner (2014), who suggested that exemplary leaders develop confidence in themselves to take on new challenges. A possible explanation for this finding might be that collegiate women have a sense of self-knowledge and self-awareness of their inner strengths that motivated them to become student leaders and develop their leadership potential.

The results of this study showed that collegiate women have the passion for and interest in leadership. The findings indicated that there is an internalized passion that drives them to continue developing themselves and their leadership potential. This finding seems to be consistent with the work of Komives et al. (1998) and SCM (HERI, 1996; Komives \& Wagner, 2009), which showed that leaders' enhanced self-awareness contributes to their passion and commitment for change. For collegiate women of this study, their passion for and interest in leadership transcends beyond themselves. It seems possible that these results are due to changes they are witnessing to the role of women in the Saudi Arabian society.

Moreover, this study found that collegiate women have the motivation to develop their leadership potential to advance their future careers. By developing leadership, they feel that they are able to achieve their career goals and pursue leadership positions in their professional fields. This particular finding has not previously been described in the literature. One explanation for this is might be that collegiate women of this study are aware of the challenges they might face in terms of unemployment of college-educated women, as well as the underrepresentation of women in leadership in the country 
(GASTAT, 2016a, 2016b, 2017a, 2017b; Kemp et al., 2015). Further research should be done to investigate and understand the relationship between college student leadership development and career development and readiness.

Thus, collegiate women in Saudi Arabia's private non-profit universities develop leadership to develop their self-confidence, enhance their self-awareness and selfknowledge, pursue their passion for and interest in leadership, and advance their future careers. While these findings may suggest that they are leader-centric views, additional findings indicated that collegiate women develop themselves, along with others, and they develop leadership to inspire others. The following sub-section provides a discussion on collegiate women's motivation to develop leadership for the development of others.

\section{Development of Others}

In addition to collegiate women's self-motivations for leadership development, the findings of this study showed that they develop leadership to inspire others and influence others in a positive way. For collegiate women in Saudi Arabia's private nonprofit universities, they develop leadership to bring people together, foster collaboration, motivate and inspire others to be better leaders, and develop a community of leaders. Moreover, they develop leadership to set an example for others and become role models. These findings corroborate the ideas of Komives et al. (1998) and SCM (HERI, 1996; Komives \& Wagner, 2009), who suggested that setting an example and role modeling are powerful ways to influence people.

A possible explanation for this finding is the value these young women place on the collective effort to achieve the aspired change. Given the relational dynamics of Saudi Arabia's social context, influencing others in a positive way and inspiring them can bring 
about the change they want and need to thrive as equal members in society. Another possible explanation for this finding is that these collegiate women are likely aware of the lack of women leaders underrepresentation of women in leadership. Despite the changes to women's role in Saudi Arabia's society, women continue to be underrepresented in leadership (Kemp et al., 2015). This study's finding, while preliminary, suggests that collegiate women in Saudi Arabia's private non-profit universities develop leadership to develop women leaders for the future of the society. This finding has important implications for the developing women leaders in Saudi Arabia.

For collegiate women in Saudi Arabia's private non-profit universities, they develop leadership for themselves and for the development of others. Collegiate women develop leadership to inspire others and build a strong community of young and motivated leaders. It can thus be suggested that collegiate women understand that through their self-empowerment and the empowerment of each other, they can bring about change in society. The following sub-section elaborates on the significance of developing leadership as women living in Saudi Arabia.

\section{Importance of Leadership Development}

This study found that collegiate women in Saudi Arabia's private non-profit universities feel that it is important for women to develop leadership. A possible explanation for this finding is reflective of the most salient social and legal factors that hinder opportunities for them to thrive and succeed in life. These factors emerged as findings of this study. For instance, the participants, as described in Chapter Four, reflected on social factors that are in place in Saudi Arabia. The findings showed that social norms and practices in terms of social influence, social expectations on women, 
and social approval are overpowering. These norms and practices are found to impact collegiate women's decisions, dictate what they can and cannot do, influence their family's perspective, and hinder opportunities for them to develop leadership. These results are consistent with those of other studies about women and leadership in Saudi Arabia (Abalkhail, 2017; Albakry, 2016; Aldawsari, 2016; Alyahya, 2016; Hodges, 2017), which found that social norms and practices hinder opportunities for women's advancement in leadership.

Another interesting finding of this study was that collegiate women in Saudi Arabia's private non-profit universities develop leadership to challenge these social norms and practices that hinder opportunities for them to succeed. A possible explanation for this is that these young women, and perhaps others, have been marginalized and overlooked by society as a source of untapped potential for leadership and social change. Another possible explanation is that these young women are becoming self-empowered to affect the changes they longed for in Saudi Arabia's society by using their voice and demanding to be heard. This finding, while preliminary, suggests that these collegiate women have the capability and self-determination to make a difference.

Moreover, the findings of this study revealed that collegiate women viewed the male-guardianship law in Saudi Arabia as a factor hindering opportunities for them to develop leadership. In addition, the findings showed that social mindsets and views regarding the male-guardianship law perpetuate gender inequality, discrimination, and biases against women in Saudi Arabia. These results are consistent with those of others studies (Abalkhail, 2017; Albakry, 2016; Aldawsari, 2016; Hodges, 2017; Thompson, 2015) which found that male-guardianship and gender-segregation laws in Saudi Arabia 
marginalize and exclude women from advancing to senior leadership roles and positions. Although most collegiate women in this study affirm their family's support to travel and work, among other things, without a male-guardian's permission, they are aware of their family privilege that most women in Saudi Arabia do not have. It can thus be suggested that these collegiate women are aware of the social injustices that are precipitated by the male-guardianship law, which impact the lives of women in Saudi Arabia.

One unanticipated finding was that by developing leadership, collegiate women of this study feel they are able to shatter stereotypes about Muslim women and women in Saudi Arabia, change the social misperceptions about gender and leadership, and break down barriers of gender bias, discrimination, and inequality. A possible explanation for this may be that these young women want to change people's views of them and demonstrate that they are as equally capable as men. Furthermore, another important finding is that collegiate women develop leadership to contribute to the social changes that are happening in Saudi Arabia. It is possible, therefore, that these findings suggest that collegiate women in Saudi Arabia's private non-profit universities are perhaps being the change by directly or indirectly serving as catalysts for young women in the country in an effort to achieve transformative change in society. However, further research on the topic should be done to investigate this phenomenon.

This study has shown that collegiate women in Saudi Arabia's private non-profit universities have the motivation to develop leadership. They feel it is important for them as women to develop their leadership potential. They develop leadership to develop themselves and for the development of others. Moreover, collegiate women of this study develop leadership, along with others, to disrupt the status quo by becoming change 
agents who use their voice to transform the Saudi Arabian society. The following section addresses the second part of the first research question with respect to collegiate women's understanding of leadership opportunities. In addition, it provides a discussion of the opportunities and experiences collegiate women have to develop leadership.

\section{Leadership Development Opportunities and Experiences}

This study set out with the aim of exploring and investigating the opportunities collegiate women have in Saudi Arabia's private non-profit universities to develop leadership, and how they develop leadership. On the question of what leadership development opportunities do collegiate women have, the findings indicated that opportunities for leadership development at the collegiate level include co-curricular programs and, to a limited degree, formal leadership programs. Moreover, an important finding revealed that the way collegiate women in Saudi Arabia's private non-profit universities develop leadership is inconsistent and informal. The following sub-sections discuss the findings on collegiate women's understanding of leadership opportunities, the opportunities they have to develop leadership, and the ways they develop leadership.

\section{Opportunities}

The findings of this study indicated that there are existing student leadership opportunities for collegiate women in Saudi Arabia's private non-profit universities. These student leadership opportunities occur mostly through co-curricular programs such as student clubs, organizations, government, competitions, and group projects. Moreover, the findings revealed that collegiate women of this study perceive co-curricular programs as opportunities for them to develop leadership. This finding supports the previous work of Dugan (2011), who provided an understanding about college student leadership 
development within the context of American higher education, and the practices that foster student learning through co-curricular programs such as their involvement in student organizations. In addition, the findings from this study revealed that there are limited opportunities collegiate women have to develop leadership through trainings, workshops, seminars, and academic courses. Although the opportunities for collegiate women of this study to engage in formal leadership programs are limited, previous studies (Dugan \& Komives, 2007; Haber \& Komives, 2009) found college students' participation in formal leadership programs contributes to their leadership development.

However, what is surprising is that although collegiate women of this study recognized the role their respective universities play in promoting opportunities for leadership development, the results showed that these universities hinder opportunities for collegiate women to develop leadership. For example, a few participants indicated that their respective universities failed to provide them with formal leadership trainings and sufficient seminars to support their co-curricular leadership experiences. A possible explanation for this might be that the co-curricular programs these universities provide may not have been purposefully designed to develop collegiate women's leadership potential. Contrary to previous findings that identified student learning outcomes as central to student leadership development in American higher education (McIntire, 1989), these private non-profit universities in Saudi Arabia may have overlooked the significance of and the need for assessing and evaluating learning outcomes of cocurricular programs. Another possible explanation for this is that while only a few participants in this study attended and benefitted from formal leadership development trainings, these trainings did not occur at their respective university campuses. It is 
possible, therefore, that designing formal leadership programs with intentional practices to develop collegiate women's leadership potential may be underemphasized by these universities. Thus, these findings and possible explanations are worth exploring further in future research.

In short, collegiate women in Saudi Arabia's private non-profit universities perceive leadership opportunities within the context of co-curricular programs such as leading student clubs, government, organizations, competitions, or group projects. Moreover, they recognize these co-curricular programs as leadership development opportunities. However, there is a lack of intentional design, and on-going assessment, of co-curricular programs and formal leadership programs at these universities with respect to their learning content, experiences, and outcomes. It is therefore likely that the existing programs may not have been intended to enhance collegiate women's leadership potential. As presented in Chapter Two, research studies (Madsen, 2009b, 2010a; Wright \& Bennett, 2013) demonstrated that higher education in the UAE offers unintentional opportunities for collegiate women to develop their leadership potential through cocurricular and formal leadership programs. Given the similar educational and social challenges women face in the UAE and Saudi Arabia (Metcalfe, 2007, 2011), it is therefore an important domain to explore in future research within the context of these two countries. The following sub-section expands on leadership development opportunities through a discussion about the ways collegiate women develop leadership.

\section{Experiences}

The third research question of this study asked how collegiate women in Saudi Arabia's private non-profit universities develop leadership. While the findings showed 
that they are developing leadership in some capacity, the findings also showed that the ways in which collegiate women develop leadership tend to be inconsistent and informal. As revealed in Chapter Four, formal leadership programs such as workshops, trainings, and academic courses were reported by only a few participants. However, the findings revealed that collegiate women create their own processes or informal approaches to develop leadership such as peer mentoring, rotating practices in student organizations and clubs, and trial-and-error experiences. Given the limited support collegiate women of this study receive from their respective universities in terms of leadership development, it seemed that they are trying to make meaning of their leadership experiences and develop their potential as they engage in student leadership opportunities. A possible explanation for this result may be the lack of adequate formal leadership programs to support their cocurricular learning experiences, which leads them to think of and engage in leadership development in their own way. It could, therefore, be assumed that collegiate women are left to interpret the meanings they make of their experiences on their own, which may lead them to experience leadership without having to fully develop their leadership potential.

As described in Chapter Four, collegiate women identified volunteering, peer mentorships, and memberships in organizations and clubs as opportunities to develop leadership through observation and experiential learning. This finding corroborates the literature on Kolb's (1984) experiential leaning model that suggest students internalize their learning by testing and adapting their knowledge to their environment. Although this particular finding of the study showed that collegiate women in Saudi Arabia's private non-profit universities develop leadership by preparing for or experiencing 
leadership roles and positions, there are inconsistencies and informalities in how they develop leadership through these experiential learning processes. An explanation for this might be the lack of intentional design and on-going assessment of co-curricular programs. It can therefore be assumed that these universities in Saudi Arabia may be overlooking collegiate women's leadership learning and development.

Surprisingly, many of the collegiate women of this study shared experiences that may explain the informal ways they engage in to develop leadership. For example, the findings indicated that collegiate women credited their respective universities for providing them with the space, environment, and opportunities to experience student leadership through co-curricular programs, which may support them in developing leadership in some capacity. This finding corroborates Western practices of college student leadership development (Dugan, 2011). However, the findings also showed that these universities in Saudi Arabia overlooked the need to mentor student leaders, provide formal leadership programs, or adequately and equally inform all collegiate women of opportunities to develop leadership. What is interesting is that a group of participants in this study pointed to the exclusive and selective practices happening within university systems that tend to minimize equal opportunities for all collegiate women to develop leadership. For these participants, the contradictions demonstrated by their respective universities in terms of providing limited support to their students may be a possible explanation of the informal ways collegiate women engage in to develop leadership.

Although there are answers to the third research question of this study, the ways in which collegiate women in Saudi Arabia's private non-profit universities develop leadership are inconsistent and informal. The answers to how the participants of this 
study develop leadership are concerning. Collegiate women of this study do not develop leadership in formal ways that are based on standard leadership practices that are guided by theory and research. Furthermore, they do not develop leadership in a formal way that provides an assessment of and an actual understanding to their leadership knowledge, learning outcomes, and experiences to support the development of their leadership potential. Rather, these collegiate women are depending on themselves and on each other in developing their leadership potential and in assessing their learning outcomes. It is possible, therefore, that these young women are trying to make the best out the resources and opportunities that are available to them. These findings suggest that collegiate women in Saudi Arabia's private non-profit universities are interested in and have the motivation for leadership development, which means there are several areas to further investigate the phenomenon of college student leadership development within Saudi university systems.

To summarize this section on leadership development, this study showed that collegiate women in Saudi Arabia's private non-profit universities understand leadership opportunities to occur through co-curricular programs, and to some extent through formal leadership programs. The study found that co-curricular programs at these universities provide opportunities for collegiate women to develop leadership. Although there is enough evidence to suggest that these collegiate women experience leadership at their respective universities and may develop leadership in some capacity, the ways they develop leadership are inconsistent and informal. Given collegiate women's involvement and engagement in different student leadership opportunities, it seems that they are determined to make the best out of the opportunities they have. Thus, it can be implied 
that these young women are interested in and motivated to develop their leadership potential, but have limited access and resources to do so. The following section addresses the first research question of this study about the participants' leadership understandings.

\section{Leadership as Relational}

One of the aims of this study was to explore and investigate the leadership understandings of collegiate women in Saudi Arabia's private non-profit universities. This study found five interrelated concepts collegiate women have of leadership, as: (1) collaboration, (2) setting an example, (3) non-positional, (4) a learning process, and (5) understanding others. These findings suggest the notion of leadership as a relational practice. The following sub-sections discuss each of these concepts.

\section{Collaboration}

An interesting finding of this study included the value participants placed on collaboration as part of their understanding of leadership. For them, collaboration occurs by working with others and involving others in the leadership process, whether it may be making decisions or sharing ideas and responsibilities. As cited frequently in the literature, collaboration is often a common notion in leadership. For example, the SCM (HERI, 1996) defines leadership as "a purposeful, collaborative, value-based process that results in positive social change" (Komives \& Wagner, 2009, xii). Also, the relational leadership model (Komives et al., 1998) defines leadership as a relational process rooted in collaboration. By collaborating and working with others, it can therefore be suggested that collegiate women of this study are likely to build relationships with others. 


\section{Setting an Example}

This study found that participants viewed leadership as setting an example for

others. The finding corroborates the ideas of Kouzes and Posner's $(2008,2012)$

leadership challenge framework that identified the practice of modeling the way as one of five practices of exemplary leaders. Through this practice of walking the talk, the authors (Kouzes \& Posner, 2008, 2012) indicated that it enhances one's credibility as a leader and motivates others to follow the example. Moreover, this finding supports previous studies (Alexander, 2013) that revealed collegiate women in Saudi Arabia perceive effective female leaders as role models who set a good example for other women.

In this study, variations of this view of leadership is revealed through concepts such as inspiring others, being a role model for others, and influencing and motivating others. This finding may be explained by how the participants identified themselves as role models for others and as leaders who inspire and motivate others. It can be suggested that their idea of setting an example for others reflects notions of authentic leadership theory (Avolio \& Gardner, 2005) that may be impactful in the development process of themselves and of others, which is something worth exploring in future research. Another possible explanation for this finding is the value collegiate women perceive in leadership as an ethical practice for the betterment of the Saudi Arabian society. This explanation is important as it has been discussed earlier in this chapter as a motivational factor for them to develop leadership.

\section{Non-positional View}

In addition to viewing leadership as setting an example for others, the findings showed that collegiate women rejected the notion of leadership as a position of power by 
indicating that leadership is not about controlling others, compelling, or giving out orders. This view of position as being unnecessary supports the non-positional view of leadership found in college student leadership development frameworks such as the relational leadership model (Komives et al., 1998) and the leadership identity development model (Komives et al., 2005).

However, this finding differs from previous studies (Alexander, 2013; Hamdan et al., 2016) that examined the leadership understandings and perceptions of collegiate women in Saudi Arabia. Despite their limitations, these studies revealed collegiate women in Saudi Arabia have leader-centric and positional views of leadership. A possible explanation for this difference might be that the methodologies utilized in those studies (Alexander, 2011, 2013; Hamdan et al., 2016), such as mixed methods and survey research, failed to capture an in-depth understanding of the perceptions participants have of leadership. In this current study, the use of the constructivist approach to grounded theory methodology enabled me to make analytic sense of the meanings the participants have of leadership. Thus, the non-positional view of leadership that emerged from this study's analysis is an important finding. It may be that the leadership experiences of the collegiate women of this study contributed to their understanding of leadership to be a shared process, collaborative in nature, and an ethical practice to lead by example and empower others. Further research is suggested.

\section{Learning Process}

This study found that collegiate women in Saudi Arabia's private non-profit universities view leadership as a learning process. According to the data, the participants came to this understanding of leadership from their experiences as leaders or from 
observation. By identifying people and experiences as sources of their leadership understanding, as discussed in Chapter Four, this finding further supports previous work in the field of leadership that affirm leadership is an experiential process that can be learned and developed through practice and reflection (Komives et al., 1998; Kouzes \& Posner, 2008, 2012). Moreover, this finding seem to be consistent with a previous study (Hamdan et al., 2016) that found collegiate woman in Saudi Arabia tend to believe that leadership can be learned through situations and experiences.

In this study, the notion of leadership as an experiential learning process was evident in participants' responses about understanding leadership through trial-and-error experiences and by learning from mistakes. According to Komives et al. (1998), trialand-error experiences can enhance one's ethical analysis and reflection about what is just and fair. It can therefore be assumed that collegiate women's experiential learning may influence their awareness of self in relation to others. This finding has important implications to the leadership learning and development outcomes of collegiate women in Saudi Arabia.

\section{Understanding Others}

The results of this study indicated that leadership is about understanding others. For collegiate women, this notion of leadership occurs through the intentional and purposeful practice of listening and communicating with others to understand them and what they are going through, find common ground with them, and to reciprocate through dialogue. This finding is consistent with college student leadership development frameworks such as the relational leadership model (Komives et al., 1998) and the SCM (HERI, 1996; Komives \& Wagner, 2009) that identify communication as a key 
component to successful collaboration and relationship building throughout the leadership process, which enables leaders to connect with and understand others, establish a sense of we, and be inclusive and empowering (Komives et al., 1998). A possible explanation for this study's finding might be that given the cultural practices of Arab societies that emphasize on the collective, familial, and social (Mimouni \& Metcalfe, 2011), it is not surprising to learn of the participants' perspective of leadership as an understanding of others. This explanation corroborates the idea of Gauthier (2006), who indicated that non-Western cultures emphasize collective aspects of leadership such as collaborating, building relationship, and sharing responsibilities. Moreover, although the findings provided little evidence to suggest aspects of emotional intelligence in this particular view of leadership, it can be suggested that this understanding collegiate women have of leadership reflects notions of relational leadership.

This section was able to provide an answer to one part of the first research question. Overall, collegiate women in Saudi Arabia's private non-profit universities understand and view leadership as collaboration, setting an example, non-positional, a learning process, and an understanding of others. These ideas and concepts reflect notions of leadership as a relational practice. This finding seems to be consistent with other research and scholarly work (Komives et al., 1998) that define leadership as "a relational and ethical process of people together attempting to accomplish positive change" (p. 33). However, this study's finding differs from previous research (Alexander, 2013; Hamdan et al., 2016) that revealed collegiate women in Saudi Arabia tend to perceive effective leadership as positional and hierarchal. 
For this study, there are a few possible explanations for this result. First, it seems that collegiate women of this study have a sense of awareness with respect to the interdependence nature of their relationships with their peers. Given that women in leadership is a relatively new phenomenon in Saudi Arabia, these collegiate women engage in an interdependent process of working with and learning from others, which reinforces notions of social learning and knowledge sharing in leadership. Second, their view and practice of sharing and learning may be influenced by the lack of formal leadership development programs at their respective universities, which strengthens the notion of trust building within the relational dimension of leadership. Third, as women, these participants experience the bias, marginalization, and inequality practiced within society. It is not surprising to find that they build relationships with others to not only empower themselves and their peers, but also break down barriers of social and gender inequalities.

As mentioned in the Chapter Two, very little has been published about what leadership means to collegiate women in Saudi Arabia. In this study, the findings indicated that the leadership understandings of collegiate women in Saudi Arabia's private non-profit universities reflected notions of relational practices. However, the findings must be interpreted with caution. Although the participants view and understand leadership through a relational lens, further research should be done to investigate their actual leadership practices.

To summarize, this study has found that generally collegiate women in Saudi Arabia's private non-profit universities have the motivation to develop leadership. They have a collective sense on the importance of developing leadership for the betterment of 
themselves, others, and the Saudi Arabian society. Moreover, the findings showed that they perceive leadership opportunities to occur mostly within the boundaries of cocurricular programs, which can therefore be implied that there are not that many leadership development opportunities available to them. In addition, this study has shown that they understand leadership to be a relational practice and experience. This is not surprising considering Saudi Arabia is a collectivist society and culture (see Figure 1).

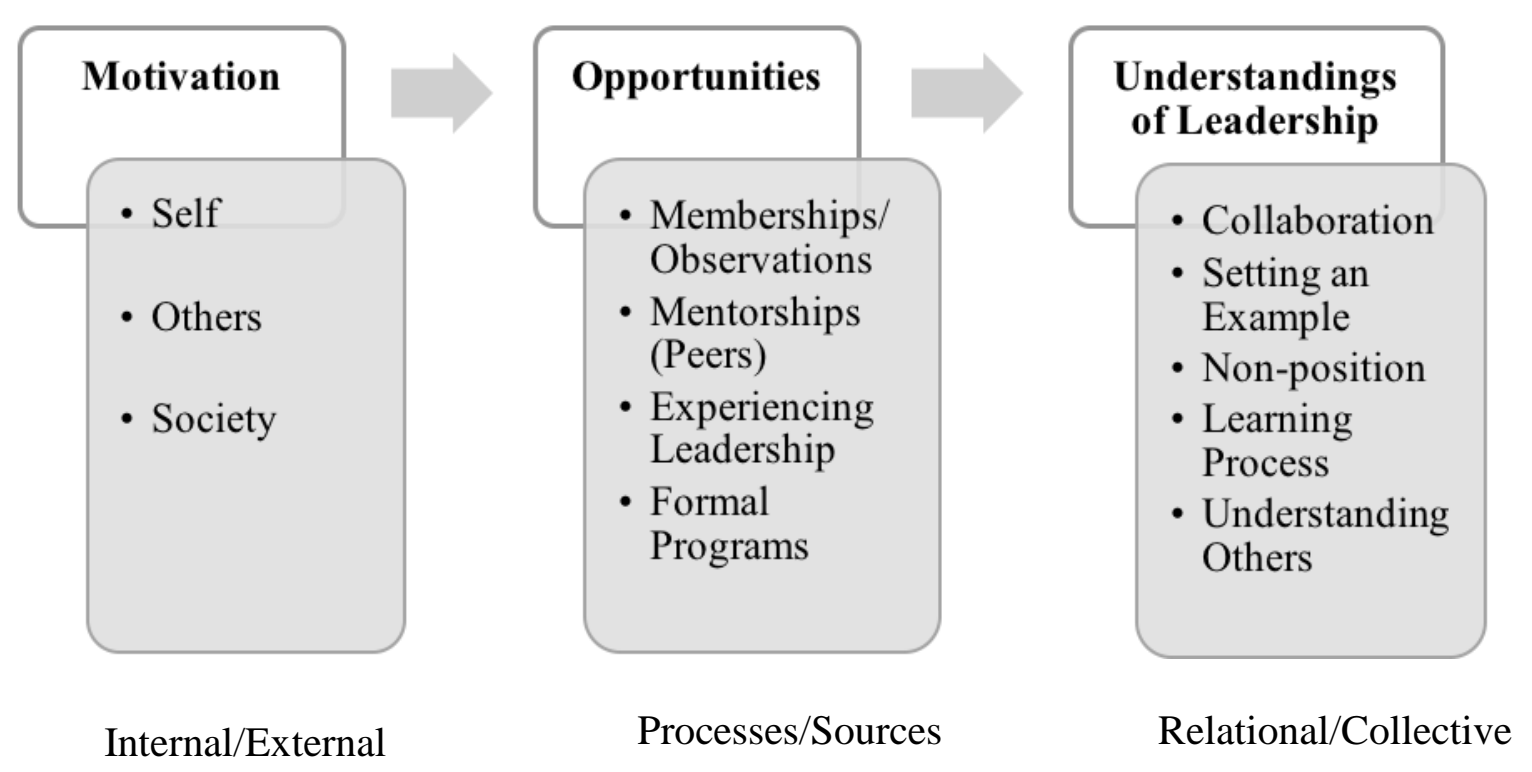

Figure 1. Relationship between motivation for leadership development and leadership understandings. Only a few participants shared leadership development experiences through formal programs independent of university systems.

Despite the limited leadership development opportunities for young women within the college environment and within the social context of Saudi Arabia that can seem to be a demotivating factor to develop leadership, collegiate women's passion and motivation for leadership development is galvanized by the changes that are happening in Saudi Arabia with respect to women's role in society. Thus, they think of these changes from a we perspective and through a relational and collective effort to move the Saudi 
Arabian society forward. There is clear evidence that they are motivated to develop their leadership potential and they are interested in leadership development.

However, the ways in which collegiate women in Saudi Arabia's private nonprofit universities develop leadership are inconsistent and informal. Although the findings showed that they develop leadership through practical experience as student leaders, they are making the most out of the resources they have to develop leadership informally. Their experiences are really dispersed, which means there are gaps within university systems or within society to support formal ways for collegiate women to develop leadership.

In the case of this study, leadership development for collegiate women in Saudi Arabia's private non-profit universities has yet to emerge within university systems. Although there is an interest, a need, and a desire by collegiate women to develop leadership, there are a lot of gaps in university systems with respect to college student leadership development that are not helping young women in Saudi Arabia. This indicates that there are opportunities to further investigate this phenomenon of collegiate leadership development in Saudi Arabia's university systems. The following section presents the implications of this study's findings.

\section{Implications}

The findings of this study have a number of important implications for government leaders, educational leaders, and practitioners in Saudi Arabia, as well as in neighboring countries that share similar complexities pertaining to women's role in society. The findings provide insight into what leadership means to collegiate women in Saudi Arabia's private non-profit universities. Their emphasis on the relational and the 
collective provide opportunities for government leaders to push for legislation and policies that promote inclusive spaces and environments that strengthen young women's sense of belonging in society and raise their awareness of self and others that can advance their active engagement, collaboration, and relationship building within and beyond their communities. Through these inclusive spaces, young women in Saudi Arabia have a good chance at succeeding and thriving as equal members of society.

Information from this study provides insight into the leadership development experiences of collegiate women in Saudi Arabia's private non-profit universities. Given the findings, collegiate women at these universities develop leadership in inconsistent and informal ways. They indicated the need for their respective universities to provide them with leadership trainings, experiential learning opportunities, and information about leadership development opportunities inside and outside college campuses. This suggests the definite need for formal leadership programs at the collegiate level that would enhance rather than limit collegiate women's leadership potential. Thus, it is necessary for educational leaders and practitioners to design and implement formal leadership programs that connect theory with practice and that are purposeful, as well as socially and culturally responsive, in serving the leadership needs of women in Saudi Arabia.

Moreover, to enhance workforce participation and employment opportunities in Saudi Arabia for young women in particular, and for the youth population in general (AlDali et al., 2013; Smith \& Abouammoh, 2013), educational leaders and practitioners need to enhance leadership development experiences and opportunities by improving student learning outcomes. Therefore, it is crucial that they pay closer attention to existing co-curricular programs at their respective universities and establish learning 
outcomes for experiential and reflective learning. In addition, formal leadership programs need to be intentionally designed to assess and evaluative learning outcome that are in accordance with their universities' mission and vision, and that advance the role of women in society.

The results of this study have important implications for the development of women leaders in Saudi Arabia. This study provided insight into the challenges shared by women in the workplace and collegiate women in Saudi Arabia that hinder leadership and leadership development opportunities. Given the Saudi government's economic plan to empower women and increase their representation in senior leadership positions (Vision 2030, 2016), it is essential for government leaders to push for laws and policies that are just and equitable that will make it possible for women to take on senior leadership positions. In addition, this study revealed collegiate women's interest in and motivation for leadership development. By becoming self-empowered and aware of gender inequalities, their determination to make a difference in society can transcend beyond the present status of women in Saudi Arabia. Thus, there is a need for leadership development programs that help them cultivate the agency and resilience needed to navigate through social, legal, and professional challenges. These challenges that collegiate women of this study pointed to are reflected, to some extent, in neighboring countries that share similar social norms and practices. Therefore, taken together, the study's findings and implications for action support the need for further research. The following section presents the limitations of this study. 


\section{Limitations}

This dissertation study contributed to the literature on college student leadership development by investigating the phenomenon within a non-Western context. However, some limitations need to be considered. First, the means of data collection, by way of online audio/video conferencing programs, were challenging at times due to weak internet signals. Therefore, it may have hindered efforts for authentic engagement with the participants. Second, all the participants were able to speak and read English. However, it is considered to be a second language for most of them. Although their use of code-switch between Arabic and English during the interviews may have been helpful for them to articulate their views in the language that is favorable to them, the use of English as the primary language for this study may have prevented them from truly articulating their accurate views and may have not generated their authentic voice.

Third, this study represents the understandings, experiences, and motivations of 25 participants. The sample cannot be considered as representation of the entire collegiate woman population at private non-profit universities in Saudi Arabia. However, by using intensive interviews, the study provided thick description of the participants' understandings of leadership, and their experiences in and motivations for leadership development. Thus, while the findings of this study are not generalizable, some dimensions can be transferrable. Last, for this study, the leadership experiences of collegiate women varied in terms of role and responsibility and the co-curricular program. This could have had an impact on how they actually develop leadership and could have contributed to their leadership development experience as inconsistent and 
informal. Future studies on the current topic are therefore recommended. The following section provides recommendations for future research.

\section{Recommendations for Future Research}

This dissertation study makes noteworthy contributions to the current literature. As indicated in Chapter Three, the use of CGT as this study's methodology not only offered the inquiry process the flexibility it needed to adapt and respond to the ways of knowing of non-Western cultures (Charmaz, 2014b), but also investigated the leadership development phenomenon that is grounded in the experiences of collegiate women of this study. As a result, using CGT uncovered the informal and unorganized leadership development experiences of collegiate women in Saudi Arabia's private non-profit universities. Hence, the present study contributes to the growing body of literature on college student leadership development, and provides valuable insight to the field of leadership that is increasingly exploring non-Western leadership perspectives and practices (Miller 2016; Toh \& Leonardelli, 2013).

Furthermore, this is an unprecedented study in the field of college student leadership development within the Saudi Arabian context. The empirical findings in this study provide a new understanding of what leadership means to collegiate women in Saudi Arabia's private non-profit universities, the opportunities they have to develop leadership, and how and why they develop leadership. Despite the study's limitations, it serves as a springboard for future studies on college student leadership development in Saudi Arabia and in other countries that share similar complexities.

The findings of this study provide the following recommendations for future research. Considerably additional studies are needed that utilize interpretive inquiry 
frameworks to gain a better understanding of how collegiate women in Saudi Arabia's private non-profit universities develop leadership. Future studies could include multiple methods of data gathering such as individual interviews, field observation, and focus groups. Moreover, it is recommended to investigate one co-curricular program such as student organizations, student government, or student clubs whereby the leadership context and experiences are not varied. It would provide researchers an opportunity to further investigate collective leadership practices and the experiential learnings of collegiate women.

This study informs us that collegiate women in Saudi Arabia's private non-profit universities are interested in and motivated to develop leadership. In addition, it informs us that there are gaps in university systems with respect to college student leadership development that are not serving the leadership needs of women in Saudi Arabia. Thus, there are opportunities to further investigate this phenomenon of collegiate student leadership development in Saudi Arabia's university systems. For example, much is unknown about the leadership development opportunities and experiences collegiate women have in Saudi Arabia's public universities. Therefore, this current study can serve as a template to explore and investigate this phenomenon of collegiate women's leadership development at public universities.

The findings of this study revealed notions of ethical leadership in collegiate women's leadership understandings and practices. Further research might explore and investigate the ways collegiate women exercise their leadership roles as student advocates. In addition, this study informs us that leadership development still has not emerged as formal programs for collegiate women at private non-profit universities in 
Saudi Arabia, which may or may not be the case for collegiate men of these universities. A future study investigating the leadership understanding and leadership development experiences of collegiate men could be very interesting. Moreover, as a group within the larger youth population in Saudi Arabia, collegiate men are living through and experiencing the waves of societal shifts with respect to women's role in society.

Pursuing a qualitative study with collegiate men may yield a range of significant and surprising outcomes regarding equal opportunities in higher education, their understanding of leadership, and their perspective of leadership practices and women in leadership.

\section{Conclusion}

This dissertation study has explored and investigated the leadership understandings of collegiate women in Saudi Arabia's private non-profit universities, the opportunities they have to develop leadership, and how and why they develop leadership. The findings generated an understanding of the perspective collegiate women in Saudi Arabia's private non-profit universities have of leadership as a relational practice they engage in to better themselves and others, and to have a greater impact on the Saudi Arabian society. This study provides empirical evidence of collegiate women's leadership understanding, as well as their experiences in and motivations for leadership development.

One of the most significant findings to emerge from this study is that collegiate women in Saudi Arabia's private non-profit universities have a collective sense of the importance in developing their leadership potential to better themselves, to better each other, and for the betterment of the Saudi Arabian society. The second major finding is 
that although they develop leadership is inconsistent and informal ways, collegiate women of this study have the motivation to develop their leadership potential. Another important finding is that collegiate women in Saudi Arabia's private non-profit universities understand leadership as a relational practice and a collective experience.

Findings of this study provide opportunities for government leaders to push for laws and policies that are just and equitable that will make it possible for women to take on senior leadership positions. Furthermore, the findings of this study provide implications for action that suggest educational leaders and practitioners need to assess learning outcomes of co-curricular programs, and design and implement formal leadership programs at the collegiate level that enhance collegiate women's opportunities for and experiences in leadership development to help them cultivate the agency and resilience needed in navigating through social, legal, and professional challenges. While this study has its limitations, it serves as a starting point for future studies on college student leadership development in Saudi Arabia and in countries that share similar sociocultural complexities. Therefore, further research should be done to investigate the phenomenon of collegiate leadership development in Saudi Arabia's university systems. 


\section{References}

Abalkhail, J. M. (2017). Women in leadership: Challenges and opportunities in Saudi higher education. Career Development International, 22(2), 165-183. doi:10.1108/CDI-03-2016-0029

Abalkhail, J. M., \& Allen, B. (2015). Women's career advancement: Mentoring and networking in Saudi Arabia and the UK. Human Resource Development International, 18(2), 153-168. doi:10.1080/13678868.20151026548

AbuSulayman, M. (2017, March 8). Saudi women: Old stereotypes no longer hold. Arab News. Retrieved from: http://www.arabnews.com/node/1064726

Albakry, A, H. (2015). Voices of women leaders in corporate institutions in Saudi Arabia. (Doctoral dissertation). Retrieved from ProQuest Dissertations and Theses database. (UMI No. 10128001).

Aldawsari, R. A. (2016). Under-representation of Saudi women leaders in Saudi higher education. (Doctoral dissertation). Retrieved from ProQuest Dissertations and Theses database. (UMI No. 10130061).

AlDoubi, S. H. (2014). Road to leadership: Experiences of Saudi women in higher education. (Doctoral dissertation). Retrieved from ProQuest Dissertations and Theses database. (UMI No. 3618167).

Alexander, N. H. (2011). Teaching leadership to female students in Saudi Arabia. Advancing Women in Leadership, 31, 199-212.

Alexander, N. H. (2013). Saudi Arabia female students' perception of effective female leaders. Advancing Women in Leadership, 33, 142-150. 
Alharbi, R. (2015). Guardianship law in Saudi Arabia an its effects on women's rights. [Working Paper]. doi:10.13140/RG.2.2.34304.12801

AlMunajjed, M. (2010). Women's employment in Saudi Arabia: A major challenge. New York: Booz \& Company Inc.

Alsubaihi, S. (2016). Challenges for women academic leaders to obtain leadership positions in higher education in Saudi Arabia. (Doctoral dissertation). Retrieved from ProQuest Dissertations and Theses database. (UMI No. 10164207).

Alyahya, R. (2016). Saudi women as leaders: Voices, challenges, and strategies for effective leadership: A qualitative study. (Doctoral dissertation). Retrieved from ProQuest Dissertations and Theses database. (UMI No. 10257064).

Al Ankari, K. M. (2013). Foreword. In P. Maassen \& J. Muller (Series Eds.), Higher Education Dynamics: Vol. 40. Higher education in Saudi Arabia: Achievements, challenges and opportunities (pp. v-vi). doi:10.1007/978-94-007-6321-0

Al Dali, W., Fnais, M., \& Newbould, I. (2013). Private higher education in the kingdom of Saudi Arabia: Reality, challenges, and aspirations. In P. Maassen \& J. Muller (Series Eds.), Higher Education Dynamics: Vol. 40. Higher education in Saudi Arabia: Achievements, challenges and opportunities (pp. 127-136). doi:10.1007/978-94007-6321-0_12

Al Fassi, H. (2010). Introduction. Saudi Arabia and women in higher education and cultural dialogue: New perspectives, Research Center on the Southern System and Wider Mediterranean (working paper No. 10). Milano, Italy: EDUCatt 
Al-Ahmadi, H. (2011). Challenges facing women leaders in Saudi Arabia. Human Resource Development International, 14(2), 149-166. doi:10.1080/13678868.2011.558311

Al-kayed, L. (2015). Leadership challenges for women managers in public universities in Saudi Arabia. Global Journal of Human Science: Arts \& Humanities-Psychology, 15(4), 34-43.

Astin, A. W., \& Astin, H. S. (2000). Leadership reconsidered: Engaging higher education in social change. Battle Creek: MI: Kellogg Foundation.

Avolio, B. J. \& Gardner, W. L. (2005). Authentic leadership development: Getting to the root of positive forms of leadership. Leadership Quarterly, 16, 315-338.

Baker, A. (2018, June 28). Is the end if Saudi Arabia's driving ban a rebrand or a revolution? Time. Retrieved from: http://time.com/5324771/is-the-end-of-saudiarabias-driving-ban-a-rebrand-or-a-revolution/

Ballandalus. (2014, March 8). 15 important Muslim women in history. Retrieved from: https://ballandalus.wordpress.com/2014/03/08/15-important-muslim-women-inhistory/

Bass, B. M., \& Riggio, R. E. (2006). Transformational leadership ( $2^{\text {nd }}$ ed.). New York, NY: Psychology Press.

Bechtold, M. C. (2014). From desert to destiny: Knowledge, attitudes, and practices of Saudi Arabian leadership. International Journal Human Resources Development and Management, 14(1/2/3), 157-169.

Bennet, D. C., Cornwell, G. H., Jamal Al-Lail, H., \& Schenck, C. (2012). An education for the stewardship of the global commons. Liberal Education, 98(4), 34- 41. 
Berryman, M., SooHoo, S., Nevin, A. (2013). Culturally responsive methodologies from the margins. In M. Berryman, S. SooHoo, \& A. Nevin (Eds.), Culturally responsive methodologies (pp. 1-31). United Kingdom: Emerald

Biermann, S. (2011). Knowledge, power, and decolonization: Implications for nonIndigenous scholars, researchers, and educators. In Dei (Ed.), Indigenous philosophies and critical education (pp.386-398). New York, NY: Peter Lang.

Black, I. (2015, December 13). Saudi Arabia elects up to 17 female councilors in historic election. The Guardian. Retrieved from: https://www.theguardian.com/world/2015/dec/13/saudi-arabia-elects-up-to-17female-councillors-in-historic-election

Bryant, A., \& Charmaz, K. (2007). Grounded theory in historical perspective: An epistemological account. In A. Bryant \& K. Charmaz (Eds.), The SAGE handbook of grounded theory. London, UK: Sage Publications.

Bukhari, F., \& Denman, B. (2013) Student scholarships in Saudi Arabia: Implications and opportunities. In P. Maassen \& J. Muller (Series Eds.), Higher Education Dynamics: Vol. 40. Higher education in Saudi Arabia: Achievements, challenges and opportunities (pp. 151-158). doi:10.1007/978-94-007-6321-0_14

Chambers, T., \& Phelps, C. E. (1993). Student activism as a form of leadership and student development. NASPA Journal, 31(1), 19-29.

Charmaz, K. (2008). The legacy of Anslem Strauss in constructivist grounded theory. In M. Washington, J. Salvo, \& N. K. Denzin (Eds.), Studies in symbolic interaction (pp. 127-141). Bingley, UK: Emerald Group Publishing Limited. 
Charmaz, K. (2011). Grounded theory methods in social justice research. In N. K. Denzin \& Y. S. Lincoln (Eds.), The SAGE handbook of qualitative research (pp. 359380). Thousand Oaks, CA: Sage Publications, Inc.

Charmaz, K. (2014a). Constructing grounded theory. ( $2^{\text {nd }}$ ed.). Los Angeles, CA: Sage Publications, Inc.

Charmaz, K. (2014b). Grounded theory in global perspective: Reviews by international researchers. Qualitative Inquiry, 20(9), 1074-1084.

Corbin, J., \& Strauss, A. (2015). Basic qualitative research: Techniques and procedures for developing grounded theory ( $4^{\text {th }}$ ed.). Thousand Oaks, CA: Sage Publications.

Cress, C. M., Astin, H. S., Zimmerman-Oster, K., \& Burkhardt, J. C. (2001). Developmental outcomes of college students' involvement in leadership activities. Journal of College Student Development, 42(1), 15-27.

Creswell, J. W. (2009). Research design: Qualitative, quantitative, and mixed methods approaches ( ${ }^{\text {rd }}$ ed.). Thousand Oaks, CA: Sage Publications, Inc.

Creswell, J. W. (2013). Five qualitative approaches to inquiry. Qualitative inquiry and research design: Choosing among five approaches. Thousand Oaks, CA: Sage Publications, Inc.

Crotty, M. (2015). The foundations of social research: Meaning and perspective in the research process. Thousand Oaks, CA: Sage Publications.

Dubai Women Establishment. (2011). Arab women leadership outlook 2009-2011 (1 $1^{\text {st }}$ ed.). Retrieved from: http://www.dwe.gov.ae/index.aspx 
Dugan, J. P. (2006a). Explorations using the social change model: Leadership development among college men and women. Journal of College Student Development, 47(2), 217-225. doi:10.1353/cds.2006.0015

Dugan, J. P. (2006b). Involvement and leadership: A descriptive analysis of socially responsible leadership. Journal of College Student Development, 47(3), 335-343. doi:10.1353/csd.2006.0028

Dugan, J. P. (2011). Research on college student leadership development. In S. R. Komives, J. P. Dugan, J. E. Owen, C. Slack, W. Wagner and Associates (Eds.), The handbook for student leadership development (pp. 59-84). San Francisco, CA: John Wiley \& Son, Inc.

Dugan, J. P., \& Komives, S. R. (2007). Developing leadership capacity in college students: Findings from a national study. A Report from the Multi-Institutional Study of Leadership. College Park, MD: National Clearinghouse for Leadership Programs.

Dugan, J. P., \& Komives, S. R. (2011). Leadership theories. In S. R. Komives, J. P. Dugan, J. E. Owen, C. Slack, W. Wagner and Associates (Eds.), The handbook for student leadership development (pp. 35-57). San Francisco, CA: John Wiley \& Son, Inc.

Elamin, A. M., \& Omair, K. (2010). Males' attitudes towards working females in Saudi Arabia. Personal Review, 39(6), 746-766. doi:10.1108/00483481011075594

Fatany, S. H. (2013). Modernizing Saudi Arabia. ISBN:9781482509984

Ferguson, D. L., \& Ferguson, P. M. (2000). Qualitative research in special education: Notes toward an open inquiry instead of a new orthodoxy? JASH, 25(3), 180-185. 
First Saudi woman appointed as the deputy minister of labor and social development. (2018, February 27). Arab News. Retrieved from: http://www.arabnews.com/node/1255331/saudi-arabia

Gaouette, N., \& Labott, E. (2017, September 27). Saudi Arabia to let women drive at last. CNN. Retrieved from: https://www.cnn.com/2017/09/26/politics/saudi-arabia-woman-drive/index.html Gauthier, A. (2006). Developing collective leadership: Partnering in multi-stakeholder contexts. Leadership is global: Bridging sectors and communities. Retrieved from: http://www.leadershiplearning.org

General Authority for Statistics, Kingdom of Saudi Arabia. (2015a). Labor force survey 2015. Retrieved from: https://www.stats.gov.sa/en/814

General Authority for Statistics, Kingdom of Saudi Arabia. (2015b). Statistical yearbook of 2015: Education and training, statistical summary of higher education students by agency (Issue No. 51). Retrieved from: https://www.stats.gov.sa/en/413-0

General Authority for Statistics, Kingdom of Saudi Arabia. (2015c). Statistical yearbook of 2015: Education and training, statistical summary on national higher education by agency (Issue No. 51). Retrieved from: https://www.stats.gov.sa/en/413-0

General Authority for Statistics, Kingdom of Saudi Arabia. (2015d). Statistical yearbook of 2015: Education and training, summary statistics for studying abroad by country (Issue No. 51). Retrieved from: https://www.stats.gov.sa/en/413-0

General Authority for Statistics, Kingdom of Saudi Arabia. (2016a). Labor force survey 2016. Retrieved from: https://www.stats.gov.sa/en/814 
General Authority for Statistics, Kingdom of Saudi Arabia. (2016b). Statistical yearbook of 2016: Education and training, statistical summary of higher education students by agency (Issue No. 52). Retrieved from: https://www.stats.gov.sa/en/867

General Authority for Statistics, Kingdom of Saudi Arabia. (2016c). Statistical yearbook of 2016: Education and training, statistical summary on national higher education by agency (Issue No. 52). Retrieved from: https://www.stats.gov.sa/en/867

General Authority for Statistics, Kingdom of Saudi Arabia. (2016d). Statistical yearbook of 2016: Education and training, summary statistics for studying abroad by country (Issue No. 52). Retrieved from: https://www.stats.gov.sa/en/867

General Authority for Statistics, Kingdom of Saudi Arabia. (2017a). Education and training survey 2017. Retrieved from: https://www.stats.gov.sa/en/903

General Authority for Statistics, Kingdom of Saudi Arabia. (2017b). Labor force survey 2017. Retrieved from: https://www.stats.gov.sa/en/814

Glaser, B. \& Strauss, A. (1967). The discovery of grounded theory: strategies for qualitative research. Chicago, IL: Aldine Publishing Company.

Greenleaf, R. (1977). Servant leadership. New York: Paulist Press.

Grogan, M. \& Shakeshaft, C. (2011). Women and educational leadership. San Francisco, CA: John Wiley \& Sons, Inc.

Haber, P. (2011a). Formal leadership program models. In S. R. Komives, J. P. Dugan, J. E. Owen, C. Slack, \& W. Wagner (Eds.), The handbook for student leadership development (231-257). San Francisco, CA: John Wiley \& Son, Inc. 
Haber, P. (2011b). Iron sharpens iron: Exploring the experiences of female college student leaders. Advancing Women in Leadership, 31, 86-101.

Haber, P. (2012). Perceptions of leadership: An examination of college students' understandings of the concept of leadership. Journal of Leadership Education, 11(2), 26-51.

Haber, P., Allen, S. J., Facca, T., \& Shankman, M. L. (2012). College students' emotionally intelligent leadership: An examination of differences by student organization involvement and formal leadership roles. International Journal of Leadership Studies, 7(2), 246-265. doi:10.12806/V11/I1/TF1

Haber, P., \& Komives, S. R. (2009). Predicting the individual values of the social change model of leadership development: The role of college students' leadership and involvement experiences. Journal of Leadership Education, 7(3), 133-166.

Haber-Curran, P. (2013). The delicate balancing act: Challenges and successes facing college student women in formal leadership roles. NASPA Journal about Women in Higher Education, 6(1), 71-97. doi:10.1515/njawhe-2013-0005

Habibi, N. (2015, July 17). Is Saudi Arabia training too many graduates? University World News. Retrieved from: http://www.universityworldnews.com/article.php?story=20150714013422488

Hamdan, A. (2005). Women and education in Saudi Arabia: Challenges and achievements. International Education Journal, 6(1), 42-64.

Hamdan, A. (2012). The role of authentic Islam: The way forward for women in Saudi Arabia. Journal of Women of the Middle East and Islamic World, 10, 200-220. doi:10.1163/15692086-12341237 
Hamdan, A. (2013). An exploration into "private" higher education in Saudi Arabia: Improving quality and accessibility? The ACPET Journal of Private Higher Education, 2(2), 33-44.

Hamdan, A., Alexander, N., \& Al-Hattami, A. (2016). Saudi female students' perceptions of leadership: An overview. Advancing Women in Leadership, 36, 36-48.

Harrison, J., MacGibbon, L., \& Morton, M. (2001). Regimes of trustworthiness in qualitative research: The rigors of reciprocity. Qualitative Inquiry, 7(3), 323-345.

Heifetz, R. A., Grashow, A, \& Linsky, M. (2009). The practice of adaptive leadership: Tools and tactics for changing your organization and the world. Boston, MA: Harvard Business Press.

Higher Education Research Institute. (1996). A social change model of leadership development: A guidebook version III. College Park, MR: National Clearing House for Leadership Program.

Hodges, J. (2017). Cracking the walls of leadership: Women in Saudi Arabia. Gender in Management: An International Journal, 32(1). doi:10.1108/GM-11-2015-0106

Hogg, L. (2014). Multiple identities: Consideration of respectful research practices. In C. McMaster \& C. Murphy (Eds.), Postgraduate study in Aotearoa New Zealand: Surviving and succeeding (pp. 153-167). Wellington, New Zealand: NZCER Press.

Ibrahim, R., \& Sarirete, A. (2014). Student development through student-monitored projects and volunteerism: Effat university case study. Online International Journal of Arts and Humanities, 3(4), 54-58. 
Jamjoom, F. B., \& Kelly, P. (2013). Higher education for women in the Kingdom of Saudi Arabia. In P. Maassen \& J. Muller (Series Eds.), Higher education dynamics: Vol. 40. Higher education in Saudi Arabia: Achievements, challenges and opportunities (pp. 117-125). doi:10.1007/978-94-007-6321-0_11

Jamjoom, Y. (2012). Understanding private higher education in Saudi Arabia: Emergence, development, and perception (Unpublished doctoral dissertation). Institute of Education, University of London, The United Kingdom.

Jankie, D. (2004). "Tell me who you are": Problematizing the construction and positionalities of "insider/outsider" of a "native" ethnographer in a postcolonial context. In Mutua, K. \& Swadener, B.B. (Eds.), Decolonizing research in crosscultural contexts (pp. 87-105). Albany, NY: State University Press.

Kattan, M. M., de Pablos Heredero, C., Montes Botella, J. L., \& Margalina, V. M. (2016). Factors of successful women leadership in Saudi Arabia. Asian Social Science, 12(5), 94-107. doi:10.5539/ass.v12n5p94

Kemp, L. J. (2013). Progress in female education and employment in the United Arab Emirates towards millennium development goal (3): Gender equality. Foresight, 15(4), 264-277.

Kemp, L. J., Madsen, S. R., \& Davis. J. (2015). Women in business leadership: A comparative study of countries in the Gulf Arab states. International Journal of Cross Cultural Management, 15(2), 215-233. doi:10.1177/1470595815594819 
Khatib, H. (2017, October 30). Saudi women high jump their way into social maneuverability. AMEInfo. Retrieved from: https://ameinfo.com/money/economy/saudi-women-high-jump-way-socialmanoeuvrability/

Kolb, D. A. (1984). Experiential learning: Experience as the source of learning and development. Englewood Cliffs, NJ: Prentice-Hall

Komives, S. R. (1994). Women student leaders: Self-perceptions of empowering leadership and achieving style. NASPA Journal, 31(2), 102-112.

Komives, S. R. (2011). Advancing leadership education. In S. R. Komives, J. P. Dugan, J. E. Owen, C. Slack, W. Wagner and Associates (Eds.), The handbook for student leadership development (pp. 1-34). San Francisco, CA: John Wiley \& Son, Inc.

Komives, S. R., Dugan, J. P., Owen, J. E., Slack, C., \& Wagner, W. (Eds.). (2011). The handbook for student leadership development. San Francisco, CA: John Wiley \& Son, Inc.

Komives, S. R., Dugan, J. P., \& Segar, T. C. (2006). The multi-institutional study of leadership: Understanding the project. Concepts \& Connections, 15(1), 5-7.

Komives, S. R., Lucas, N., \& McMahon, T. R. (1998). Exploring leadership: For college students who want to make a difference. San Francisco, CA: Jossey-Bass.

Komives, S. R., Owen, J. E., Longerbeam, S. D., Mainella, F. C., \& Osteen, L. (2005). Developing a leadership identity: A grounded theory. Journal of College Student Development, 46, 593-611. 
Komives, S. R., \& Wagner, W. (2009). Preface. In S. R. Komives, \& W. Wagner (Eds.), Leadership for a better world: Understanding the social change model of leadership development (pp. xi-xxv). San Francisco, CA: Jossey-Bass.

Kouzes, J. M., \& Posner, B. Z. (1988). The leadership practices inventory. San Diego, CA: Pfeiffer and Company.

Kouzes, J. M., \& Posner, B. Z. (2012). The leadership challenge: How to make extraordinary things happen in organizations. San Francisco, CA: A Wiley Brand.

Kouzes, J. M., \& Posner, B. Z. (2014). The student leadership challenge: Five practices for becoming an exemplary leader. San Francisco, CA: The Leadership Challenge, A Wiley Brand.

Lincoln, Y. S., Lynham, S. A., \& Guba, E. G. (2011). Paradigmatic controversies, contradictions, and emerging confluences, revisited. In N. K. Denzin \& Y. S. Lincoln (Eds.), The SAGE handbook of qualitative research (4 ${ }^{\text {th }}$ ed.) (pp. 97-127). Thousand Oaks, CA: Sage Publications, Inc.

Mabrouk, A., Warrier, R., \& Lasrado, J. (2017, July 16). The top 100 most powerful Arab businesswomen 2017. Forbes Middle East. Retrieved from: https://www.forbesmiddleeast.com/en/list/top-100-powerful-arabbusinesswomen-2017/

Madsen, S. R. (2009a). The experiences of Arab women leaders in learning to lead. Paper presented at the Fifteenth Annual International Leadership Association Global Conference, Prague, Czech Republic. Abstract retrieved from: https://works.bepress.com/susan_madsen/ 
Madsen, S. R. (2009b). The first steps toward developing programs for women in the United Arab Emirates: A survey study exploring the transformation of Emirati college students. In S. M. Nkomo (Chair), Developing women leaders in the Middle East: Generating local knowledge. Symposium conducted at the Academy of Management Annual Meeting.

Madsen, S. R. (2010a). Leadership development in the United Arab Emirates: The transformational learning experiences of women. Journal of Leadership \& Organizational Studies, 17(1), 100-110. doi:10.1177/1548051809345254

Madsen, S. R. (2010b). The experience of UAE women leaders in developing leadership early in life. Feminist Formations, 22(3), 75-95.

Madsen, S. R., \& Kemp, L. (2013). Progress for women and leadership in Qatar. Paper presented at the Fifteenth Annual International Leadership Association Global Conference, Montréal, CAN. Abstract retrieved from: https://works.bepress.com/susan_madsen/

Manning, K. (1997). Authenticity in constructivist inquiry: Methodological considerations without prescription. Qualitative Inquiry, 3(1), 93-115. doi:10.1177/107780049700300105

MBSC. (2017). About us. Prince Mohammad Bin Salman College of Business and Entrepreneurship. Retrieved from: http://www.mbsc.edu.sa/aboutus

McIntire, D. D. (1989). Student leadership development: A student affairs mandate. NASPA Journal, 27(1), 75-79.

Merriam-Webster. (2018). Hijab. Retrieved from: https://www.merriam-webster.com/dictionary/hijab 
Merriam-Webster. (2018). Niqab. Retrieved from:

https://www.merriam-webster.com/dictionary/niqab

Metcalfe, B. D. (2007). Gender and human resource management in the Middle East. International Journal of Human Resource Management, 18(1), 54-74. doi:10.1080/09585190601068292

Metcalfe, B. D. (2011). Women, empowerment and development in Arab Gulf states: A critical appraisal of governance, culture and national human resource development (HRD) frameworks. Human Resource Development International, 14(2), 131-148. doi:10.1080/13678868.2011.558310

Miller, P. (Ed.). (2017). Cultures of educational leadership: Researching and theorizing common issues in world contexts. Cultures of educational leadership: Global and intercultural perspectives, Intercultural studies in education series (pp. 1-23). Springer International Publishing.

Mimouni, F., \& Metcalfe, B. D. (2011). Leadership development philosophy and practice in Saudi Arabia. In B. D. Metcalfe \& F. Mimouni (Eds.), Leadership development in the Middle East (pp. 169- 196). Cheltenham, UK: Edward Elgar Publishing Limited.

Ministry of Education, Kingdom of Saudi Arabia. (2018). Private higher education. Retrieved from: https://www.moe.gov.sa/en/HigherEducation/PrivateHigherEducation/Pages/defa ult.aspx 
Ministry of Higher Education, Deputyship for Planning and Information, General Department for Planning and Statistics. (2010). Ministry of higher education's plan to achieve excellence in science and technology (L.D. No.1431/4352). Retrieved from: http://www.mohe.gov.sa/ar/Ministry/Deputy-Ministry-for-Planning-andInformation-affairs/The-General-Administration-ofPlanning/Documents/plans_to_achieve_excellence.pdf

Moss, G. (2004). Provisions of trustworthiness in critical narrative research: Bridging intersubjectivity and fidelity. The Qualitative Report, 9(2), 359-374.

Multi-institutional Study of Leadership. (2016). About MSL. Retrieved from: http://leadershipstudy.net/about/

National Center for Education Statistics (2014). Digest of Education Statistics, 2014 (NCES 2016-006). Washington, D.C.: U.S. Department of Education. Retrieved from: http://nces.ed.gov/fastfacts/display.asp?id=98

National Democratic Institute (2009). Leadership academy raises aspirations of young Middle Eastern women. Retrieved from: https://www.ndi.org/node/15721

Nodding, N. (2005). What does it mean to educate the whole child? In a democratic society, schools must go beyond teaching fundamental skills. Educational Leadership, 9-13.

Northouse, P. G. (2013). Leadership: Theory and practice $\left(6^{\text {th }}\right.$ ed.). Thousand Oaks, CA: Sage Publication.

Osteen, L., \& Coburn, M. (2012). Considering context: developing students’ leadership capacity. New Directions for Student Services, (140), 5-15. doi:10.1002/ss.20028 
Oxford Dictionaries. (2018). Alhamdulillah. Retrieved from:

https://en.oxforddictionaries.com/definition/alhamdulillah

Oxford Islamic Studies Online. (2017, April 16). Women. The Islamic world: Past and present. Retrieved from:

http://www.oxfordislamicstudies.com/article/opr/t243/e370

Parry, K. (1998). Grounded theory and social process: A new direction for leadership research. Leadership Quarterly 9(1) 85-106.

Posner, B. Z. (2009). A longitudinal study examining changes in students' leadership behavior. Journal of College Student Development, 50(5), 551-563. doi:10.1353/csd.0.0091

Quinn, B. (2012, June 24). Saudi Arabia to allow women to compete in 2012 Olympics. The Guardian. Retrieved from: https://www.theguardian.com/world/2012/jun/24/2012-olympics-saudi-arabiawomen-compete

Renn, K. A., \& Lytle, J. H. (2010). Student leaders at women's postsecondary institutions: A global perspective. Journal of Student Affairs Research and Practice, 47(2), 215-232. doi:10.2202/1949-66056074

Sadek, G. (2017, October 3). Saudi Arabia: Royal decree allows women to be issued driver's license. Library of Congress. Retrieved from: http://www.loc.gov/law/foreign-news/article/saudi-arabia-royal-decree-allowswomen-to-be-issued-driving-licenses/

Saldaña, J. (2013). The coding manual for qualitative researchers $\left(2^{\text {nd }}\right.$ ed.). Thousand Oaks, CA: Sage Publications Inc. 
Saudi Arabia's king appoints women to shura council. (2013, January 11). BBC News. Retrieved from: http://www.bbc.com/news/world-middle-east-20986428

Schwandt, T. A. (2007). The sage dictionary of qualitative inquiry $\left(3^{\text {rd }}\right.$ ed.). Thousand Oaks, CA: Sage Publications, Inc.

Senge, P. M. (1990). The fifth discipline: The art and practice of the learning organization. New York, NY: Doubleday.

Shankman, M. L., \& Allen, S. J. (2008). Emotionally intelligent leadership: A guide for college students. San Francisco, CA: Jossey-Bass.

Shankman, M. L., Haber, P., Facca, T., \& Allen, S. J. (2010). Gender and leadership through the lens of emotionally intelligent leadership. Leadership Review, 10, 88103.

Smist, J. (2011). Cocurricular programs. In S. R. Komives, J. P. Dugan, J. E. Owen, C. Slack, \& W. Wagner (Eds.), The handbook for student leadership development (pp. 287-304). San Francisco, CA: John Wiley \& Son, Inc.

Smith, L., \& Abouammoh, A. (Eds.). (2013). Higher education in Saudi Arabia: Reforms, challenges, and priorities. In P. Maassen \& J. Muller (Series Eds.), Higher Education Dynamics: Vol. 40. Higher education in Saudi Arabia: Achievements, challenges and opportunities (pp. 1-12). doi:10.1007/978-94-007-6321-0_1

Strauss, A. L. (1987). Qualitative analysis for social scientists. New York: Cambridge University Press.

Strauss, A., \& Corbin, J. (1998). Basics of qualitative research: Techniques and procedures for developing grounded theory. Thousand Oaks, CA: Sage Publications, Inc. 
Thompson, M. C. (2015). Saudi women leaders: Challenges and opportunities. Journal of Arabian Studies, 5(1), 15-36. doi:10.1080/21534764.2015.1050880

Tighe, C. (2014, October 12). Saudi Arabia offers cultural challenge. Financial Times. Retrieved from: http://www.ft.com/cms/s/2/99772e46-4b21-11e4-b1be00144feab7de.html\#axzz4D7EmpVqk

Tillman, L., C. (2002). Culturally sensitive research approaches: An African American perspective. Educational Researcher, 31(9), 3-12.

Toh, S. M., \& Leonardelli, G. J. (2013). Cultural constraints on the emergence of women leaders: How global leaders can promote women in different cultures. Organizational Dynamics, 42, 191-197. doi:10.1016/j.orgdyn.2013.06.004

United Nations Educational, Scientific, and Cultural Organization. (2011). Arab youth: Civic engagement and economic participation (LB/2011/SS/PI/70). UNESCO Regional Bureau for Education in the Arab States. Beirut, Lebanon: UNESCO Regional Bureau.

United Nations Educational, Scientific, and Cultural Organization. (2016). Saudi Arabia:

Education and literacy. UNESCO Institute of Statistics. Retrieved from: http://uis.unesco.org/en/country/sa?theme=education-and-literacy

Vision 2030. (2016). Saudi Vision 2030. Kingdom of Saudi Arabia. Retrieved from: http://vision2030.gov.sa/en/media-center

Vygotsky, L. S. (1978). Mind in society: The development of higher psychological processes. Cambridge, MA: Harvard University Press. 
Wagner, W. (2011). Considerations of student development in leadership. In S. R. Komives, J. P. Dugan, J. E. Owen, C. Slack, W. Wagner and Associates (Eds.), The handbook for student leadership development (pp. 85-108). San Francisco, CA: John Wiley \& Son, Inc.

Walumbwa, F. O., Avolio, B. J., Gardner, W. L., Wernsing, T. S., \& Peterson, S. J. (2008). Authentic leadership: Development and validation of a theory-based measure. Journal of Management, 34(1), 89-126.

doi:10.1177/0149206307308913

Wheatley, M. J. (1994). Leadership and the new science: Learning about organization from an orderly universe. San Francisco, CA: Berrett-Koehler.

White, S. (2016, June 1). Faculty member teaches leadership workshops in Saudi Arabia. Contact Magazine. University of North Carolina, School of Social Work. Retrieved from: http://ssw.unc.edu/contact2/2016/06/faculty-member-teaches-leadershipworkshops-in-saudi-arabia/

Wright, N. S., \& Bennett, H. (2013, November). Women and teams in the United Arab Emirates. Paper presented at the Fifteenth Annual International Leadership Association Global Conference, Montre`al, CAN. Abstract retrieved from http://www.ila-net.org/Conferences/2013/index.htm

Zimmerman-Oster, K., \& Burkhardt, J. C. (2001). Leadership in the making: Impact and insights from leadership development programs in U.S. colleges and universities. Battle Creek: MI: Kellogg Foundation. 


\section{APPENDIX A \\ Recruitment E-mail/letter to be distributed to potential participants}

Subject line: Seeking undergraduate collegiate women involved in a student leadership role(s) at a private non-profit university in Saudi Arabia.

Hello, my name is Miznah O. Alomair and I am a Doctoral Candidate at Chapman University located in Orange, California. I am working on my dissertation study to complete the program requirements for a Ph.D. in Education, emphasizing in leadership studies. I have kindly asked the Student Affairs Department at your university in Saudi Arabia to assist me in recruiting participants for my dissertation study. This email/letter is being sent to you through the Student Affairs Department, which has identified you as an active student leader on campus. For this reason, I would like to invite you to participate in my dissertation study.

The purpose of my dissertation study is to investigate the leadership understandings of collegiate women in Saudi Arabia's private non-profit universities. Moreover, the study aims to investigate the opportunities collegiate women in Saudi Arabia's private nonprofit universities have to develop leadership, as well as understand how and why they develop leadership. From this investigation, it is my hope that the findings will provide an in-depth understanding to collegiate women's experiences in and motivations for developing leadership.

Your participation will include an online audio/visual-conference meeting with me for an individual interview lasting approximately 60-90 minutes. Participating in this study is completely voluntary. Your participation will not affect your future relationship with the researcher, Chapman University, or your university in Saudi Arabia.

If you agree to participate in the study, I am kindly asking you to reach out to me by email (or phone message if preferred) in order for me to communicate with you directly and schedule a brief introductory meeting with you. This brief meeting will be scheduled at your convenience and through an online audio/visual-conference program of your choice. The meeting will take no longer than 20 minutes where I will formally introduce myself, provide you with an overview of the research agenda, and answer any inquiries or concerns you may have.

The individual interviews will be carried out between September $17^{\text {th }}, 2017$ and December $30^{\text {th }}, 2017$ at a day and time that is convenient for you.

I look forward to your email, and to speaking with you.

Respectfully,

Miznah O. Alomair

Doctoral Candidate, Chapman University

Email: aloma109@mail.chapman.edu 


\title{
APPENDIX B
}

\section{CHAPMAN UNIVERSITY CONSENT TO ACT AS A HUMAN RESEARCH SUBJECT}

TITLE OF STUDY: Leadership Development of Collegiate Women in Saudi Arabia's Private Non-profit Universities

You are being asked to participate in a research study. Participation is completely voluntary. Please read the information below and ask questions about anything that you do not understand. A researcher listed below will be available to answer your questions.

\author{
RESEARCH TEAM \\ Lead Researcher \\ Miznah O. Alomair, Ph.D. Student \\ College of Educational Studies \\ (949) 241-7099, aloma109@mail.chapman.edu \\ Faculty Sponsor \\ Dr. Whitney Mclntyre Miller, Assistant Professor \\ Graduate Leadership Programs, College of Educational Studies \\ (714) 744-2134, wmcintyr@chapman.edu
}

STUDY LOCATION(S): Orange, California with online audio/video communication to Saudi Arabia

STUDY SPONSOR(S): Chapman University

No one on the study team has a disclosable financial interest related to this research project.

\section{WHY IS THIS RESEARCH STUDY BEING DONE?}

This research study serves as the lead researcher's dissertation project to complete the program requirements for a Ph.D. in Education. The purpose of the study is to investigate and understand the leadership understandings of collegiate women in Saudi Arabia's private non-profit universities, the opportunities they have to develop leadership, and how and why they develop leadership. Very little is known about female collegiate student leadership development in the country. Through individual interviews with collegiate women in student leadership role(s), the researcher intends that the study's findings will provide an in-depth understanding of the meanings collegiate women in Saudi Arabia have of leadership and of their perspective as to how and why they develop leadership.

\section{HOW MANY PEOPLE WILL TAKE PART IN THIS STUDY?}

We expect approximately 25-30 people to participate in this research study. All study procedures will be done through individual interviews using an online audio/video-conference program at a day and time previously agreed upon by each participant and the researcher.

WHAT PROCEDURES ARE INVOLVED WITH THIS STUDY AND HOW LONG WILL THEY TAKE?

1. A semi-structured interview will be utilized to understand your perspective of leadership and how and why you develop leadership as a college student in Saudi Arabia.

\section{CHAPMAN |⿱R⿴囗丨}

UN IVERSITY APPROVAL DATE: 6/16/2017 INSTITUTIONAL REVIEW BOARD 
2. If you provide your consent to participate in this study, the interview will be audio-recorded.

3. In this study, an individual semi-structured interview will be conducted with you using an online audio or audio/video-conference program (based on your preference), which will last for approximately 6090 minutes.

4. The interview protocol will include approximately 12 open-ended questions, and will be flexible to allow for subsequent and follow-up questions to evolve throughout the study. The list of questions used in this study will not be provided in advance.

5. Participation in the study will include about $2-3$ meetings/interviews and take a total of about 2-3 hours over a period of $2-3$ sessions scheduled within 3 months.

\section{AM I ELIGIBLE TO PARTICIPATE IN THIS STUDY?}

Please note this may not be a complete list of eligibility criteria. We have included a few examples of study criteria to help you better understand how your eligibility in the study will be determined; your study team will go through the study eligibility criteria with you to verify if you qualify for participation in this study.

\section{Inclusion Requirements}

You can participate in this study if you are at least 18 years of age or older, female, undergraduate collegiate student; enrolled at a private non-profit university in Saudi Arabia; involved as a student leader in one or more co-curricular or extra-curricular learning program at their respective university (i.e., student organization, student council, committee, etc.); and able to read and speak English.

\section{Exclusion Requirements}

You cannot participate in this study if you are not 18 years of age or older, female, undergraduate collegiate student; enrolled at a private non-profit university in Saudi Arabia; involved as a student leader in one or more co-curricular or extra-curricular learning program at your respective university (i.e., student organization, student council, committee, etc.); and able to read and speak English.

\section{WHAT ARE THE POSSIBLE DISCOMFORTS OR RISKS RELATED TO THE STUDY?}

There are no known harms or discomforts associated with this study beyond those encountered in normal daily life. The possible risks and/or discomforts associated with the procedures described in this study include: minor emotional discomfort and minimal risk such as breach of privacy and confidentiality during the interview. However, you may choose to skip any question at any time, and you may withdraw from the study at any time without penalty.

\section{Minor Emotional Discomfort}

Emotional discomfort may occur during the interview process by reflecting on your own experiences in developing leadership capacities. If discomfort occurs, it should be brief and short-lived, and ameliorated through the changing of topic.

\section{Minimal Risk of Beach of Privacy and Confidentiality}

As with any study involving collection of data, there is the possibility of breach of privacy and confidentiality of data. Every precaution will be taken to secure your personal information to ensure confidentiality. To minimize breach of privacy and confidentiality, your participation in this study will not be disclosed to any individual. Personal information (i.e., your name, contact information) will be maintained in a separate file and will be deleted upon the end of the study. You will be assigned a pseudonym and only de-identified data will be stored onto the researcher's password-protected personal 
laptop computer that only the researcher will access. All audio-recorded interviews and interview transcripts will be de-identified and password-protected on the researcher's personal laptop computer. Al audio and transcript files will be coded in a way that will protect your identity. These files will be stored in the researcher's password-protected personal laptop computer that only the researcher will access. Data will be discarded no later than 7 years after this study is presented and published.

\section{ARE THERE BENEFITS TO TAKING PART IN THE STUDY? \\ Participant Benefits}

You will not directly benefit from participation in this study. However, you may benefit from participating in this study by sharing your understanding of leadership and your perspective as to how and why you develop leadership as a collegiate woman in Saudi Arabia. Thus, you may benefit by knowing that you are contributing to any new knowledge that will emerge from this study.

\section{Benefits to Others or Society}

This study will hopefully inform the field of college student leadership development by gaining an understanding of a non-Western perspective of leadership and leadership development, and furthering the notions of leadership development of young women in Saudi Arabia.

\section{WILL I BE PAID FOR TAKING PART IN THIS STUDY?}

Compensation

You will not be compensated for your participation in this research study.

\section{Reimbursement}

You will not be reimbursed for any out of pocket expenses, such as parking or transportation fees.

\section{Costs}

No costs are associated with with this study.

\section{WHAT HAPPENS IF I WANT TO STOP TAKING PART IN THIS STUDY?}

You are free to withdraw from this study at any time. If you decide to withdraw from this study you should notify the research team immediately. The research team may also end your participation in this study if you do not follow instructions, miss scheduled meetings and/or interviews, or if your safety and welfare are at risk.

If you withdraw or are removed from the study, the researcher may ask you if you are still interested in participating in data analysis, should your data be used for this study (see below).

If you elect to withdraw or are withdrawn from this research study, the researchers will discuss with you what they intend to do with your study data. Researchers may choose to analyze the study data already collected or they may choose to exclude your data from the analysis of study data and destroy it, as per your request.

\section{HOW WILL MY PERSONAL INFORMATION BE KEPT?}


All identifiable information collected about you will be removed and replaced with a pseudonym. A list linking the pseudonym and your identifiable information will be kept separate from the research data and will be deleted upon the end of the study.

\section{Data Storage}

Research data will be stored electronically on a secure laptop computer in an encrypted file and is password protected. The audio recordings will also be stored in a secure location; then transcribed and erased at the end of the study.

\section{Data Retention}

The researchers intend to keep the research data for no later than 7 years after the research is presented and published.

\section{WHO WILL HAVE ACCESS TO MY STUDY DATA?}

The research team, authorized Chapman University personnel, and regulatory entities such as the Office of Human Research Protections (OHRP), may have access to your study records to protect your safety and welfare.

Any information derived from this research project that personally identifies you will not be voluntarily released or disclosed by these entities without your separate consent, except as specifically required by law. Study records provided to authorized, non-Chapman University entities will not contain identifiable information about you; nor will any publications and/or presentations without your separate consent.

While the research team will make every effort to keep your personal information confidential, it is possible that an unauthorized person might see it. We cannot guarantee total privacy.

\section{WHO CAN ANSWER MY QUESTIONS ABOUT THE STUDY?}

If you have questions, concerns, or complaints, or think the research has hurt you, talk to the research team at (949) 241-7099 aloma109@mail.chapman.edu or (714) 744-2134 wmcintyr@chapman.edu

This research has been reviewed and approved by an Institutional Review Board ("IRB"). You may talk to them at 714-628-2833 or irb@chapman.edu if:

- Your questions, concerns, or complaints are not being answered by the research team.

- You cannot reach the research team.

- You want to talk to someone besides the research team.

- You have questions about your rights as a research participant.

- You want to get information or provide input about this research.

\section{HOW DO I AGREE TO PARTICIPATE IN THIS STUDY?}

You should not sign this consent form until all of your questions about this study have been answered by a member of the research team listed at the top of this form. You will be given a copy of this signed and dated consent form to keep. Participation in this study is voluntary. You may refuse to answer any question or discontinue your involvement at any time without penalty or loss of benefits to which you 
might otherwise be entitled. Your decision will not affect your future relationship with Chapman University

AUDIO RECORDING:
I have received an adequate description of the purpose and procedures for audio-recording sessions
during the course of the proposed research. I give my consent to allow myself to be audio-recorded
during participation in this study, and for those records to be reviewed by persons involved in the
study, as well as for other professional purposes as described to me.
Yes, I agree to allow the research team to audio record my interview(s).
Signature of Participant

Your signature below indicates you have read the information in this consent form and have had a chance to ask any questions you have about this study.

I agree to participate in the study.

Subject Signature

Printed Name of Subject

Researcher Signature

Miznah O. Alomair

Printed Name of Researcher
Date

Date 


\section{CHAPMAN UNIVERSITY \\ Experimental Subject's Bill of Rights}

The rights listed below are the right of every individual asked to participate in a research study. You have the right:

1. To be told about the nature and purpose of the study.

2. To be told about the procedures to be followed in the research study, and whether any of the drugs, devices, or procedures is different from what would be used in standard practice.

3. To receive a description of any side effects, discomforts, or risks that you can reasonably expect to occur during the study.

4. To be told of any benefits that you may reasonably expect from the participation in the study, if applicable.

5. To receive a description of any alternative procedures, drugs, or devices that might be helpful, and their risks and benefits compared to the proposed procedures, drugs or devices.

6. To be told of what sort of medical treatment, if any, will be available if any complications should arise.

7. To be given a chance to ask any questions concerning the research study both before agreeing to participate and at any time during the course of the study.

8. To refuse to participate in the research study. Participation is voluntary. You may refuse to answer any question or discontinue your involvement at any time without penalty or loss of benefits to which you might otherwise be entitled. Your decision will not affect your right to receive the care you would receive if you were not in the experiment.

9. To receive a copy of the signed and dated written consent form and a copy of this form.

10. To be given the opportunity to freely decide whether or not to consent to the research study without any force, coercion, or undue influence.

If you have any concerns or questions regarding the research study you should contact the research team listed at the top of the consent form.

If you are unable to reach a member of the research team and have general questions, or you have concerns or complaints about the research study, research team, or questions about your rights as a research subject, please contact the Chapman University IRB staff at 714-628-2833 or irb@chapman.edu. 


\section{APPENDIX C}

\section{$\triangle$ CHAPMAN DONNA FORD ATTALLAH $\triangle$ UNIVERSITY COLLEGE OF EDUCATIONAL STUDIES}

One University Drive

(714) $997-6781 \cdot$ Fax: (714) 744-7035

Orange, CaLifornia 92866

CHAPMAN.EDU/EDUCATION

September 29, 2017

To Whom it May Concern,

I write you this letter to verify that Miznah O. Alomair is a doctoral student at Chapman University's Attallah College of Educational Studies. She is currently in her final year of the Ph.D. in education program, emphasizing in leadership studies. In May of this year, Ms. Alomair was able to defend her dissertation proposal titled: "Leadership Development of Collegiate Students at Saudi Arabia's Private Non-profit Universities" and was granted approval by Chapman University's Institutional Review Board (IRB) to carry out her dissertation study.

As Ms. Alomair's academic advisor, and the chair of her doctoral dissertation committee at Chapman University, I confirm that her request to conduct individual interviews with female undergraduate students from your university is part of her dissertation study. Furthermore, Ms. Alomair's request is part of an approved research plan by her doctoral dissertation committee and the IRB committee at Chapman University.

I would be glad to answer any questions or concerns you may have regarding Ms. Alomair's study, IRB approval, or dissertation process. I can be reached by e-mail at wmcintyr@chapman.edu, or by phone at 01-714-744-2134.

Sincerely,

\section{wongerabo}

Whitney McIntyre Miller, Ph.D.

Assistant Professor, Graduate Leadership Programs

College of Educational Studies

Chapman University 


\section{APPENDIX D}

Interview Protocol

1. Describe what leadership means to you?

2. How did you come to understand what leadership is?

3. In what ways do you see yourself as a leader?

4. What does student leadership look like at your university?

5. How did you decide to become a leader?

6. What helped to prepare you for your leadership role?

7. What types of opportunities or experiences have you had to develop leadership?

8. What motivated you to develop leadership?

9. Do you feel it is important to develop leadership? why or why not?

10. What promoted and/or hindered opportunities or experiences for you to develop leadership?

11. What do you anticipate or expect as a result of developing leadership?

12. What recommendations or suggestions would you provide to improve opportunities for collegiate women to develop leadership? 